http://dx.doi.org/10.11646/zootaxa.3700.3.7

http://zoobank.org/urn:lsid:zoobank.org:pub:E3FA2E4B-DDF4-4FDB-8CF1-FFBA215D40CA

\title{
Pamphagidae (Orthoptera: Caelifera) of North Africa: key to genera and the annotated check-list of species
}

\author{
BRUNO MASSA \\ Department of Agricultural and Forest Sciences, University of Palermo, V.le Scienze 13, 90128 Palermo, Italy. \\ E-mail: bruno.massa@unipa.it
}

\begin{abstract}
At least 95 species of Pamphagidae belonging to 17 genera are known in North Africa. Taxonomic status is fairly known, with some exception, mainly due to scarcity of available specimens of some genera in museums and collections. In this paper, the author proposes a new key to genera and reports the annotated list of all the known species, based on specimens examined in different European museums. Concerning the subfamily Thrinchinae, he proposes to consider only the following species of the genus Tmethis: T. cisti, T. harterti new status, T. maroccanus and T. pulchripennis. He also considers Neotmethis bidentatus synonym of $T$. harterti, and the three newly described species of the genus Tuarega as synonyms of $T$. insignis. In addition, he proposes to remove Batrachotettix elephas from the synonyms of T. insignis, because its description consents to establish that it belongs to a South African Porthetinae, not to a Thrinchinae. With regard to the subfamily Pamphaginae, the author recognizes the presence in North Africa of three tribes, until now containing 90 species: Finotiini, Pamphagini and Euryparyphini; Amigus is definitively considered a valid genus within the tribe Pamphagini, with the only species A. nigroadspersus. Additionally, he proposes a new key to species of the genus Paracinipe. He considers Paracinipe theryi as a valid species; previously it has been listed as subspecies of $P$. dolichocera. He also establishes that Acinipe calabra of Italy is the same taxon living in North Africa. Further, he describes Euryparyphes rungsi new species from Middle Atlas, and Paraeumigus lopezi new species from West Morocco, and synonymizes Eunapiodes granosus rungsi with E. atlantis. Finally, he reports biometric data of the genera Tmethis, Paracinipe, Paraeumigus and Eunapiodes.
\end{abstract}

Key words: Thrinchinae, Pamphaginae, Euryparyphes rungsi n. sp., Paraeumigus lopezi n. sp., Synonymies

\section{Introduction}

This paper is mainly based on the study of specimens preserved in the following institutions: Museo Nacional de Ciencias Naturales, Madrid (MNCN); Muséum National d'Histoire Naturelle, Paris (MNHN); Naturhistorisches Museum, Vienna (NMW); Museo Civico di Storia Naturale, Milan (MSNM); Museo Civico di Storia Naturale 'G. Doria', Genoa (MSNG); Museo Regionale di Scienze Naturali, Turin (MSNT); Museo di Zoologia Università La Sapienza, Rome (MZR); Dipartimento di Agraria Università, Portici (Naples) (DAP); collection B. Massa Università, Palermo (BMCP). Some specimens were photographed with a Nikon Coolpix 4500 digital camera, mounted on a Wild M5 Stereomicroscope. Mounted specimens were measured with a digital calliper (precision $0.01 \mathrm{~mm}$ ); as precise measurement of wingless insects with large abdomen is difficult, total length was measured from the vertex to the apex of hind femur. New synonyms are reported within square brackets.

\section{Results}

\section{Key to North African subfamilies of Pamphagidae}

1. Fully winged species . . . .

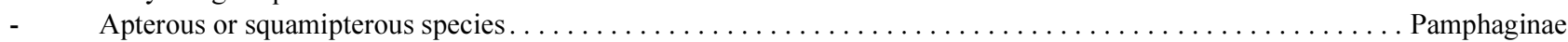




\section{Key to North African genera of Thrinchinae}

1. Body and wings long, pronotum depressed with keel just evident, sulcus not evident.

Gen. Tuarega Uvarov, 1943

Body and wings shorter, pronotum keel raised, laterally compressed or depressed, but evident sulcus.

Gen. Tmethis Fieber, 1853

\section{Key to North African genera of Pamphaginae}

1. Krauss's organ absent, hind border of pronotum provided with spines or festooned (Figs. 1-6), wings absent or very small . . 2

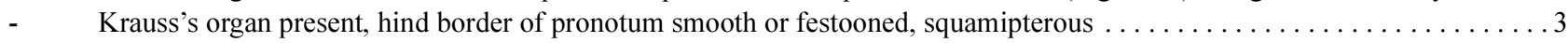

2. Hind border of pronotum with spines, tympanum partially covered, body dorso-ventrally compressed, wings absent, upper border of hind femurs provided with spines (Figs. 1-2). Tunisia and Libya. . . . . . . . . . . . . Gen. Finotia Bonnet, 1884. Hind border of pronotum festooned or with small tubercles, tympanum not covered, wings absent (Fig. 5) or present; in this case they may be very short (Fig. 4) or not exceeding the metanotum (Fig. 6); in the latter case microscopic hind wings are present. Upper border of hind femurs undulate and notched after the middle (Figs. 5-6). Morocco to Libya and Italy (Sicily). .

Gen. Ocneridia Bolivar, 1912.

3. Hind femurs with upper and lower borders laterally flattened and provided with tubercles, upper border constricted just before the genicular lobe. Tegmina spatular (Fig. 7). Prosternum process narrow, bifid and cuneiform. Morocco and West Algeria

Gen Eunapiodes Bolivar, 1907. Hind femurs normal, with upper border declining after the middle, smooth (Fig. 8) or with some small spines (Fig. 9). . . . .4

4. Prosternum process absent, only a fore collar present, vertex two times wider than long (Fig. 10), 11-12 antennal segments, pronotum clearly interrupted by the typical sulcus (Figs. 10-13), epiproct divided by a longitudinal concavity. . . . . . .5 Prosternum process present, vertex less than two times wider than long, 15-18 antennal segments, pronotum not or interrupted

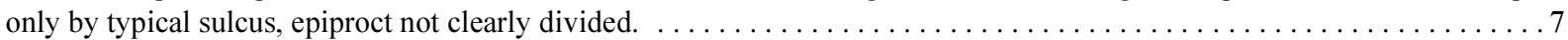

5. Pronotum interrupted by $2-3$ sulci (Figs. 11, 13), arolia longer than half claws, hind border of epiphallus raised, male cerci incurved, subgenital plate of male not convex, inside of hind femurs dark. $\ldots \ldots \ldots \ldots \ldots \ldots \ldots \ldots \ldots \ldots \ldots \ldots \ldots \ldots$ Pronotum interrupted by one sulcus (Fig. 12), arolia shorter than half claws, hind border of epiphallus cut, male cerci straight and flattened, subgenital plate of male convex, inside of hind femurs pale. South Morocco.

Gen. Pseudoglauia Morales Agacino et Descamps, 1968.

Body not dorso-ventrally compressed, hind border of pronotum more or less straight, pronotum interrupted by $2-3$ sulci (Fig.

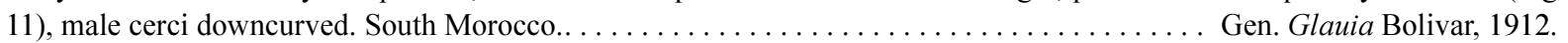
Body compressed dorso-ventrally, pronotum flat and wide (Fig. 13), hind border of pronotum much concave, tegmina covering only partially the tympanum, male cerci incurved, male epiphallus as long as the entire phallic complex. South Morocco. ....

Gen. Glauvarovia Morales Agacino, 1945.

7. Pronotum keel furrowed dorsally (only in rare cases it is not furrowed), presence of lateral keels on the pronotum (Figs. 1516). Tegmina more or less oval, with lower border convex (Figs. 17-20). Aedeagus valves provided with columnar keels (Figs.

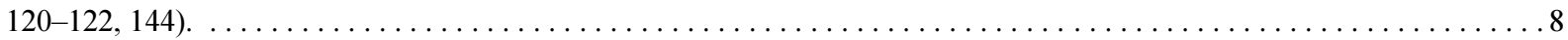
Pronotum keel not furrowed dorsally, lateral keels absent, tegmina narrow, with lower border straight and only enlarged api-

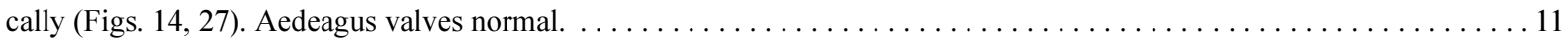

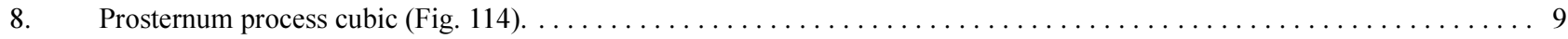

- $\quad$ Prosternum process with a fore border and two hind pointed tubercles (Figs. 142, 149, 153). Morocco and Algeria.........

Gen Paraeumigus Bolivar, 1914

9. Prosternum process with four evident pointed tubercles, abdomen clearly keeled (Figs. 16, 20). From Morocco to Libya. ....

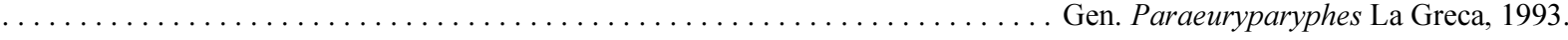
Prosternum process with two pointed tubercles, abdomen just keeled. $\ldots \ldots \ldots \ldots \ldots \ldots \ldots \ldots \ldots \ldots \ldots \ldots \ldots$

10. Aedeagus valves long, narrow and tubular, apically open, epiphallus ancorae reduced to two tuberosities, hind border deeply concave between lophi, that bear some small black spines. Morocco.............. Gen. Nadigeumigus La Greca, 1993. Aedeagus valves characterized by columnar keels (Figs.), epiphallus normal. Morocco and Algeria.

Gen. Euryparyphes Fischer, 1853.

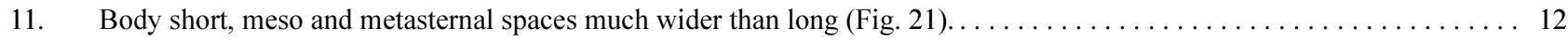

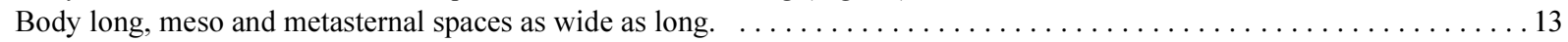

12. Pronotum raised, borders of the vertex evident, hind femurs and tibiae much hairy, also on the upper border. Central Morocco.

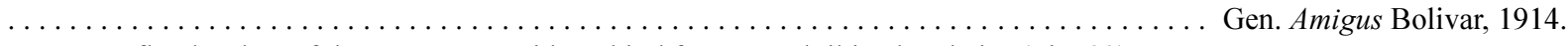
Pronotum flat, borders of the vertex not evident, hind femurs and tibiae less hairy (Fig. 22). Morocco.

Gen. Pseudoamigus Chopard, 1943.

13. Hind femurs stout, with a pre-genicular narrowing less evident (Fig. 23), fore and hind borders of pronotum clearly protruding (Figs. 25-26), hind tibiae hairless. From Morocco to Libya and Italy (Sardinia and Sicily). Gen. Pamphagus Thunberg, 1815. Hind femurs slender, with a pre-genicular narrowing more evident (Figs. 8, 24), borders of pronotum less protruding (Fig. 27),

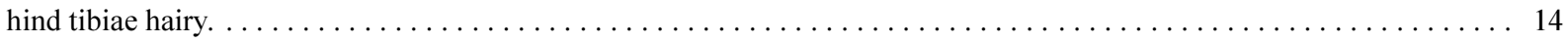

14. Subgenital plate of the male not divided into two parts (Fig. 28). Hind border of epiphallus never bilobate (Fig. 31). From Morocco to Tunisia, Italy (Calabria and Sicily) and Iberian peninsula. . . . . . . . . . . . Gen. Acinipe Rambur, 1838. Subgenital plate of the male divided into two parts (Fig. 29). Hind border of epiphallus generally bilobate (Fig. 30). From Morocco to Egypt and Middle East. . . . . . . . . . . . . . . . . Gen. Paracinipe Descamps et Mounassif, 1972. 
North African Thrinchinae have been more or less extensively treated by different authors (e.g., Krauss 1902, Vosseler 1903, Bolivar 1908, Salfi 1926, Uvarov 1943). They belong only to two genera, namely Tmethis Fieber, 1853 and Tuarega Uvarov, 1943. The speciation centre of the subfamily was Asia and North African representatives eventually colonized Egypt and other North African countries through the Middle East and Sinai. Three species belonging to the genus Tmethis are known (with many subspecies), and only one species of Tuarega was known till 2011, when other three species were described from Sahara. Taxonomy of species and subspecies recorded in North Africa is confusing. The study of many specimens preserved in European museums consented me to clarify their actual taxonomical status; I report here the results of my study.

\section{Tmethis Fieber, 1853 (type-species: Gryllus cisti Fabricius)}

Fieber (1853) did not explain the origin of the name Tmethis; thank to my Greek colleague Haralabos Tsolakis, it was possible to trace a link with the verb "temno" ( $\tau \dot{\varepsilon} \mu v \omega)$, which means "to cut", possibly referred to the particular shape of pronotum, with a distinct sulcus between prozona and metazona. I consider that Tmethis is of masculine gender, and consequently I will agree taxa with it. In his excellent revision of all Palaearctic Thrinchinae, Uvarov (1943) pointed out the high variability of many species, mainly belonging to genera Tmethis and Asiotmethis Uvarov, that may have wrinkled or smooth integuments; sculpturing of exposed parts (mainly pronotum) may be devoid of the usual tubercles and keel. Thus, taxa belonging to the genus Tmethis are much variable, not only in their general colour and in the length of wings, but also in their integuments and body structure, which may be more or less stout or slender. Some specimens appear squat and broad (Figs. 73, 75). In addition, the colour of hind tibiae varies from red to yellow and to purple or bluish-violet; it seems that this variation characterizes single populations. The arrangement of species within the genus was much unclear, in particular the separation of T. cisti from T. pulchripennis. Reading Chopard (1943) it is evident that many populations of T. pulchripennis were actually $T$. cisti (e.g., those living on Djerba and Kerkenna Is.). The first author who defined characters to identify species was Uvarov (1943); he recognized T. maroccanus from T. cisti and T. pulchripennis by the shape of the metazona of pronotum, which is broadly parabolic with convex margins in the former and triangular, with the sides straight or somewhat incurved in the other two species. Additionally, he identified $T$. cisti and T. pulchripennis by the shape of their male epiphallus, and by small differences on the lower valve of the ovipositor and length of spurs of hind tibiae. Thus, records of species in North African countries may be considered reliable only if criteria used by Uvarov (1943) were followed. However, La Greca (1969) considered much variable the shape of lower valve of the ovipositor (according to Uvarov (1943) in $T$. pulchripennis with a distinct shoulder, which appears as a tooth in lateral view, while in $T$. cisti it appears without a projection, not dentate), and identified some T. pulchripennis from Libya, following criteria of Chopard (1943), based on the pronotum shape, that during this study resulted to be a very variable character. Tegmina length is also a variable character, as supposed by Jannone (1938). Eight subspecies or varieties have been described for T. cisti, three for T. pulchripennis and three for T. maroccanus, in some cases overlapping. I will examine each of them to establish if their taxonomic status is justified.

\section{Tmethis cisti (Fabricius, 1787)}

Material examined. Morocco: Melilla, $3 \hat{\partial}, 8 \odot$; El Guerruau, $3 \hat{\partial}, 8 \circ$; Mulay Rechid (Ulad Settut), $3 \hat{\jmath}$; Toco El

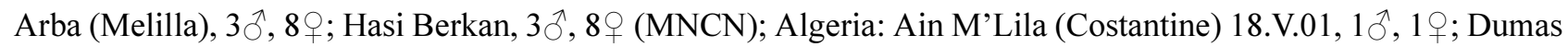
20.V.49, 1; Tunisia: Tamerza 26.V.1873, 6ภ, 9क; Ludien 23.IV.1873, 1; Hammam el Lif 2.VII.1875, 5 q

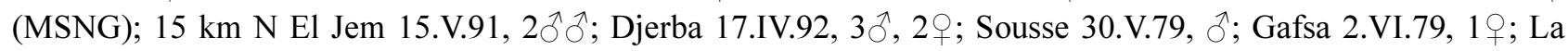

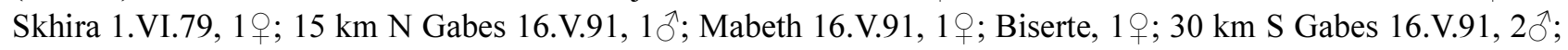

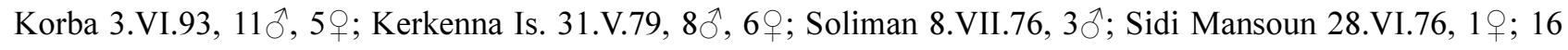

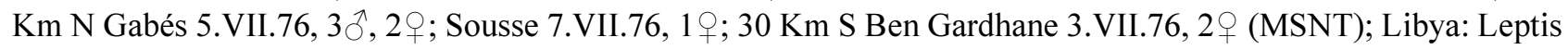
Magna 18.IV.05, 2ð; Tagiura 14.IV.98, 19 (BMCP); U. Caàm, Mizda, Tinaiat ben Galan, 4^, 5 ㅇ (MSNM); Ain Zara, 10ิ, 1ㅇ; Homs, $2 \hat{\jmath}$ (MZR). 
T. cisti covers North Africa, from Morocco to Libya (Tripolitania and Cyrenaica). Uvarov (1943) established that the type locality was Northern Tunisia. It is well characterized by a high pronotum keel, with deep transverse sulcus (mainly in males) (Figs. 32-36), male epiphallus with apical lobes large and broadly separated (Figs. 54a, 55a), spurs of hind tibiae long and slender (Fig. 54b). Tegmina are long and generally exceed the hind knees (Figs. $42-43,55)$, hind wings are red inside with a central brown spot, which reaches the base of the red area, but this colour is very variable; for example in Tunisia yellow (Djerba Is., Sousse), purple (Gafsa, Mareth, Gabes), blue (Skhira, Kerkenna Is.) and red tibiae (Korba, Biserte) have been found; in Libya bluish with red apex (Leptis Magna, East of Sirte), blue (East of Sirte, Agedabia) and vinaceous tibiae with red apex (Tagiura) have been detected; in Algeria red (El Kantara, Tebessa, Constantine) and yellow tibiae (Dumas) have been recorded. Concerning the length of tegmina, specimens with abbreviated wings exist in different localities (e.g., Kerkenna Is., Korba); generally, when tegmina are shorter than abdomen, hind wings are shorter than tegmina and show a simplified colour pattern (less coloured, with faint brown spots).

In the following paragraphs I will examine the different populations listed as subspecies by Eades et al. (2013).

\section{[Tmethis cisti algericus Saussure, 1888]}

Material examined. Algeria: Tagremaret V.49, $3 \hat{\jmath}, 19$; Sebdou, 2 우; Oran, $5 \hat{\jmath}, 5 q$ (MNCN).

Saussure (1888) described it as variety of T. pulchripennis. Chopard (1943) agreed with him, while Uvarov (1943) listed it as synonym of $T$. cisti clavelii. It is a long-winged Tmethis, but its characteristics do not differ from those of T. cisti. In addition, the epiphallus of specimens identified as "algerica" by Bolivar and Escalera and collected in the inner Algeria actually matches with the cisti-type. Altogether, characters of this taxon lie within the variability of $T$. cisti, of which it has to be considered a junior synonym.

\section{[Tmethis cisti barcaeus Salfi, 1926]}

Material examined. Benghasi, $1 q$ holotype (MZR).

Salfi (1926) described this taxon from a locality (Benghasi) within the area inhabited by harterti (see below); the sole female on which he based the description has yellow tibiae, hyaline hind wings with brown indefinite spots, long tegmina (as long as in T. cisti), with hind wings shorter than tegmina, and trilobed prozona. Roughness of integuments may be very variable in Thrinchinae (Uvarov 1943), as well as the pattern of hind wings colour (see specimens of Kerkenna Is., above listed). Thus, I consider $T$. cisti barcaeus a synonym of $T$. cisti, which in Cyrenaica overlaps with $T$. harterti (see below).

\section{[Tmethis cisti clavelii Lucas, 1851]}

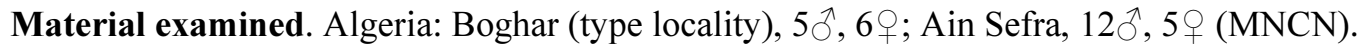

Described as species and afterwards considered a subspecies of T. cisti (Uvarov 1943). According to Lucas (1851) main characteristics of this taxon are: trilobate prozona (Figs. 32-33, 40-41), long tegmina (more than abdomen) (Figs. 40-41, 54), hind wings just shorter than tegmina, pink-reddish inside with a central brown stripe (consisting of separated wide spots) just reaching half of the pink-reddish area. Three small spots are present on the fore border of the wing, above the brown area (Fig. 54). Hind tibiae are yellow, as the inner side of femurs, that bear a brown spot inside, shorter than that of other populations. It has been cited only from Algeria (Lucas 1851, Krauss 1902) and has been considered by Saussure (1888) a possible variety of T. pulchripennis, by Chopard (1943) a synonym of T. pulchripennis, and by Uvarov (1943) a subspecies of $T$. cisti. Its distribution overlaps with that of T. cisti and T. pulchripennis and covers the western part of inner Algeria. Concerning its biometrics (cf. Table 1), they lie within the variability of $T$. cisti, as well as the pattern of hind wings colour. Therefore, I think that it could be treated as a synonym of $T$. cisti.

\section{[Tmethis cisti gracilis Saussure, 1888]}

Concerning the variety gracilis, also described by Saussure (1888) from Tunisia (Gabes, following Uvarov 1943), and recorded by Chopard (1943) also from Algeria (Chott Melrirh), the peculiar characters listed by the author are 
the slender body, long and narrow tegmina and pale colour, hind tibiae dark blue, all characters that lie within the wide variability of $T$. cisti. Consequently, I consider gracilis as a junior synonym of $T$. cisti, too.

\section{[Tmethis cisti tunensis Saussure (1888)]}

Saussure (1888) described it as a variety of T. clavelii from coastal dunes and grasslands. Characters are red tibiae and tegmina somewhat abbreviated (mainly in the female). Chopard (1943) considered it to be identical to the type of T. pulchripennis var. algerica Saussure, 1888 (that really was a T. cisti). Uvarov (1943) wrote that he found these characteristics in specimens from outskirts of Tunis and Gafsa. It may be observed that in Tunisia tibiae colour cannot be used as taxonomic character and in the same locality (e.g., Gafsa) they may be red or blue. Specimens examined by me (see material listed below $T$. cisti) came from many localities of Tunisia, included coastal dunes and grasslands; in consideration of the wide variability of the taxon, I think that also tunensis is a junior synonym of $T$. cisti.

\section{[Tmethis cisti mozabiticus Krauss, 1902]}

Material examined. Algeria: Oued Mzab (Ghardaja, Algerian Sahara) 4.IV.1893, $2 \widehat{\jmath}$ syntypes; Beni Abbès (Algerian Sahara) 5-6.IV.51, 5 $\hat{\jmath}, 3$ + (MNCN).

Krauss (1902) described this taxon as variety of T. clavelii from Oued Mzab (Ghardaia, Algerian Sahara), mainly on the base of wing coloration, very different from that of $T$. cisti and related taxa. Wings appear just bluish inside, with a narrow brown stripe not reaching the fore border (Fig. 56). Tegmina are as long as the abdomen (Figs. 44-45) and hind tibiae and inside of hind femurs are yellow-orange. Pronotum keel is moderately low (Figs. 38-39), and the eyes appear more bulging than in related taxa. It has been considered subspecies of $T$. pulchripennis by Chopard (1943) and of T. cisti by Uvarov (1943). I found a similar pattern of hind wings colour in the population living on Kerkenna Is. (Tunisia), which however has blue tibiae and somewhat abbreviated wings. Consequently, this taxon may be considered one of a lot of morphological variations of $T$. cisti, localised in the inner Algeria.

\section{Tmethis harterti Uvarov, 1923 new status}

Material examined. Libya: Merg (Benghasi) (type locality) 10.IV, 2へ, $2 \propto$ (MNCN); Ain Mara, $1 \hat{\jmath}, 1 \%$;

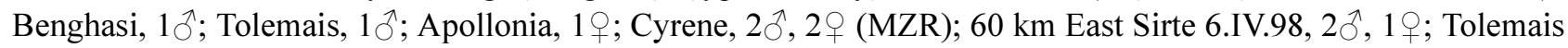

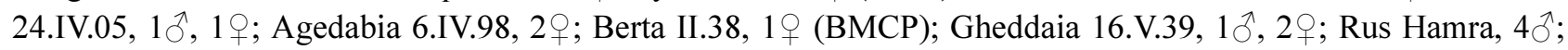
Tobruk IV.14, 1 우 (MSNG).

Described from Merg (Cyrenaica, Libya), its characteristics are the shortness of tegmina, mainly in the female (where they just exceed the middle of femurs) (Figs. 50-51), the faintly bluish colour inside of hind wings (Figs. 58a-58b), hind tibiae uniformly red, inside of hind femurs vinaceous-red, darker towards the base, but without a definite spot. Salfi (1926) disposed of many specimens of this taxon and observed that the blue colour of wings may be variable and much soften, with very small brown spots. In addition, he pointed out that male tegmina may reach the abdomen apex. I examined further specimens coming from Cyrenaica, other than those cited by Salfi (1926), finding a variability in the tibiae colour and length of male tegmina, but I found in all the females very abbreviated tegmina, as they were detected by Uvarov (1943) only in the type locality (Merg); a female with this characteristics has been detected by Ajaili \& Usmani (1999) in Fezzan and named as T. cisti $k$ haledi. When tegmina are abbreviated, hind wings are always shorter than tegmina, and the brown spot in the hind wings is more or less faint. However, the structure of hind border of pronotum in this taxon is similar to that of T. maroccanus (parabolic), and pronotum keel is more or less similar to that of T. cisti (Figs. 34, 50-51). Biometrics show the general shortness of female tegmina (Table 1). This taxon lives only in Cyrenaica and Fezzan, and I believe that it could be considered a valid species, that overlaps with $T$. cisti in Cyrenaica (cf. $T$. cisti barcaeus Salfi, 1926). 
Its description was based on the yellow colour of hind tibiae and peculiar brachypterism of two females collected in Fezzan (Sebha, Libya) (Ajaili \& Usmani 1999), characters lying within the variability of T. harterti from Cyrenaica (Libya) (see above).

\section{[Neotmethis bidentatus Usmani, 2008]}

Usmani (2008) described the genus Neotmethis, which should differ from Tmethis for the following characters: vertex moderately broad, weakly sloping forward, pronotum with median carina in prozona bilobate, in metazona not raised, metazona of pronotum thin, plate-like, hardly longer than prozona, much wider than its own length; hind wing without dark band.

As it has been discussed in the previous sections, the genus Tmethis and its species are much variable both in the structure, integuments, stoutness, presence of hairs and colour of wings and legs; characters of the genus Neotmethis lie within the variability of Tmethis. Neotmethis bidentatus has been described only on a single female, from Sebha (Fezzan) but characters listed by Usmani (2008) match rather well with the variability of $T$. harterti, of which it should be considered a junior synonym.

\section{Tmethis maroccanus Bolivar, 1908}

Material examined. Morocco, Marrakech, $7 \widehat{\partial}, 4 \uparrow$ syntypes of T. maroccanus and T. maroccanus var. incristata; El Glaui, 1ठ, 2ㅇ; Bou Lourane 15.VI.49, 2 ㅇ (MNCN).

The description was based mainly on the smooth integuments, with rounded tubercles and on the peculiar colour of hind wings, with an isolated brown spot (Bolivar 1908); these characters were also reported by Chopard (1943). Only Uvarov (1943) showed the characteristics of this taxon, that consent to separate it from T. cisti and T. pulchripennis: the shape of the pronotum is broadly parabolic, with convex margins and low keel (Figs. 36-37, 46$49,57)$. Hind tibiae are yellow, hind wings are shorter than tegmina, and in the female tegmina hardly reach hind knees. The epiphallus is similar to that of T. pulchripennis, with hind lobes relatively small and narrowly separated. When Bolivar (1908) described this species from Marrakech, from the same locality described also the var. incristata, which is an extreme case of specimens without pronotum keel and of course has no taxonomical value. It covers an inner area of Morocco (Bolivar 1908, Werner 1932). Concerning the record from Colomb-Bechar (Algeria) by Chopard (1943) see the subspecies hirtus. In addition, considering the high variability of $T$. cisti, Massa (2009) considered unlikely also the record by Usmani (2007) from South Libya (Fezzan), that in the light of characters above reported for T. harterti, could belong to this taxon (see also Neotmethis bidentatus). Consequently, T. maroccanus should cover only the inner western area of Morocco and West Algeria (see below).

\section{[Tmethis maroccanus hirtus Uvarov, 1943]}

Described from East Morocco and West Algeria (Colomb-Bechar), characterized by hind tibiae and the inside of hind femurs from bright-red to dark-red, and body and legs unusually covered by dense and long hairs. As we observed above, the genus Tmethis is very variable and the colour of hind tibiae cannot be used as diagnostic character; hairs also in some specimens may be denser than in others (e.g., T. cisti mozabiticus). Additionally, some localities of hirtus cited by Uvarov (1943) (Talialit, Midelt) overlap with the distribution of maroccanus. For these reasons I consider T. maroccanus monotypic, with hirtus its synonym.

\section{Tmethis pulchripennis (Serville, 1838)}

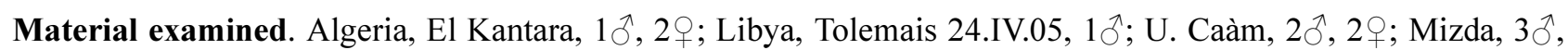
$2 \circ$; Tinaiat ben Galan, $2 \hat{\jmath}, 3 \circ$; Sebha, $1 \hat{\jmath}$; Egypt, 10, 1 + (BMCP).

According to Uvarov (1943), we may separate males of T. pulchripennis from T. cisti by the shape of epiphallus, which in the former has hind lobes relatively small and narrowly separated (Figs. 59b, 59c), whereas in the latter they are large, broadly separated (Figs. 54a, 55a). The shape of the lower valves of the ovipositor, claimed 
by Uvarov (1943) as diagnostic, actually revealed to be much variable (cf. La Greca 1969). In addition, both sexes of the two species should be separated by spurs of hind tibiae, shorter and stouter in T. pulchripennis (Fig. 59a), long and slender in T. cisti (Fig. 54b). Finally, first tarsal joint in T. pulchripennis is short, its second pulvillus is not longer than the first or the third (Fig. 59a), while in T. cisti the first tarsal joint is long, and its second pulvillus is longer than the first or third (Fig. 54b). Three subspecies have been described, namely pulchripennis (type locality: Egypt) (Figs. 52, 53), asiaticus (type locality: Khedeira, Palestine) and algericus (type locality: Algeria); the latter was found to belong to T. cisti (see above). I would preliminary confirm that the shape of lower valve of females cannot separate T. cisti from T. pulchripennis, being a very variable character. T. pulchripennis has been cited from Algeria (e.g., Maurel 2008, Benkenana et al. 2012, as algerica, which resulted to belong to $T$. cisti). However, following diagnostic characters above listed, the presence of T. pulchripennis is here confirmed in Algeria, at least in the eastern area; following the same criteria, future researches might confirm its presence in other areas of the country. In accordance with Uvarov (1943), the Egyptian taxon is smaller than that living in the Middle East, and is characterized by red hind tibiae and edges of inner hind femurs. Nevertheless, biometrics reported in Table 1 show that measurements of North African specimens are bigger than those of Middle East, which in turn show a higher s.d., depending on the higher variability. In addition, among specimens from North Africa some have yellow hind legs.

\section{[Tmethis pulchripennis asiaticus Uvarov, 1943]}

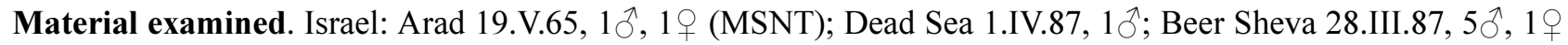

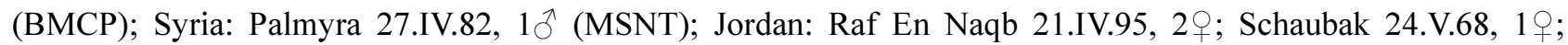

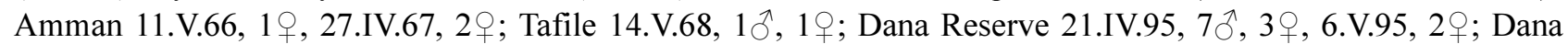

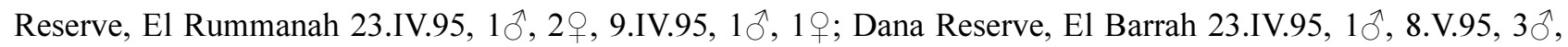

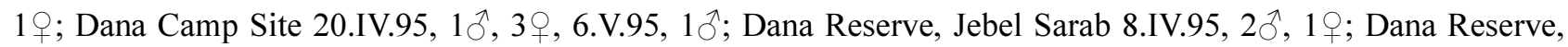
Wadi Dahel 7.V.95, 1; Wadi Dana 17.V.95, 1 \% ; End of Wadi Dana 5.IV.95, 5ð, 3ㅇ, 3.V.95, 1 ㅇ (MZR); Dana

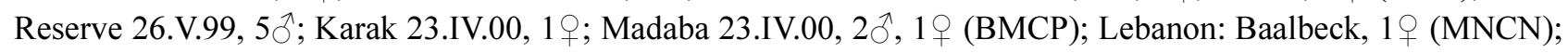

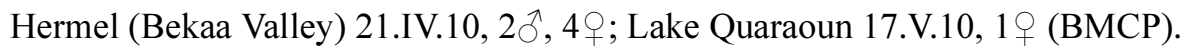

According to Uvarov (1943) it is characterized by larger size than the nominate taxon and yellow hind tibiae and edges of inner hind femurs. As above reported, specimens of Middle East resulted to be of smaller size than those of North Africa. I may confirm only the character of the hind legs, that however has been detected also in some North African specimens. Thus, also considering the high variability of T. pulchripennis, I believe that it is unjustified the taxonomic division of this taxon into subspecies.

TABLE 1. Biometrics (mean \pm standard deviation) of species of the genus Tmethis (cisti, harterti, maroccanus, pulchripennis) and its populations. Total length has been measured from the vertex to the apex of hind femurs. In parenthesis sample size: males/females.

\begin{tabular}{|c|c|c|c|c|c|c|c|c|c|c|c|c|}
\hline \multirow[t]{2}{*}{ Species/sex } & \multicolumn{2}{|c|}{ Total length } & \multicolumn{2}{|c|}{$\begin{array}{l}\text { Length of } \\
\text { pronotum }\end{array}$} & \multicolumn{2}{|c|}{$\begin{array}{l}\text { Height of } \\
\text { pronotum }\end{array}$} & \multicolumn{2}{|c|}{$\begin{array}{l}\text { Length of hind } \\
\text { femurs }\end{array}$} & \multicolumn{2}{|c|}{$\begin{array}{l}\text { Height of hind } \\
\text { femurs }\end{array}$} & \multicolumn{2}{|c|}{ Length of tegmina } \\
\hline & ठ઼ & 우안 & $\hat{\partial}$ & q9+ & $\widehat{\partial}$ & q9+ & ठ઼ & 우 & $\widehat{\partial}$ & 우 & $\hat{\partial}$ & 우우 \\
\hline & $29.7 \pm 1.4$ & $41.7 \pm 2.5$ & $8.3 \pm 0.8$ & $12.4 \pm 1.1$ & $8.3 \pm 0.7$ & $11.4 \pm 1.6$ & $15.5 \pm 0.9$ & $21.8 \pm 1.6$ & $5.3 \pm 0.5$ & $8.1 \pm 0.6$ & $24.1 \pm 1.1$ & $33.2 \pm 1.7$ \\
\hline & $26.5 \pm 0.1$ & $38.6 \pm 2.7$ & $7.2 \pm 0.6$ & $11.1 \pm 0.5$ & $7.0 \pm 0.8$ & $10.8 \pm 0.6$ & $14.5 \pm 0.1$ & $20.5 \pm 1.1$ & $4.5 \pm 0.1$ & $7.1 \pm 0.9$ & $24.4 \pm 0.6$ & $35.8 \pm 2.0$ \\
\hline & $25.7 \pm 0.9$ & $39.8 \pm 0.5$ & $7.2 \pm 0.1$ & $10.6 \pm 0.2$ & $6.8 \pm 0.1$ & $9.7 \pm 0.1$ & $13.6 \pm 0.1$ & $20.7 \pm 0.4$ & $4.0 \pm 0.1$ & $6.6 \pm 0.1$ & $22.4 \pm 0.8$ & $33.6 \pm 0.1$ \\
\hline 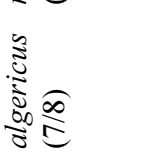 & $28.7 \pm 0.8$ & $44.0 \pm 1.5$ & $7.9 \pm 1.0$ & $12.8 \pm 1.0$ & $7.7 \pm 0.5$ & $11.9 \pm 0.8$ & $15.1 \pm 0.5$ & $22.1 \pm 0.9$ & $5.0 \pm 0.3$ & $7.4 \pm 0.6$ & $25.8 \pm 1.3$ & $35.9 \pm 1.2$ \\
\hline
\end{tabular}

......continued on the next page 
TABLE 1. (Continued)

\begin{tabular}{|c|c|c|c|c|c|c|c|c|c|c|c|c|}
\hline \multirow[t]{2}{*}{ Species/sex } & \multicolumn{2}{|c|}{ Total length } & \multicolumn{2}{|c|}{$\begin{array}{l}\text { Length of } \\
\text { pronotum }\end{array}$} & \multicolumn{2}{|c|}{$\begin{array}{l}\text { Height of } \\
\text { pronotum }\end{array}$} & \multicolumn{2}{|c|}{$\begin{array}{l}\text { Length of hind } \\
\text { femurs }\end{array}$} & \multicolumn{2}{|c|}{$\begin{array}{l}\text { Height of hind } \\
\text { femurs }\end{array}$} & \multicolumn{2}{|c|}{ Length of tegmina } \\
\hline & ठे & 우우 & $\partial \hat{\sigma}$ & 우우 & ठิં & 우 & ठ઼ & 우우 & के & 우우 & ठ઼ & 우우 \\
\hline
\end{tabular}

\section{ํํㄹำ}

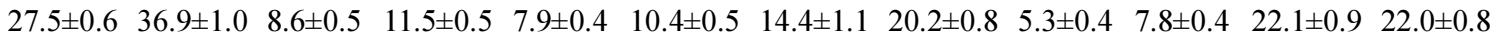

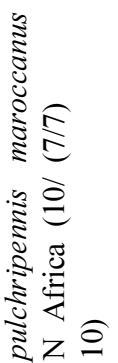

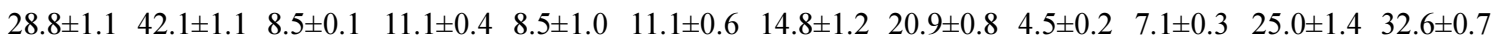

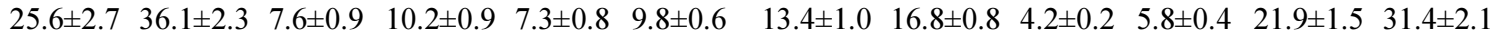

\section{Tuarega Uvarov, 1943 (type species: Tuarega insignis Uvarov)}

Uvarov (1943) erected this genus to separate the North African species Eremocharis insignis Lucas, 1851 from Asiatic ones, basing the description on the following characters: vertex narrow, frontal ridge broad, absence of pronotum keel, metazona flat and parabolic, tegmina very long, reaching the apex of hind tibiae.

\section{Tuarega insignis (Lucas, 1851)}

Material examined. Tunisia: Ludien 23.IV.1873, 2今; Mamelissa V.1873, 1 ㅇ (MSNG); Sidi Mansoun 28.VI.76, $1 \uparrow$ (MSNT); Gabés-Gafsa 1.VI.79, 1 (BMCP); Bled Segui IV.1884,

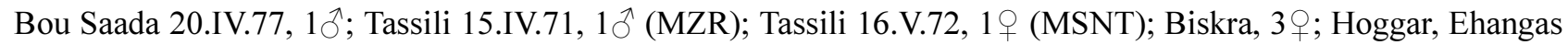
18.V.1951, ๆ; Hoggar, Terhenanet, $\odot$; Beni Abbès 27.III.1952, $\odot$; Beni Abbès, $~$ + paratype of T. sahara; Morocco: Ouarzazate 25.IV.95, $1 \delta^{\lambda}$ (BMCP); El Adoua, o; Seguiat el Amara, ô paratype of T. sahara; Smara, ô paratype of

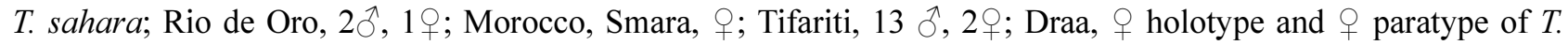

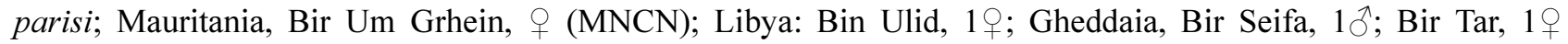
(MSNG); Ghadames, 1 ㅇ (MSNT).

Lucas (1851) described Oedipoda insignis from Algerian desert (Kefoum-Tebouc, the $q$ holotype, that should be preserved at MNHN, is not present there and probably it has been lost). According to Kirby (1910), its synonyms are Eremobia jamini Lucas, 1853 (type-locality Biskra, Algeria) and Batrachotettix elephas Saussure, 1884 (type-locality South Africa). Following authors have repeated his opinion. Nevertheless, Saussure (1884) described only the female of B. elephas and from his writing it seems evident that he referred to a species of Pamphagidae with sexual dimorphism (winged male, apterous female); in fact he wrote: "Elytra et alae?"; additionally, he described a femur shape (with enlarged upper and lower borders) that is different from that of $T$. insignis; thus, seemingly he referred to a species of South African Porthetinae, not a Thrinchinae, subfamily absent South of Sahara. Consequently, this taxon should be removed from the synonyms of $T$. insignis.

Recently Yin et al. (2011) and Yin \& Li (2011) have described other three species from Sahara desert, namely T. ouarzazatensis Yin, Husemann et Li, 2011 (Morocco), T. parisi Yin et Li, 2011 (Morocco) and T. sahara Yin et Li, 2011 (Algeria and Morocco). According to Yin et al. (2011), T. ouarzazatensis differs from T. insignis by the following characters: width of metazona of the pronotum is longer than the length of metazona (in $T$. insignis it should be shorter), median vein of tegmina is not combined with cubital vein (in $T$. insignis it is combined at 
posterior end), and cubital vein of tegmina has two branches (in T. insignis it has three branches). According to Yin \& Li (2011), T. parisi differs from T. insignis by the following characters: width of metazona of the pronotum is longer than the length of metazona, median vein of tegmina is not combined with cubital vein, median vein of tegmina has two branches (in T. insignis it has only one branch), and cubital vein of tegmina has two branches; $T$. sahara differs from $T$. insignis by the following characters: width of metazona of the pronotum is longer than the length of metazona, median vein of tegmina is not combined with cubital vein, radius vein of tegmina has five branches (in T. insignis and T. parisi it has seven branches), and cubital vein of tegmina has two branches.

Within the series of specimens examined by me, tegmina veins and the number of their branches appeared more or less variable (Figs. 60-71), independently from the geographic area of origin, including also topotypical locality of T. ouarzazatensis. This occurs frequently also in the related genus Tmethis; these characters indeed are not used to separate taxa in Thrinchinae. Concerning the ratio between the width and the length of metazona, I measured it in 50 specimens of both sexes with characters of $T$. insignis sensu Yin et al. (2011), and found in 40 cases a width shorter than length, in 2 cases width and length resulted equal, and in 8 width was longer than length. I carefully examined latter specimens and actually they showed a stout pronotum, clearly laterally enlarged. However, this sometimes occurs in Pamphagidae, mainly in species with dorso-ventrally compressed body, as Tuarega, and also Tmethis, where this ratio is very variable (cf. Figs. 73, 75 and compare them with Fig. 74). Within long series of Pamphagidae it is possible to observe single specimens showing stouter and wider body, as previously reported by Uvarov (1943). In addition, Tuarega insignis is a long-winged insect (Fig. 72), that is able to carry very long flights; this consents to cross wide desert areas without being subject to any kind of isolation. In absence of additional elements (e.g., biomolecular analysis), this is a further reason to consider the newly described species of Tuarega from Sahara as synonyms of T. insignis, a species that covers all Sahara desert.

\section{Conclusions on North African Thrinchinae}

Species of this subfamily are winged (except some taxa living in Asia); in particular the two genera living in North Africa are fully winged, only Tmethis may be represented by populations with abbreviated wings, that in some cases may be considered nearly brachypterous. While in general the isolation of long winged populations is difficult, when at least one gender has abbreviated tegmina, isolation is easier, as it occurs in squamipterous representatives of Asiatic Thrinchinae or representatives of subfamily Pamphaginae. I failed to demonstrate any clinal variation both on tibiae or wing colour and on tegmina length of Tmethis taxa; altogether, populations of North African Tmethis have a high variability, but without any seeming pattern. They are widespread in desert zones, bare grounds, grasslands, highlands and coastal dunes. It seems that populations which acquire some peculiar character, possibly due to their high mobility, merge into other populations, losing acquired characters. Thus, even if it is possible to find single populations with distinctive characters, the mixing with other populations does not consent to isolate them entirely. My conclusions are the following. Four monotypic species live in North Africa, namely T. maroccanus in Morocco and Algeria (females with abbreviated tegmina), T. cisti from Morocco to Cyrenaica (Libya), T. harterti in Cyrenaica (Libya) (females with abbreviated tegmina) and T. pulchripennis from inner Algeria to Egypt, with an extension to the Middle East (Israel, Jordan, Lebanon, Turkey, Iraq and Iran). They may be sympatric (e.g., T. cisti and T. pulchripennis in Libya, T. harterti, T. cisti and T. pulchripennis in Libya, $T$. cisti and T. maroccanus in Morocco). The genus Tuarega should be represented by only one species, that covers all desert areas of North Africa.

\section{Subfam. Pamphaginae Burmeister, 1840}

North African Pamphaginae have been studied by different orthopterists (e.g., Vosseler 1903, Bolivar 1907, 1908, 1912, 1914, Werner 1932, 1933, Chopard 1943, Uvarov 1943, Descamps 1968, Descamps \& Mounassif 1972, La Greca 1993). Nearly all the species are squamipterous, character that has been almost lost in Asian species (it is maintained only in few Middle East genera, others are completely apterous). Thus, we may consider that squamipterous Pamphaginae should have evolved in North Africa. 


\section{Finotia Bonnet, 1884 (type-species: Finotia spinicollis Bonnet)}

The genus Finotia is characterized by the absence of wings and Krauss's organ, and the tympanum partially covered. The presence/absence of the Krauss's organ is a character used to divide Pamphagidae into subfamilies (e.g., Storozhenko \& Paik 2011); the loss of this ancestral character in the genera Finotia and Ocneridia should be considered apomorphic, and consequently it does not seem useful to distinguish subfamilies (cf. Massa 2012a).

\section{Finotia spinicollis Bonnet, 1884}

Material examined. Tunisia, Bir Arrach, $1 \hat{\jmath}$ holotype, $1 \propto$ allotype, $1 \propto$ paratype; Sfax, $2 \hat{\jmath}, 1 \propto$; B. Ali ben Habid, $1 \uparrow(\mathrm{MNHN})$; Bir Arrach, $3{ }^{\lambda}, 2 \circ$; Gafsa, $1 \uparrow(\mathrm{MNCN})$.

This taxon is endemic to central Tunisia.

\section{Finotia maxima Jannone, 1938}

Material examined. Libya, Gasr Garabulli (Tripolitania), $1 \hat{\jmath}$ allotype, 1 ㅇ holotype, $3 \hat{\jmath}, 3 \uparrow$ paratypes (DAP). Jannone (1938) listed the following main characters to separate maxima from spinicollis: larger size, longer antennae, mesonotum longer in the middle, epiproct larger than long. It lives in Libya (Tripolitania).

\section{Tribe Pamphagini Burmeister, 1840}

\section{Ocneridia Bolivar, 1912 (type-species: Porthetis canonicus Fischer)}

This is the only genus of the tribe Pamphagini without the Krauss's organ; this absence is found also in the genus Finotia, belonging to the tribe Finotiini. Massa \& Biondi (1986) revised the genus Ocneridia and proposed a key to the following valid species: Ocneridia volxemii (Bolivar, 1878) (Morocco and Algeria), Ocneridia microptera (Brisout de Barneville, 1851) (Algeria) (Fig. 4) and Ocneridia nigropunctata (Lucas, 1849) [= Ocneridia canonica Fischer, 1853] (Algeria, Tunisia, North-West Libya and Italy (Sicily)) (Figs. 3, 6).

\section{Glauia Bolivar, 1912 (type species: Nocarodes durieui Bolivar)}

A key to species is reported by Massa (2012b). Currently, only three are considered as valid species: Glauia saharae Morales Agacino et Descamps, 1968, Glauia tricolor Morales Agacino et Descamps, 1968 and Glauia durieui (Bolivar, 1878).

\section{Glauvarovia Morales Agacino, 1945 (type species: Glauvarovia mendizabali Morales Agacino)}

Only one species is known in Morocco, Glauvarovia mendizabali Morales Agacino, 1945.

\section{Pseudoglauia Morales Agacino et Descamps, 1968 (type species: Glauia terrea Bolivar)}

A key to species is reported by Morales Agacino \& Descamps (1968); see also Massa (2012b). Currently only two species are known, both in the South of Morocco, Pseudoglauia tarudantica (Bolivar, 1914) and Pseudoglauia terrea (Bolivar, 1912).

\section{Amigus Bolivar, 1914 (type species: Eumigus nigroadspersus Bolivar)}

\section{Amigus nigroadspersus (Bolivar, 1907)}

Material examined. Morocco, Marrakech, 21 $\hat{\partial}, 5$ 우 syntypes (MNCN); $30 \mathrm{~km} \mathrm{~N}$ Marrakech 14.IV.1995, 3ภ, 2 우 (BMCP). 
Bolivar (1914) established nigroadspersus as the type-species of this genus; I agree with La Greca (1993) who moved again this species to the genus Amigus, previously synonymized with Paraeumigus by Dirsh (1958). The shape of the pronotum, tegmina, prosternal tubercle and genitalia (Figs. 146-148) consent to establish that it is not related to Paraeumigus nor to Euryparyphes, but to Acinipe and related genera; thus, it belongs to the tribe Pamphagini.

\section{Pseudoamigus Chopard, 1943 (type species: Paraeumigus villiersi Chopard)}

This Moroccan genus has been described only on a female; another female has been reported by La Greca (1993), who wrote that in absence of the male it is not possible to establish to which tribe it belongs. The sole species known, Pseudoamigus villiersi (Chopard, 1939) (Fig. 22), has not oval tegmina, typical character of Euryparyphini; thus, I place provisionally it within the tribe Pamphagini.

\section{Pamphagus Thunberg, 1815 (type-species: Gryllus elephas Linnaeus)}

A key to species has been proposed by Massa et al. (1993); it includes the following taxa, three of which live in Italy and are not present in North Africa: Pamphagus caprai Massa, 1992 (East Morocco and West Algeria), Pamphagus elephas (Linnaeus, 1758) (Central-North Algeria), Pamphagus cristatus Descamps et Mounassif, 1972 (East Algeria and West Tunisia), Pamphagus djelfensis Vosseler, 1902 (central inner Algeria, also found at Belezma, near Batna, by Benkenana et al. 2012), Pamphagus tunetanus Vosseler, 1902 (North Tunisia and West Libya), Pamphagus meridionalis Descamps et Mounassif, 1972 (Central Tunisia), Pamphagus marmoratus Burmeister, 1838 (Italy, Sicily), Pamphagus sardeus Herrich-Schaeffer, 1840 (Italy, Sardinia), Pamphagus ortolanii Cusimano et Massa, 1976 (Italy, Lampedusa Is.), Pamphagus auresianus Massa, 1992 (Algeria, Aurés Mts.) and the recently described Pamphagus batnensis Benkenana et Petit, 2012 (Aurés Mts.). Bounechada et al. (2006) and Benkenana et al. (2012) have also listed from Algeria Pamphagus marmoratus, that Massa et al. (1993, 2012) consider an endemic taxon to Sicily (Italy). A deeper comparison of specimens should be carried out and for the moment I consider Algerian specimens as $P$. cf. marmoratus. In addition, the record of P. elephas from Fezzan by Usmani (2007) should be revisited on the light of keys proposed in the papers of Descamps \& Mounassif (1972) and Massa et al. (1993).

\section{Paracinipe Descamps et Mounassif, 1972 (type-species: Pamphagus mauritanicus Bolivar)}

This genus has been described by Descamps \& Mounassif (1972) to distinguish species with the subgenital plate of males divided into two parts from the true Acinipe, with undivided subgenital plate. Paracinipe is widespread from Morocco to Egypt and the Middle East, while Acinipe has a more western distribution, that covers Iberian peninsula, North Africa (from Morocco to Tunisia) and Italy (Calabria and Sicily). On the whole, 17 species of Paracinipe are currently known. Four groups of species are recognized, exarata, zebrata, dolichocera and mauritanica; after the revision of Descamps \& Mounassif (1972), Massa $(1996,1998)$ examined the zebrata group, proposing a key to species of that group. Now I propose a new key that includes the four groups.

1. Hind border of pronotum more or less straight, not narrowing along paranota (Fig. 81); hind tibiae very hairy; upper surface of scape and pedicellus red. Aedeagus valves slender, epiphallus short with few spines and small hind concavity (Figs. 92-93). Central Morocco . . . . . . . . . . . . . . . . . . . . . . . . . . . . . . . . Paracinipe exarata (Bolivar, 1936). Hind border of pronotum clearly narrowing along paranota; hind tibiae less hairy; upper surface of scapus and pedicellus never

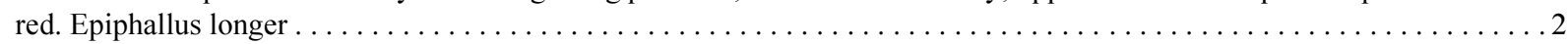

2. Metanotum and first abdominal tergite wrinkled and covered by 4-6 small longitudinal keels on the sides of central keel; pronotum with rounded and evident tubercles; if these are not evident, wide blue spots inside of hind femurs. From South Algeria

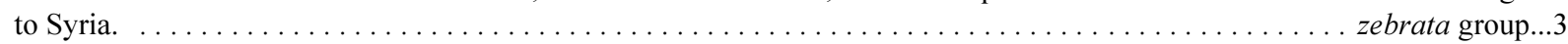

- $\quad$ Metanotum and first abdominal tergite smooth or just wrinkled, without lateral keels; pronotum without evident tubercles; inside of hind femurs without blue spots; pronotum keel more raised . . . . . . . . . . . . . . dolichocera group...10

3. Antennae not longer than head and pronotum together; basal carinula of inside of hind femurs sinuous; inside of hind femurs with some white spots. Aedeagus valves stout, epiphallus with big spines (Figs. 88-89). Egypt and Israel . . . . . . . . . .

Paracinipe zebrata (Brunner von Wattenwyl, 1882). Antennae longer than head and pronotum together; upper surface of scape and pedicellus white; basal carinula of inside of hind femurs not sinuous; inside of hind femurs white or with dark spots. Libya, Tunisia and Algeria $\ldots \ldots \ldots \ldots \ldots \ldots \ldots$ 
4. Head, pronotum, metanotum and first abdominal tergites with many impressed points; sometimes pronotum covered by a net-

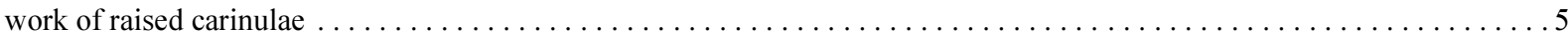
Head smooth, often with some small white points and a network of carinulae behind the eyes. Pronotum covered by more or less wide tubercles, evidently raised. Fore and hind borders of the pronotum thick, with white and dark spots . . . . . . . 8

5. Pronotum keel in lateral view arched or sinuous. Abdominal keel toothed. Inside of hind femurs white or with some dark spots. Inside of hind tibiae grey, yellowish or pink, spines with base and tip black-bluish or with only tip black. Subgenital plate of

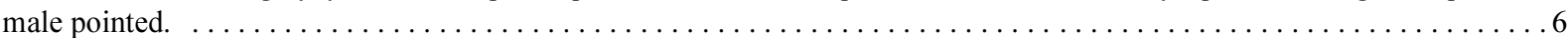
Pronotum keel in lateral view not arched, more or less straight; abdomen rounded without evident keel. Inside of hind femurs white with evident dark spots. Inside of hind tibiae dark grey or blue, spines red or yellow with base and tip black-bluish, or yellow with blue at the base. Subgenital plate of male rounded. $\ldots \ldots \ldots \ldots \ldots \ldots \ldots \ldots \ldots \ldots \ldots \ldots \ldots$

6. Teguments covered by many impressed points. Pronotum arched and raised (Fig. 85). Inside of hind femurs with some dark spots only along carinulae. Inside of hind tibiae grey or yellowish, spines with black tip. Cerci of the male ca. 1.7 times longer than wide. Aedeagus valves long and slender, epiphallus with raised keels bearing small spines (Figs. 90-91). North-eastern Libya. . . . . . . . . . . . . . . . . . . . . . . . . . . . . . . . . . . . . . . Paracinipe orientalis (Werner, 1908). Teguments smooth, with some impressed points and a network of raised carinulae. Pronotum keel not evidently raised or sinuous (Fig. 82). Inside of hind femurs with dark spots in the medial area. Inside of hind tibiae yellowish or pinkish, spines with black base and tip. Cerci of the male ca. 1.2 times longer than wide. Aedeagus valves long and stout, epiphallus with big spines (Figs. 98-99). North-western Libya. . . . . . . . . . . . . . . . . . . . . . . . . . . . . Paracinipe adelaidae Massa, 1996.

7. Pronotum more wrinkled, pronotum keel straight (Fig. 83). Inside of hind tibiae blue or dark grey, spines red or yellow with blue base and tip. Aedeagus valves stout, epiphallus with few big spines, and hind border deeply concave (Figs. 100-101). Central-western Tunisia and eastern Algeria. . . . . . . . . . . . . . . Paracinipe saharae (Pictet et Saussure, 1891).

- $\quad$ Pronotum less wrinkled, pronotum keel just arched. Inside of hind tibiae yellow, spines with blue base. Hauts Plateaux and Aurés Mts. (Algeria) . . . . . . . . . . . . . . . . . . . . . . . . Paracinipe sulphuripes $($ Uvarov, 1942)

8. Pronotum and metanotum saddle shaped, pronotum keel after sulcus going down and metanotum going up, often sinuous; pronotum in dorsal view with some broad tubercles along its borders. Hind border of pronotum straight. Abdomen more or less rounded, dorso-ventrally compressed; second tergite larger than pronotum. Subgenital plate of male rounded. . . . . . . .99 Pronotum and metanotum not saddle shaped, pronotum in dorsal view without tubercles on its borders (Fig. 86). Hind border of pronotum with acute angle. Abdominal keel more evident, abdomen just laterally compressed; pronotum larger than second tergite. Inside of hind tibiae yellowish, spines with black-bluish base and tip. Subgenital plate of male pointed upwards. Aedeagus valves stout, epiphallus with big spines (Figs. 96-97). North Libya. . . . . . . . . . . . Paracinipe baccettii Massa, 1996.

9. Pronotum tubercles less pointed (Fig. 84). Male cerci ca. 1.2 times longer than wide. Inside of hind femurs white or with some brown spots. Inside of hind tibiae bluish, yellow spines with bluish base and tip. Body less stout and large. Aedeagus valves slender, epiphallus with small spines and concave hind border (Figs. 94-95). Central Tunisia. . . . . . . . . . . . . . . . . . .

Paracinipe foreli (Pictet et Saussure, 1891).

- $\quad$ Pronotum tubercles broader and more pointed (particularly in males). Pronotum more or less undulate (Fig. 87). Body stouter and larger. Male cerci ca. 1.6-1.8 times longer than wide. Inside of hind tibiae yellowish, bluish, pinkish or reddish, spines with black tip and in some specimens with bluish base. Aedeagus valves slender, epiphallus with small spines and a small hind concavity (Figs. 102-103). North Libya. . . . . . . . . . . . . . . . . . . . . . . . . Paracinipe marmarica (Salfi, 1924).

10. Krauss's organ wrinkled; inside of hind tibiae unicoloured, red, yellow, grey, spines with black base. . . . . . . . . 11

- Krauss's organ smooth; inside of hind tibiae bicoloured, blue with yellow or red apex or yellow with spines without dark base.

11. Larger size (Fig. 76, Table 2), inside of hind femurs without white spots, inside of hind tibiae of male generally yellow. Central Morocco (Fig. 107) . . . . . . . . . . . . . . . . . . . . . . . . . . . . . . . . . . . . . . Paracinipe dolichocera (Bolivar, 1907) Smaller size (Fig. 77, Table 2), inside of hind femurs with white spots, inside of hind tibiae of male generally red. South west-

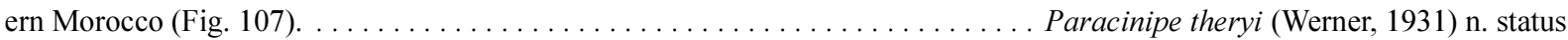

12. Yellow colour of hind tibiae not exceeding the fourth spine from the apex; interval between the fourth and the fifth spines

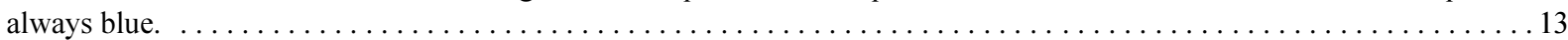
Yellow or red colour of hind tibiae reaching at least the fifth spine from the apex. $\ldots \ldots \ldots \ldots \ldots \ldots \ldots \ldots \ldots 14$

13. Male cerci ca. 2 times longer than wide; hind tibiae often red; epiphallus without bilobate hind border (Fig. 106). West Morocco. . . . . . . . . . . . . . . . . . . . . . . . . . . . . . . . . Paracinipe alticola (Werner, 1932) (Fig. 79) Male cerci ca. 1.2 times longer than wide; hind tibiae often yellow; epiphallus with bilobate hind border. Morocco (from High Atlas to Toubkal National Park). . . . . . . . . . . . . . . . . Paracinipe luteomaculata Descamps et Mounassif, 1972

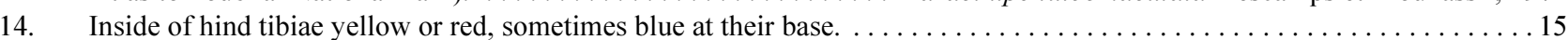

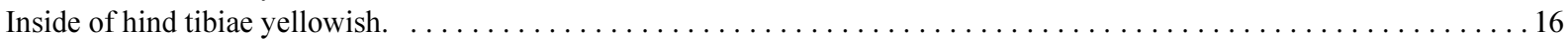

15. Inside of hind tibiae yellow; hind part of epiphallus much wide in lateral view. Morocco (High Atlas) . . . . . . . . . . . .

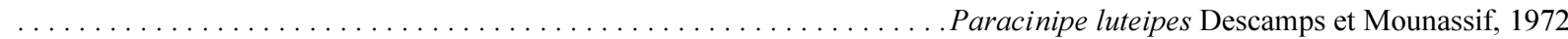
Inside of hind tibiae red; hind part of epiphallus narrow in lateral view. Morocco (High Atlas).

Paracinipe rubripes Descamps et Mounassif 1972

16. Pronotum less raised (Fig. 78), prosternum process cubic, not longer than wide; mesosternal space just longer than wide. Aedeagus valves short and stout, hind part of epiphallus narrow and with long apexes (Figs. 104-105). Western Morocco. .......

Paracinipe mauritanica (Bolivar, 1878)

Pronotum more raised (Fig. 80), prosternum process parallelepiped, clearly longer than wide, mesosternal space ca. two times longer than wide; hind part of epiphallus bulging in lateral view. Western Morocco. . Paracinipe crassicornis (Bolivar, 1907) 
Material examined. Morocco, Tiliuin, $\widehat{\partial}$ paratype, $1 \uparrow$ paratype; Ain Aguisgal, $q$ paratype; El Mahasser (Sous),

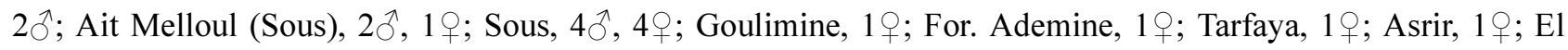
Aioun du Draa, $1 \uparrow(\mathrm{MNHN})$; Sidi Ifni, Tiliuin, $\widehat{\partial}$ holotype, $q$ allotype; Tiliuin, $\hat{o}$ paratype, $1 \uparrow$ paratype; Amel-lù

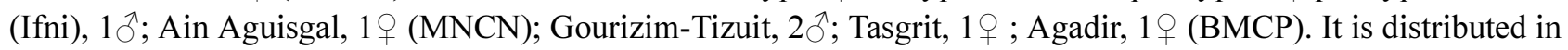
the western area of Morocco.

\section{Paracinipe adelaidae Massa, 1996}

Material examined. Libya, Homs IV.1926, ðึ holotype (MSNG); Tauorga 30.VIII.1938, đo paratype; Bu Gheilan

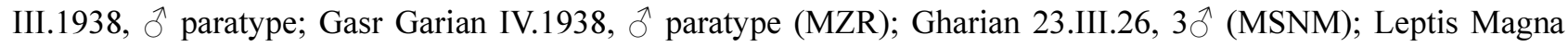
5.IV.98, $2 \widehat{\jmath}, 2$; $20 . \mathrm{IV} .2005,19$ (BMCP). It is endemic to Tripolitania (Libya).

\section{Paracinipe baccettii Massa, 1996}

Material examined. Libya, Ain Zara V.1928, $1 \delta^{\Uparrow}$ holotype, $1 \delta^{\lambda}, 1 q$ paratypes; Homs V.1926, $1 q$ paratype; Castel Benito IV.1937, $1 \propto$ paratype (MZR); Homs IV.1926, 19 paratype (MSNG); Gasr Garabulli 16.IV.37, $2 \hat{\jmath}, 2$; Benghasi 1935, $2 \overbrace{}^{\lambda}$ (DAP); En Ngila 13.III.26, $3 \jmath^{\lambda}, 2$ (MSNM). It is distributed in North Libya.

\section{Paracinipe foreli Pictet et Saussure, 1893}

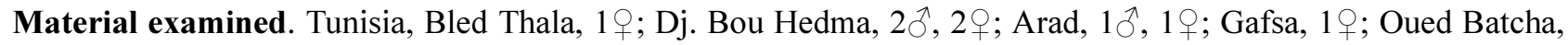

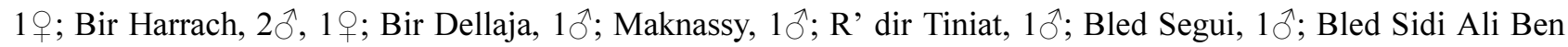

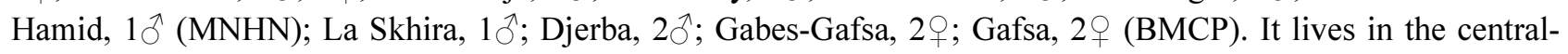
South Tunisia (Djerba Is. included).

\section{Paracinipe marmarica (Salfi, 1925)}

Material examined. Libya, Tobruk III.24, $1 \delta^{\lambda}$ holotype; Maten Giofer III.33, 1 ๙, 1 \% ; Ghemines III.1928, $1 \delta^{\lambda}$; Bir

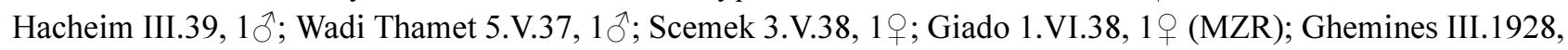
$1 \hat{\jmath}$ (MSNG); 40 miles South of Mizda 1.IV.52 1§; Beni Ulid 13.VII.55, 1 q (MNHN). It is distributed in North Libya.

\section{Paracinipe orientalis (Werner, 1908)}

Material examined. Libya, Cyrene 10.V.24, $1 \hat{O}, 1 q$ syntypes of $P$. orientalis cyrenaica Salfi, 1926; Derna

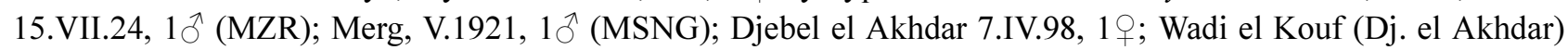

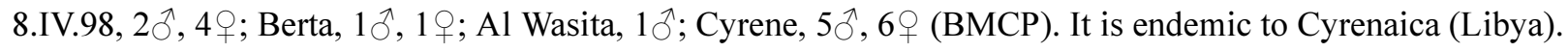

\section{Paracinipe saharae (Pictet et Saussure, 1893)}

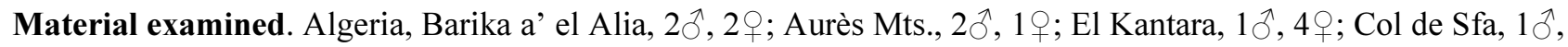

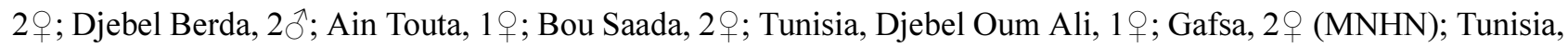
Djebel Bireno, 1 $\delta^{\lambda}$; Tamerza, $1 \delta^{\lambda}$ (BMCP). It lives in central-South Tunisia and East Algeria. The record from Fezzan reported by Usmani (2007) should be revisited on the light of keys proposed by Descamps \& Mounassif (1972) and Massa (1996, 1998); however, Usmani (2007) records from Fezzan the presence of Acinipe expansa, of which has depicted male genitalia; the shape of epiphallus, with hind evident concavity, is typical of the genus Paracinipe, and probably the species actually belongs to P. saharae (see also Massa 2009). 
Material examined. Algeria, El Gouttaya, $1 \hat{\partial}, 1 \propto(\mathrm{MNHN})$. It lives on the Hauts Plateaux (central Algeria) and in the Batna Wilaya, at Belezma (East Algeria) (Benkenana et al. 2012).

\section{Paracinipe zebrata (Brunner von Wattenwyl, 1882)}

Material examined. "Syria" (probably the area now belonging to Israel), $1 \hat{\jmath}, 1 \uparrow$ lectotypes (NMW). It covers Egypt and Israel.

\section{Paracinipe dolichocera (Bolivar, 1907) [= Paracinipe dolichocera ornata (Werner, 1932)]}

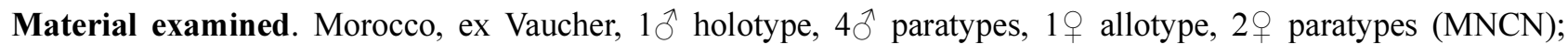

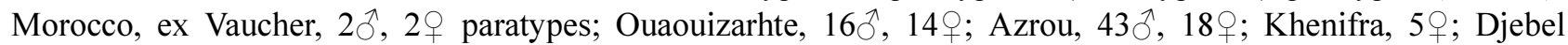

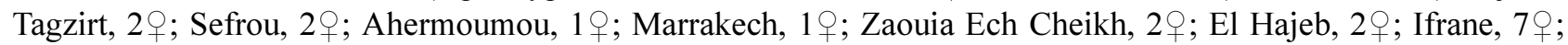
Immouzer du Kandar, 3 ? (MNHN). It inhabits the West Morocco (Fig. 107).

\section{Paracinipe theryi (Werner, 1931) new status [= Acinipe mauritanica f. prasina Bolivar, 1935]}

Material examined. Morocco, ex Vaucher, $3 \hat{\gamma}, 1 \%$; Msuda (=M'Zouda), $\hat{\delta}$ syntype of Acinipe mauritanica $\mathrm{f}$.

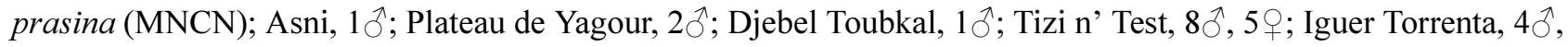
5 은 $(\mathrm{MNHN})$.

Descamps \& Mounassif (1972) considered this taxon as subspecies of P. dolichocera; actually the two taxa are confined to three different mountainous Morocco areas, Ifrane National Park (between Sefrou and Azrou), Zaida National Park (between Khenifra and Marrakech) and Toubkal National Park (between Marrakech and Ouarzazate). P. dolichocera lives only on the first two areas, while the other taxon only on the third area and between Marrakech and Chichaoua (Fig. 107). Biometrics of the two taxa are rather different, being P. dolichocera stouter than $P$. theryi. In particular hind femurs of the former are clearly stouter than those of the latter (Table 2). Figs. 108-109 show the ratio length/height of hind femurs versus length/height of pronotum of both sexes; it seems evident that the overlap is very low. Other than measurements, $P$. dolichocera differs from $P$. theryi also for the absence of white spots inside of the hind femurs, instead of presence in the other taxon. Thus, I consider $P$. theryi as a valid species. Acinipe mauritanica f. prasina described by Bolivar (1935) from Msuda (=M'Zouda) and characterized by a white stripe on the abdomen and green colour, actually is Paracinipe theryi.

\section{Paracinipe luteipes Descamps et Mounassif, 1972}

This species, not examined in my study, is known only from South-West Morocco (Timkyet, South of Tafraoute).

\section{Paracinipe rubripes Descamps et Mounassif, 1972}

This species, not examined in my study, is known only from Djebel Azourki (Morocco, East of Marrakech).

\section{Paracinipe alticola (Werner, 1932)}

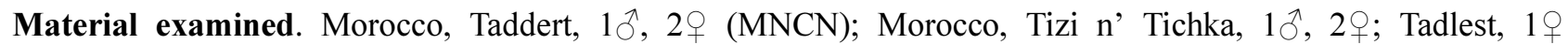
(MNHN). It is known from central Morocco; the type-locality (Tadlest) is placed North of Ouarzazate, Taddert is South of Agadir, and Tizi n' Tichka between Ouarzazate and Marrakech.

\section{Paracinipe luteomaculata Descamps et Mounassif, 1972}

Material examined. Morocco, Ijoukak, $1 \hat{\jmath}$ holotype, $1 \uparrow$ allotype, $1 \uparrow$ paratype; Tizi n’ Test, $1 \hat{\jmath}$ paratype, $2 q$ paratypes; Dar Goundafi, $2 \hat{\jmath}, 5 \circ$ paratypes; Idni, $1+$ paratype (MNHN). It lives from High Atlas to Toubkal National Park (central-South Morocco). 


\section{Paracinipe mauritanica (Bolivar, 1878)}

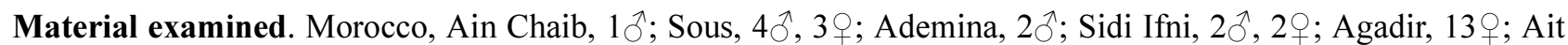

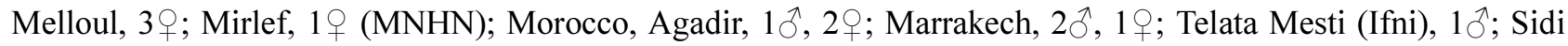

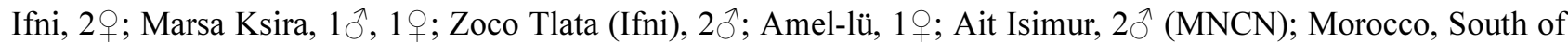

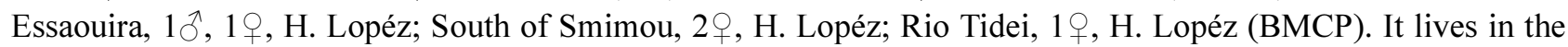
central-South Morocco. Acinipe mauritanica f. prasina described by Bolivar (1935) from Msuda (=M'Zouda) actually is Paracinipe theryi.

\section{Paracinipe crassicornis (Bolivar, 1907)}

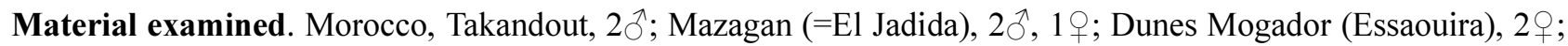
Casablanca, $1 \circ$; Sidi Ahmed Said, $19(\mathrm{MNHN})$; Mazagan (=El Jadida), $5{ }^{\lambda}, 5 \circ$ syntypes; Mogador (Essaouira), 6 $\lambda, 7$ ㅇ syntypes (MNCN). It lives in West Morocco.

TABLE 2. Biometrics (mean \pm standard deviation) of species of the genus Paracinipe. Total length has been measured from the vertex to the apex of hind femurs. In parenthesis sample size: males/females.

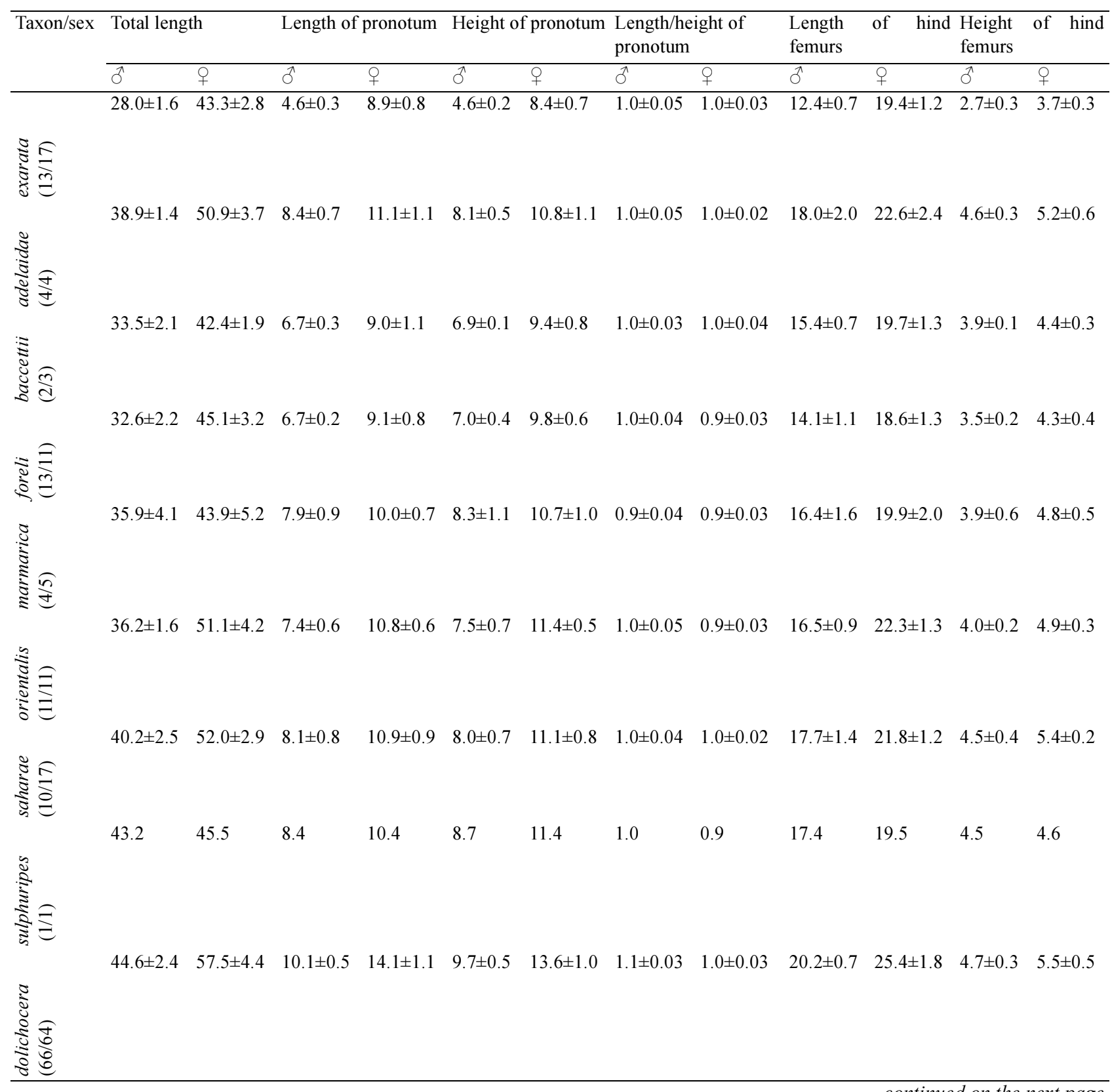


TABLE 2. (Continued)

\begin{tabular}{|c|c|c|c|c|c|c|c|c|c|c|c|c|}
\hline \multirow[t]{2}{*}{ Taxon/sex } & \multicolumn{2}{|c|}{ Total length } & \multicolumn{2}{|c|}{ Length of pronotum } & \multicolumn{2}{|c|}{ Height of pronotum } & \multicolumn{2}{|c|}{$\begin{array}{l}\text { Length/height of } \\
\text { pronotum }\end{array}$} & \multirow{2}{*}{$\begin{array}{l}\text { Length } \\
\text { femurs } \\
0\end{array}$} & of hind & $\begin{array}{l}\text { Height } \\
\text { femurs }\end{array}$ & \multirow[t]{2}{*}{ of hind } \\
\hline & $\bar{\sigma}$ & P & $\hat{0}$ & P & $\hat{\sigma}$ & P & $\hat{0}$ & P & & क & $\pi$ & \\
\hline & $32.8 \pm 1.7$ & $44.2 \pm 2.6$ & $6.7 \pm 0.3$ & $9.8 \pm 0.9$ & $6.9 \pm 0.4$ & $10.4 \pm 0.8$ & $1.0 \pm 0.03$ & $0.9 \pm 0.02$ & $14.9 \pm 0.6$ & $19.4 \pm 1.6$ & $3.2 \pm 0.2$ & $3.9 \pm 0.4$ \\
\hline & 27.2 & $39.5 \pm 0.7$ & 5.4 & $9.1 \pm 0.1$ & 5.8 & $9.4 \pm 0.6$ & 0.9 & $1.0 \pm 0.04$ & 12.7 & $17.1 \pm 0.6$ & 2.9 & $3.8 \pm 0.1$ \\
\hline 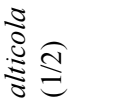 & & & & & & & & & & & & \\
\hline 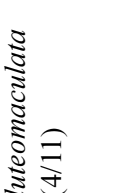 & $30.9 \pm 1.7$ & $43.1 \pm 2.9$ & $6.5 \pm 0.4$ & $10.3 \pm 0.5$ & $6.7 \pm 0.5$ & $10.7 \pm 0.4$ & $1.0 \pm 0.03$ & $1.0 \pm 0.03$ & $13.5 \pm 0.5$ & $17.9 \pm 0.8$ & $3.6 \pm 0.1$ & $4.3 \pm 0.2$ \\
\hline 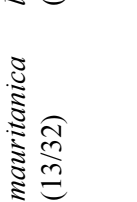 & $28.5 \pm 2.3$ & $40.2 \pm 3.2$ & $5.7 \pm 0.6$ & $8.7 \pm 0.9$ & $5.6 \pm 0.7$ & $8.9 \pm 0.8$ & $1.0 \pm 0.05$ & $1.0 \pm 0.03$ & $12.1 \pm 0.8$ & $16.7 \pm 1.4$ & $3.1 \pm 0.3$ & $3.7 \pm 0.3$ \\
\hline 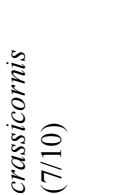 & $30.8 \pm 2.5$ & $42.0 \pm 3.2$ & $6.8 \pm 0.6$ & $9.9 \pm 1.1$ & $7.1 \pm 0.7$ & $10.4 \pm 0.9$ & $0.9 \pm 0.02$ & $1.0 \pm 0.03$ & $14.1 \pm 1.0$ & $18.5 \pm 2.0$ & $3.5 \pm 0.1$ & $4.0 \pm 0.2$ \\
\hline
\end{tabular}

\section{Acinipe Rambur, 1838 (type-species: Acinipe hesperica Rambur)}

This genus has been revised by Descamps \& Mounassif (1972), Biondi \& Massa (1995) (with the exclusion of Iberian species) and Llorente del Moral \& Presa Asensio (1997) (only Iberian species); thus, keys to all the species are available. On the whole, 18 species are known in North Africa, of which one (A. hesperica) is represented by six subspecies. Further eight species are known from the Iberian peninsula. When Biondi \& Massa (1995) revised the genus, they did not dispose of specimens of Acinipe calabra from Calabria (type locality) to compare with $A$. calabra from North Africa; now I examined 3 males from Bova (Reggio Calabria) and found the same small differences detected comparing specimens from Sicily with those of North Africa: aedeagus valves from back view are just wider in typical calabra than in North African specimens. However, I did not find other differences. Biondi \& Massa (1995) did not find biometric differences between North African and Sicilian specimens; thus, I consider them conspecific. This is the current list of North African species: Acinipe algerica (Brunner von Wattenwyl, 1882), Acinipe algeriensis Descamps et Mounassif, 1972, Acinipe angustipennis Chopard, 1943, Acinipe arthemisiae Descamps et Mounassif, 1972, Acinipe atlantis Descamps et Mounassif, 1972, Acinipe bicoloripes Descamps et Mounassif, 1972, Acinipe calabra (Costa, 1836), Acinipe dissipata Descamps et Mounassif, 1972 , Acinipe expansa (Brunner von Wattenwyl, 1882), Acinipe hesperica hesperica Rambur, 1838 (with the following subspecies, that should deserve further studies: Acinipe hesperica ahansala Descamps et Mounassif, 1972, Acinipe hesperica coerulipes Descamps et Mounassif, 1972, Acinipe hesperica lepineyi Chopard, 1943, Acinipe hesperica melillensis Bolivar, 1912, Acinipe hesperica pygmaea Descamps et Mounassif, 1972), Acinipe minima Werner, 1931, Acinipe muelleri (Krauss, 1893), Acinipe nadigi Descamps et Mounassif, 1972 [= Acinipe nadigi punctata Descamps et Mounassif, 1972], Acinipe rifensis Descamps et Mounassif, 1972, Acinipe rungsi Descamps et Mounassif, 1972, Acinipe strigata Roberts, 1938, Acinipe tibialis (Fieber, 1853), Acinipe tubericollis Werner, 1932. 


\section{Nadigeumigus La Greca, 1993 (type-species: Nadigeumigus mirabilis La Greca)}

This genus has been erected by La Greca (1993) to include the species Nadigeumigus mirabilis La Greca, 1993; it is closely related to Euryparyphes, from which it differs only by its phallic complex characteristics. The aedeagus valves are long, narrow and tubular, apically open; in addition, the epiphallus has ancorae reduced to two tuberosities, the hind border is deeply concave between lophi, that bear some small black spines.

\section{Euryparyphes Fischer, 1853 (type-species: Porthetis terrulenta Serville)}

A revision of the genus has been carried out by La Greca (1993), and a key to species by Massa (2012b). Characters of the genus are: prosternal process straight or slightly sloping, bi-pointed, vertex not protruding; median pronotal keel longitudinally furrowed (in some taxa only visible at high magnification), more or less raised, generally interrupted by the transverse sulcus (with some exceptions); pronotal lateral keels present or just evident (more evident when the median keel is straight). Mesosternal space is as wide as long or just wider than long in males and wider than long in females, metasternal space two times wider than long in males, three times in females. Hind border of pronotum is undulated or festooned; tegmina are oval, ca. two times longer than broad, brown with a whitish dorsal side, marked with a narrow brown line (absent in some species). First abdominal tergites are more or less toothed. Dorsal keel of hind femora is undulated or with very small spines, inner ventral keel with more or less evident spines (La Greca 1993, Llorente del Moral \& Presa Asensio 1997, Massa 2012b). It is closely related to Paraeumigus Bolivar, 1914. According to Chopard (1943) the latter is characterized by a prosternal gorget (Figs. 142, 149, 153), but La Greca (1993) considers that only the shape of the aedeagus valves permits the separation of the two genera. In Euryparyphes, valves in ventral view are more or less rhomboidal and may be of two types: 1) present in the species characterized by raised pronotum, in which the central part of aedeagus is concave and consists of two triangular median plates, each paired with a main keel; lateral secondary keels are present, which produce a lateral concavity; 2) present in the species with low or straight pronotum keel, in which the apical borders are much longer than basal ones, the base of apical valves shows short columnar keels, separated by similar furrows; main keels do not differ from secondary keels, and the lateral concavity is absent. In contrast to Euryparyphes, Paraeumigus shows a swollen base of valves, provided with columnar keels, without distinction between main and secondary keels; the apical part over the base is narrow, develops parallel to one other, and enlarges apically in two pairs of membranous lobes, one pair per valve; the base of apical valves is characterized by 3-4 columnar keels per side. Additionally, Euryparyphes species have clearly oval tegmina (Figs. 110-113), while Paraeumigus ones have less oval tegmina, with upper border more or less straight (Figs. 123-145, 150-160). Massa (2012b) recognized 14 species of Euryparyphes; another one is here described from Middle Atlas, amounting to 15 species on the whole.

\section{Species with aedeagus of the type 1}

Euryparyphes bolivari (Stål, 1876) [= Euryparyphes vaucherianus (Saussure, 1887) = Euryparyphes olcesei (Bolivar, 1907) = Euryparyphes kenitranus Werner, 1932], Euryparyphes gharbensis Defaut, 1987, Euryparyphes defauti La Greca, 1993, Euryparyphes tazzekensis La Greca, 1993, Euryparyphes laetus (Bolivar, 1907) [= Euryparyphes stali $($ Bormans, 1879) = Euryparyphes septentrionalis Werner, 1932], Euryparyphes mamorensis Defaut, 1987, Euryparyphes flexuosus Uvarov, 1927 [= Euryparyphes paraflexuosus La Greca, 1993], Euryparyphes maroccanus (Saussure, 1887).

\section{Species with aedeagus of the type 2}

Euryparyphes cinerascens La Greca, 1993, Euryparyphes pictipes Uvarov, 1927, Euryparyphes atlasicus La Greca, 1993, Euryparyphes nigripes La Greca, 1993, Euryparyphes breviphallus La Greca, 1993, Euryparyphes sitifensis (Brisout, 1854), Euryparyphes rungsi n. sp. 


\section{Euryparyphes rungsi $\mathrm{n} . \mathrm{sp}$.}

Material examined. Middle Atlas, Col du Zad 27.VIII.1954 (2200 m), C. Rungs, $\widehat{\jmath}$ holotype, $\uparrow$ allotype, + paratype (MNCN)

Among the long series of Euryparyphes collected in Morocco, preserved in the Museo Nacional de Ciencias Naturales of Madrid there are three specimens collected by Charles Rungs, who wrote on a second label: Euryparyphes sp. nov. aff. pictipes.

Diagnosis. It is a very small Euryparyphes (see Measurements), similar to E. pictipes and E. atlasicus. Its pronotum is straight in lateral view, just enlarged, with stout median keel; lateral keels are evident and converging backwards.

Description. Small differences between the sexes. Size small (see measurements). Antennae 13- (male) and 17- (female) segmented, shorter than head and pronotum together. Median keel stout, interrupted by the typical sulcus, furrowed, straight, fore border just protruding, hind border cut straight (Figs. 110-113, 115, 118). Lateral keels evident and converging posteriorly. Paranota are wrinkled. The area between median keel and lateral keels is flat. Metanotum with lateral keels, more evident in the male, less in the female. Abdomen is moderately carinate in the male, and slightly carinate in the female. Tegmina are 1.3 (in males) and 2.2 (in the female) longer than high. Mesosternal space just wider than long in the male, evidently wider than long in the female, metasternal space wider than long in the male, three times wider than long in the female (Figs. 116-117). Krauss's organ smooth. Prosternal process is cubic, with an interrupted fore collar and two hind tubercles (Fig. 114). Aedeagus valves are sub-triangular, apical sides longer than basal ones; basal part consisting of 12 columnar keels (six per side); only basal part of apical sides show small keels, the remaining part is not interested by keels, but it is evidently wrinkled and provided with enlarged apical borders. In lateral view the phallic complex shows long valves, covered by columnar reliefs. The epiphallus has ca. 15 small scattered spines on the sides (Figs. 119-122). Inner hind femurs of male are reddish, of female dark with orange base; hind tibiae of male and female are purple-reddish, spines red with black base and apex.

Measurements. Holotype male: total length 25.2; length of pronotum 6.2; height of pronotum 5.5; length of hind femurs: 11.0; height of hind femurs 3.1. Allotype female: total length 28; length of pronotum 6.7; height of pronotum 6.3; length of hind femurs: 11.2; height of hind femurs 3.6.

Affinities. In E. pictipes the pronotum is similar to that of $E$. rungsi, mainly in the male, slightly wider than long, and clearly enlarged in the metazona; the paranota are callused-wrinkled. The median keel of males is straight, and the area between it and the lateral keels is concave. In female the median keel is slightly raised and the paranota are less callused and wrinkled than in males. Brown stripe in the light dorsal area of the tegmina is generally absent in E. pictipes (but present in the holotype). Abdominal keels are evident in the metanotum and first tergites. Inner side of hind femora is orange or brown-blackish, tibiae are red, their inner spines red, but differently from what has been reported by La Greca (1993) and Massa (2012b) they may be black at base and apex or only at apex. E. pictipes is also known from Middle Atlas. E. atlasicus is a very distinctive species, with a flat pronotum, not tuberculated nor wrinkled; its median keel does not protrude forward, and its lateral keels are straight and evident, just converging posteriorly. Fore border of the pronotum is straight, hind border cut straight. The prosternal process is cubic, the brown stripe in the light dorsal area of the tegmina is absent. The abdominal keel is present, but not very evident; the lateral keels are visible only in the metanotum. The inner side of the hind femora is yellow-ochreous, and the tibiae are ochreous or pinkish. E. atlasicus has been recorded only in the eastern part of the High Atlas.

Derivatio nominis. Euryparyphes rungsi is named after Charles Rungs (1908-1999), who was a clever insect collector and appreciated specialist of Orthoptera, mainly from North Africa. He was head of the Centre de Lutte Antiacridienne de Aït Melloul (Agadir). Rungs carried out some collections of Acridoidea in North Africa, mainly in Morocco in 1949-1950. Many specimens of Pamphagidae preserved in the Museum National d'Histoire Naturelle of Paris and in the Museo Nacional de Ciencias Naturales of Madrid were collected by Rungs, together with Pasquier and Thami, and seven valid taxa of Orthoptera have been named after Rungs (Eades et al. 2013).

\section{Key to species. The key of Massa (2012b) should be modified as follows.}




\section{Paraeumigus Bolivar, 1914 (type-species: Eumigus fortius Bolivar)}

The first Moroccan species were described in the Spanish genus Eumigus Bolivar, 1878, but in 1914 Bolivar established for the Moroccan species the genus Paraeumigus. Differences lie in the general body aspect, mainly in the pronotum, tegmina, hind femurs, abdomen keel, prosternum and phallic complex shape. Actually, the two genera are considered to belong to two different tribes (Eumigus belongs to Pamphagini). Concerning details about differences between Euryparyphes and Paraeumigus see the genus Euryparyphes. La Greca (1993) recognized 11 species of Paraeumigus; another one is here described from West Morocco, amounting to 12 species on the whole. However, this genus is still poorly known and further material is needed to define better the validity of some taxa. It covers Morocco, as well as Algeria; indeed Maurel (2006) has recorded an unidentified female of Paraeumigus from the Atlas Tellien (Djurjura), very far from the border with Morocco. Thus, I presume that in the future new taxa will be discovered in this wide country.

\section{Paraeumigus escalerai (Bolivar, 1912)}

Material examined. Morocco, Msuda de Haha à Mtonga, 18 $\delta^{\lambda}, 7$ s syntypes; El Glaui, $1 \delta^{\lambda}$; Temrilt, $1 \delta^{\lambda}$; High

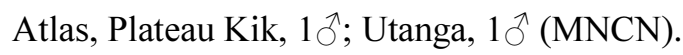

This species is characterized by a raised pronotum with evident central and lateral keels, continued on the abdomen (Figs. 125, 154). The phallic complex shows short apex of aedeagus valves, that are moderately wide; the basal part, which is rather narrow, shows 3 columnar keels per side (Fig. 126). Its distribution covers Middle and High Atlas.

\section{Paraeumigus sobrinus (Bolivar, 1912)}

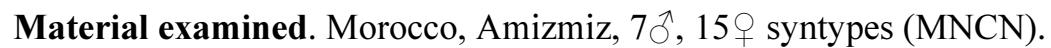

This taxon is very similar to P. escalerai, and differs only by its smaller size (Table 3), but much of comparison has been carried out by only two populations, one from Msuda (actually M'Zouda) of $P$. escalerai, the other from Amizmiz of $P$. sobrinus. The first locality is placed $30 \mathrm{kms}$ West of Amizmiz. It seems that $P$. sobrinus is a small sized sample of $P$. escalerai (Fig. 131). There are not differences in the genitalia (Fig. 132). New material from intermediate localities is needed to establish the eventual synonymy.

\section{Paraeumigus sabulosus Uvarov, 1927}

I did not examine any specimen of this taxon of western High Atlas (types from Tizi Machou); Uvarov (1927) wrote that it is closely allied to P. sobrinus, but differs from it by the fastigium of vertex more narrow and acute, pronotal keel less raised and less convex, and lateral pronotal keels well developed. Its size is similar to that of $P$. sobrinus and P. escalerai (Uvarov 1927). According to La Greca (1993), who examined the types, apical lobes of aedeagus valves are narrow, long and pointed, laterally concave, dorsal lobes are shorter than ventral ones, and the basal part is as long as apical one (Fig. 137).

\section{Paraeumigus fortius (Bolivar, 1907)}

Material examined. Morocco, ex Vaucher, $3 \widehat{\partial}, 2$ ㅇ syntypes (MNCN); Morocco, ex Vaucher, $1{ }^{\Uparrow}$ syntype; Telouet Glaoua, $1 \overbrace{}^{\Uparrow}, 2$ ( $\mathrm{MNHN}$ ).

The type locality of this species is unknown (only the collector is known). The size of this taxon is the biggest within the genus Paraeumigus. It is characterized by raised and laterally compressed pronotum (Figs. 127, 150); the phallic complex shows very short apex of aedeagus valves, with dorsal lobes longer than ventral ones; basal part is wider than long (Fig. 128). 


\section{Paraeumigus montanus (Werner, 1931)}

I did not examine any specimen, and report only characters listed by La Greca (1993). This taxon, present on the western High Atlas of Morocco, is characterized by raised pronotum keel (Fig. 157), and aedeagus valves narrow and long, with apical lobes rounded, the dorsal are longer than ventral ones; the basal part is as wide as long, with 3 columnar keels per side (Fig. 135).

\section{Paraeumigus nadigi La Greca, 1993}

I did not examine any specimen, and report only characters listed by La Greca (1993). This taxon has been described on specimens collected at Amizmiz (western High Atlas), the same type locality of P. sobrinus. The apex of aedeagus valves (Fig. 136) is short, the basal part is as wide as long and shows 3 columnar keels.

\section{Paraeumigus ouchedenensis Werner, 1934}

Types were collected at Djebel Oucheddene (High Atlas). I did not examine specimens of this taxon, and report only characters listed by La Greca (1993). It has a raised pronotum keel, and its aedeagus valves are laterally enlarged, with apical lobes as long as basal part, which shows 4 columnar keels not reaching distal lobes (Fig. 140).

\section{Paraeumigus parvulus (Bolivar, 1907)}

Material examined. Morocco, ex Vaucher, $1 \delta^{\lambda} \uparrow$ syntypes; Morocco, High Atlas, Tsauritz Entzagoutz, $1 \delta^{\lambda}, 1 q$ (MNCN); Morocco, High Atlas, Tizi-n-Tuagane 10.VII.1937, 1 q (BMCP); Morocco, High Atlas, Asni V.1931, 10, 1\%; High Atlas, Arround, V.1931, 19 (MZR).

The type locality is unknown; labels on syntypes report only the name of the collector (Vaucher); La Greca (1993) considered that the type locality should be in the western High Atlas. This very small species (Table 3) is characterized by flat pronotum and low pronotum keel (Figs. 133, 160); the phallic complex shows very short apex of aedeagus valves, that are wide and not pedunculate; the basal part shows 4-5 columnar keels per side (Fig. 134). Mesosternal space in females is 1.5-2.0 times wider than long, and metasternal space 2.0-2.5 times wider than long (Fig. 159).

\section{[Paraeumigus pedemontanus Werner, 1932]}

Werner (1932) described this taxon on a female collected on 31.V.1930 at Asni, a locality below the High Atlas, $1300 \mathrm{~m}$ a.s.l.; the holotype, which should be preserved at NMW, has been lost (La Greca 1993). One pair of specimens collected in the same locality, listed above (cf. P. parvulus), resulted to belong to P. parvulus, both in morphology and phallic complex, and here I establish the consequent synonymy.

\section{Paraeumigus diversipes Uvarov, 1927}

Material examined. Morocco, High Atlas, Dj. Tachdirt, ô paratype (MNCN).

This taxon, collected at 3,000 m a.s.l., following Uvarov (1927) differs from P. parvulus mainly in the colouration of the hind legs. La Greca (1993) did not confirm the colour difference between the two species, but considered $P$. diversipes (Fig. 123) as a valid species, much related to $P$. parvulus, differing from it mainly for the shape of the phallic complex, which shows aedeagus valves more slender than that of the latter species, ending in a sub-acute angle (Fig. 124).

\section{[Paraeumigus tachdirtensis Werner, 1934]}

It was collected in the same type-locality of $P$. diversipes (Tachdirt) and has been synonymized with it by Chopard (1943). 
Material examined. Morocco, High Atlas, Oukaimeden VII.1955, 1ðð, 2 (MNCN); Oukaimeden 20.VII.1965,

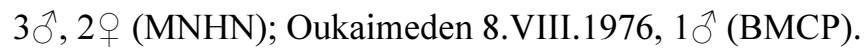

Species of high altitudes of High Atlas, is characterized by low pronotum keel (similar to that of $P$. diversipes), fore border of pronotum obtusely protruding, hind border straight (Figs. 129, 158). The colour of hind tibiae and femurs, considered diagnostic by La Greca (1993), is variable; in particular tibiae may be reddish-orange to yellowish. The phallic complex shows wide apical lobes of aedeagus valves; the basal part, as long as wide, shows three columnar keels per side (Fig. 130).

\section{Paraeumigus bolivari La Greca, 1993}

Material examined. Morocco, High Atlas, Tizi-n-Tichka 18.IV.1967, 1§^, 19 paratypes (MSNM); Tizi-n-Tichka 16.VI.2013, A. Carapezza, 2 (BMCP).

It has a low pronotum keel, hind border with black and white spots, abdominal keel is rather evident (Figs. 138, 156). The pronotum keel is stout and pronotum is posteriorly enlarged. Apical lobes of aedeagus valves are long and enlarged, dorsal lobes are longer than ventral ones; the basal part is longer than wide and shows 3-4 columnar keels per side (Fig. 139).

\section{Paraeumigus lopezi n. sp.}

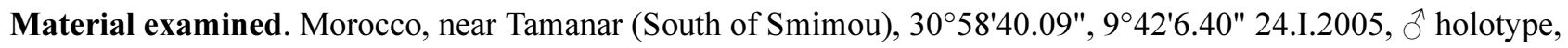
q allotype, ổ paratype, leg. Heriberto Lopéz (BMCP).

Among some specimens of Pamphagidae collected by the Spanish colleague Heriberto Lopéz in Morocco I found three small specimens whose characteristics are not matching with those of any described species; the locality where they were collected, next to the Atlantic coast, is far from any other housing Paraeumigus species, that till now were considered as typical mountainous elements.

Diagnosis. It is a small sized species (see Table 3), with moderately raised pronotum keel; body is laterally compressed.

Description. Antennae 15-16 (males) and 16- (female) segmented, shorter than head and pronotum together. Teguments are rather wrinkled, fore and hind borders of pronotum clearly protruding, pronotum posteriorly enlarged, with a central stout keel (not furrowed in the males, just furrowed in the female) and two lateral keels, more or less parallel (Figs. 141, 143, 145). Pronotum keel in lateral view is just raised in the males, clearly raised in the female, gently interrupted by typical sulcus (Figs. 141, 145). Central keel is visible also on the first segments of the abdomen. Tegmina are 2.4-2.5 longer than high and are more or less unicolor, with the upper part just clearer than lower one. Mesosternal space is 2.0 times wider than long, and metasternal space 2.5 times wider than long (Fig. 155). Krauss organ smooth. Prosternal process has an evident fore collar and two pointed hind tubercles (Fig. 142). Aedeagus valves, from back view, have long and narrow lobes, enlarged at the apex; central columnar keels arrive to the apex, while the other two remain only in the basal part, which is as wide as long (Fig. 144). In lateral view, aedeagus valves are apically flattened and pointed, the epiphallus shows ca. 35 small spines on the central sides (Fig. 144).

Habitat. Specimens were collected in a plain with dispersed Argania trees and a high density of annual grasses.

Biological notes. The collector, H. Lopéz, found the specimens as nymphs; they were kept in a plastic container and were feeding with Plantago sp., mulberry, Rumex lunaria and lettuce. Every day, the container was revised to detect possible moulting, mating and/or song emissions. Males were adult on $16^{\text {th }}$ March and $21^{\text {st }}$ April, the female on $29^{\text {th }}$ March. One male remained at the second nymph instar for 55 days and at the third instar for 11 days, the other male remained at the third instar for 50 days; the female remained at the third instar for 38 days and at the fourth instar for other 25 days. Mating occurred in the first days of May (Fig. 161).

Derivatio nominis. I gratefully name this species after Heriberto Lopéz, specialist of Orthoptera from Tenerife, who in the last years has published some valuable papers on endemic species of Pamphagidae of Canary Islands and collected and sent me a series of Moroccan interesting specimens. 


\section{Paraeuryparyphes La Greca, 1993 (type-species: Acinipe quadridentata Brisout de Barneville)}

This genus, currently with only one species, Paraeuryparyphes quadridentatus (Brisout de Barneville, 1852), distributed from Morocco to Libya, is very characterized by its keeled abdomen (Fig. 20).

TABLE 3. Biometrics (mean \pm standard deviation) of taxa of the genus Paraeumigus. Total length has been measured from the vertex to the apex of hind femurs. In parenthesis sample size: males/females.

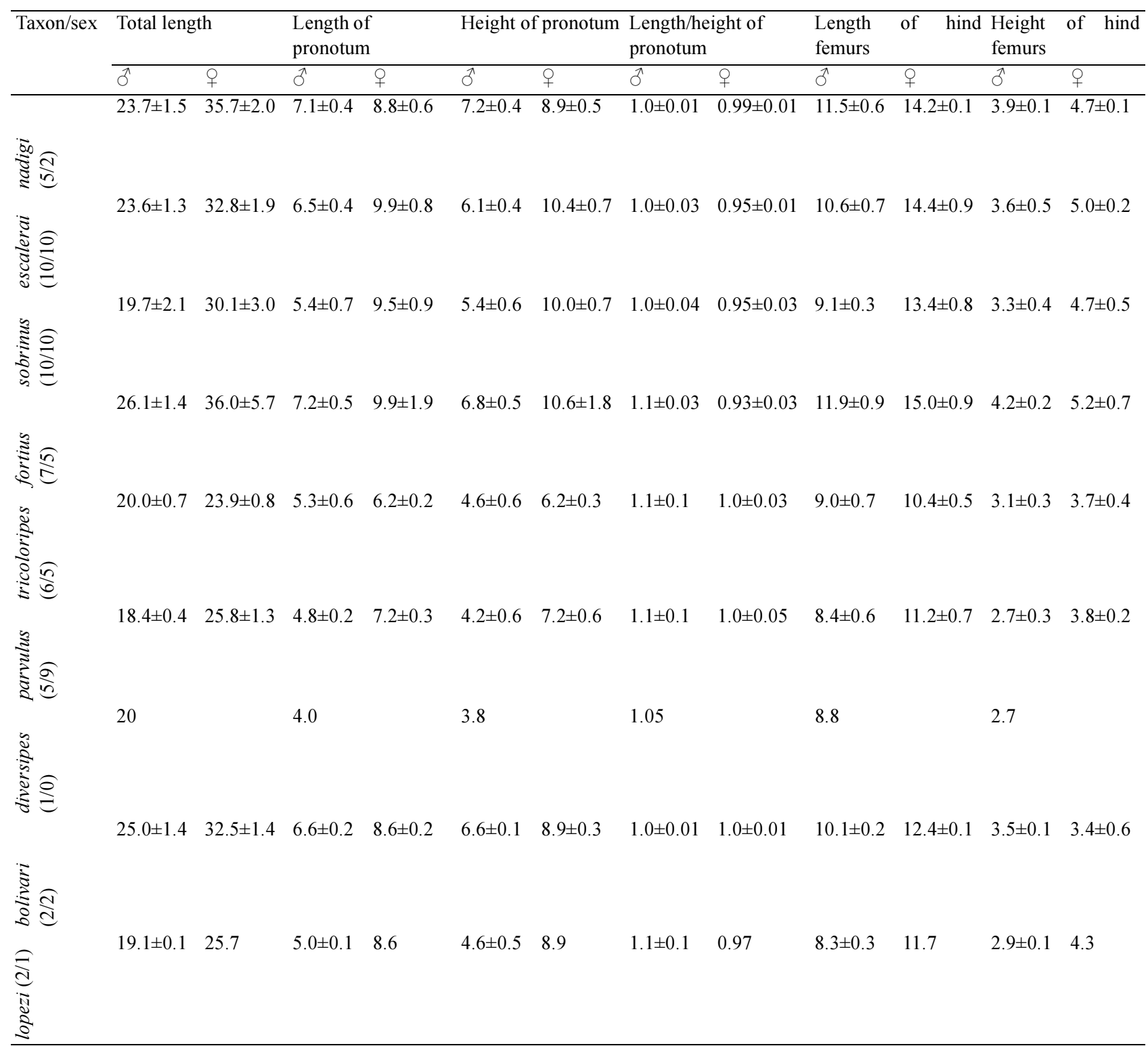

\section{Eunapiodes Bolivar, 1907 (type-species: Pamphagus granosus Stål)}

Bolivar (1907) described this genus to separate it from Euryparyphes (formerly Eunapius); the name Eunapiodes just means "related to Eunapius". Typical characters of this genus are the hind femurs with upper and lower borders laterally flattened and provided with tubercles, upper border constricted just before the genicular lobe, prosternal process bi-toothed, and pronotum keel not longitudinally furrowed. According to Descamps (1968) aedeagus valves have the shape with columnar keels, character that La Greca (1993) has used to include them within Euryparyphini. The revision of this genus by Descamps (1968) concluded that only one species, E. granosus, represented by five subspecies, is present in Morocco; this author presented a key to subspecies (only males), mainly based on femur and tibiae colour and on their mean size. He also described E. granosus rungsi from the 
North-West of Middle Atlas, characterized by inner border of hind femurs red or orange. In the MNCN I found three specimens from Ifrane (North of Azrou) identified by Escalera as E. acutithorax, and six specimens from Bou Angueur (actually Bou Anguer, South of Azrou), Middle Atlas, identified by Escalera as E. pasquieri. The comparison of the series of E. acutithorax (MNCN) with topotypic specimens of $E$. ifranensis from Ifrane (MNHN) consented to establish that E. ifranensis (Werner, 1932) and E. acutithorax are the same taxon. In addition, the comparison of the type series of E. granosus rungsi (MNHN) with the series of E. pasquieri (MNCN) consented to establish that they belong to the same taxon. However, I was unable to find any reference where $E$. acutithorax and E. pasquieri were described; they are considered as nomina dubia by Eades et al. (2013).

I redraw the map performed by Descamps (1968), including all the localities known for each taxon (Fig. 176); populations till now considered as subspecies resulted to be allopatric, even if in the same geographic area of Middle Atlas. I also tried to elaborate a pair of figures with biometric data (Figs. 174-175 showing total length versus pronotum length in males and females); it seems evident that rungsi and atlantis lie in the same area of graphs, less granosus and latipes, and ifranensis and latipes. This is less evident in the females, very difficult to separate without males, as pointed out by Descamps (1968). E. granosus and E. latipes may be recognized also by their mesosternal and metasternal spaces, clearly wider than long in granosus (Fig. 172), less in latipes (Fig. 173), which also shows a less raised pronotum (Figs. 170-171). Probably much material is needed, but I tentatively should consider the following valid taxa: Eunapiodes granosus (Figs. 162-163), E. ifranensis (Figs. 164-165), E. latipes (Figs. 170-171) and E. atlantis (Figs. 166-167), with E. rungsi its junior synonym.

\section{Eunapiodes granosus (Stål, 1876)}

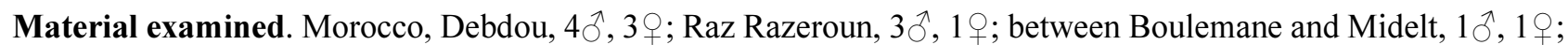

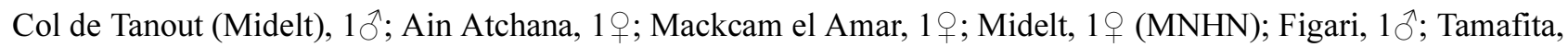

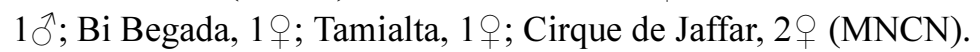

It was described on a female from West Algeria; it also lives on the North-Eastern Middle Atlas.

\section{Eunapiodes latipes (Bolivar, 1912)}

Material examined. Morocco, Melilla, $q$ holotype, $q$ paratype, $1 \hat{\jmath}, 2+$; Mulay Rechid, $1 \hat{\jmath}, 1 \uparrow$; Villa Sanjurjo,

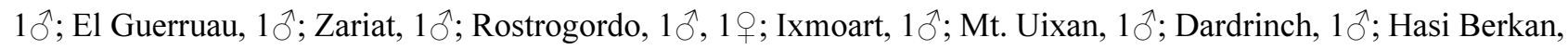

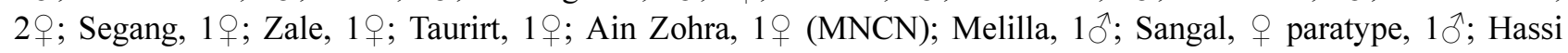
Medina, $1 \sigma^{\widehat{\lambda}}(\mathrm{MNHN})$.

Bolivar (1912) described it on a female from Melilla (Morocco), differing from E. granosus by the following characters: small differences in the prosternum process and less tuberculated upper border of hind femurs (Figs. 170-171). I found also differences in the pronotum shape and meso- and metasternal spaces. It lives near Melilla and on the Rif (Fig. 176).

\section{Eunapiodes ifranensis (Werner, 1932)}

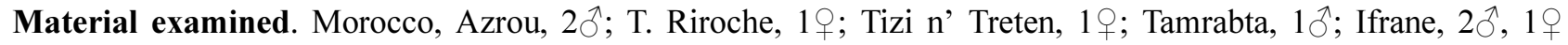
(MNHN); Ifrane, 39 identified by Escalera as E. acutithorax (MNCN).

This taxon is easily recognized from other Eunapiodes, for its roof-like pronotum, higher and longer than in related taxa (Figs. 164-165). It lives in the North-western part of Middle Atlas (Fig. 176).

\section{Eunapiodes atlantis (Chopard, 1943)}

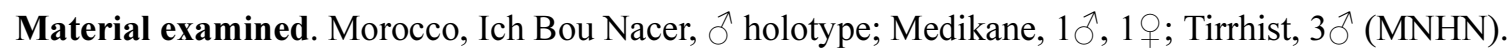
It is a small sized taxon (see Table 4), that lives in the South-western part of the Middle Atlas. 


\section{[Eunapiodes granosus rungsi Descamps, 1968]}

Material examined. Morocco, Boulemane, $\widehat{\partial}$ holotype, $q$ allotype, $2 q$ paratypes; between Ifrane and Boulemane, $\uparrow$ paratype; Ait Mohammed, $4 \hat{\jmath}, 1+$ paratypes; Recif, $2 \circ$ paratypes; Ain Nokra, $q$ paratype; (MNHN); Morocco, Bou Angueur, $4 \hat{\bigcirc}, 2$ + labeled as "syntypes" of E. pasquieri (MNCN).

I consider this small sized taxon (see Table 4 ) as a junior synonym of $E$. atlantis.

TABLE 4. Biometrics (mean \pm standard deviation) of taxa of the genus Eunapiodes. Total length has been measured from the vertex to the apex of hind femurs. In parenthesis sample size: males/females.

\begin{tabular}{|c|c|c|c|c|c|c|c|c|c|c|c|c|}
\hline \multirow[t]{2}{*}{ Taxon/sex } & \multicolumn{2}{|c|}{ Total length } & \multicolumn{2}{|c|}{ Length of pronotum } & \multicolumn{2}{|c|}{ Height of pronotum } & \multicolumn{2}{|c|}{$\begin{array}{l}\text { Length/height of } \\
\text { pronotum }\end{array}$} & \multirow{2}{*}{$\begin{array}{l}\begin{array}{l}\text { Length } \\
\text { femurs }\end{array} \\
\hat{\sigma}\end{array}$} & \multirow{2}{*}{$\begin{array}{l}\text { of } \\
\text { ㅇ }\end{array}$} & \multirow{2}{*}{$\begin{array}{l}\text { Height } \\
\text { femurs } \\
\delta\end{array}$} & \multirow{2}{*}{$\begin{array}{ll}\text { of hind } \\
q & \end{array}$} \\
\hline & $\overline{0}$ & 우 & 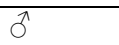 & q & $\sigma^{1}$ & q & $\hat{\sigma}$ & क & & & & \\
\hline \multirow{2}{*}{ 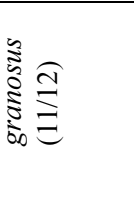 } & $30.1 \pm 1.8$ & $44.1 \pm 2.6$ & $10.5 \pm 0.5$ & $15.8 \pm 1.1$ & $10.2 \pm 0.5$ & $15.7 \pm 0.9$ & $1.0 \pm 0.04$ & $1.0 \pm 0.03$ & $12.9 \pm 0.7$ & $17.7 \pm 1.3$ & $5.6 \pm 0.2$ & $7.1 \pm 0.3$ \\
\hline & $31.4 \pm 2.2$ & $47.6 \pm 5.7$ & $10.6 \pm 1.2$ & $16.8 \pm 2.3$ & $10.5 \pm 0.8$ & $17.1 \pm 2.1$ & $1.0 \pm 0.04$ & $0.98 \pm 0.04$ & $13.6 \pm 1.2$ & $18.7 \pm 2.3$ & $5.7 \pm 0.4$ & $7.2 \pm 0.7$ \\
\hline 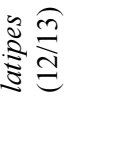 & $33.1 \pm 1.9$ & $46.7 \pm 3.6$ & $12.0 \pm 0.5$ & $18.6 \pm 1.4$ & $11.1 \pm 0.5$ & $17.5 \pm 0.9$ & $1.1 \pm 0.01$ & $1.0 \pm 0.02$ & $14.7 \pm 0.7$ & $19.5 \pm 0.5$ & $6.3 \pm 0.4$ & $7.2 \pm 0.3$ \\
\hline \multirow{2}{*}{ 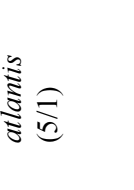 } & $26.0 \pm 1.8$ & 38.5 & $8.5 \pm 1.2$ & 13.3 & $8.4 \pm 0.8$ & 13.3 & $1.0 \pm 0.04$ & 1.0 & $11.2 \pm 0.7$ & 15.4 & $4.5 \pm 0.4$ & 6.3 \\
\hline & $26.9 \pm 1.5$ & $38.5 \pm 2.2$ & $8.6 \pm 0.5$ & $13.5 \pm 1.2$ & $8.8 \pm 0.5$ & $14.0 \pm 0.7$ & $1.0 \pm 0.05$ & $1.0 \pm 0.03$ & $11.7 \pm 0.6$ & $15.6 \pm 0.9$ & $5.0 \pm 0.1$ & $6.2 \pm 0.2$ \\
\hline 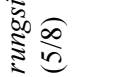 & & & & & & & & & & & & \\
\hline
\end{tabular}

\section{Conclusions on North African Pamphaginae}

Differently from Thrinchinae, squamipterous Pamphaginae are subject to isolation and local differentiation, due to low or absent genic flow, genetic drift and to the founder principle. In many cases, mainly in mountain taxa, it is possible to find cryptic species living one next to other. Some taxa, previously considered subspecies, actually overlap geographically and it is not justified the use of the taxonomic category of subspecies. This should be limited only to geographically isolated taxa, when it seems evident a process of differentiation in progress, that will be very probably accelerated by their isolation. For this reason, I used here only the taxonomic category of species. On the whole, 90 species of Pamphaginae are known from North Africa, 2 belong to the tribe Finotiini, 55 (one represented by five subspecies, whose status should be better examined) to the tribe Pamphagini and 33 to the tribe Euryparyphini. Pamphagini are well represented in all North African countries, with many endemic taxa, Euryparyphini are nearly exclusive of Morocco (Euryparyphes sitifensis and Paraeuryparyphes quadridentatus cover respectively Algeria and from Morocco to West Libya, one unidentified species of Paraeumigus has been found in Algeria, and Eunapiodes lives also on West Algeria). It seems fairly evident that the speciation centre of Euryparyphini was the central area of Morocco, the Rif, the Middle and High Atlas. Some species within critical genera of Pamphaginae revealed to be very rare and known only by few (e.g., Finotia) or single specimens (e.g., Pseudoamigus, Nadigeumigus), sometimes collected few times (e.g., Glauvarovia). Even though large collections of most North African genera of Pamphaginae are preserved in the European museums, I think that the knowledge of this group of species will grow in the future if new collections are carried out in some inner areas of less explored countries, as Algeria and Libya. 


\section{Acknowledgements}

This research received support from the Synthesys Project (http://www.synthesys.info/) which is financed by European Community Research Infrastructure Action under the FP7 "Capacities" Programme at the Museo Nacional de Ciencias Naturales of Madrid (CSIC). I am especially indebted to Mercedes Paris and Josefina Cabarga (Museo Nacional de Ciencias Naturales of Madrid), Laure Desutter and Simon Poulain (Muséum National d'Histoire Naturelle of Paris), Fabrizio Rigato and Maurizio Pavesi (La Greca's collection, Museo Civico di Storia Naturale of Milan), Roberto Poggi (Museo Civico di Storia Naturale 'G. Doria' of Genoa), Mauro Daccordi and Luca Picciau (Giglio-Tos' collection, Museo Regionale di Scienze Naturali of Turin), Emanuele Piattella and Augusto Vigna Taglianti (Salfi collection, Museo di Zoologia, Università La Sapienza of Rome), Antonio Garonna (Jannone collection, Dipartimento di Agraria Università of Portici, Naples), who facilitated my study of specimens preserved in their museums. I thank very much the Museo Nacional de Ciencias Naturales of Madrid and the Muséum National d'Histoire Naturelle of Paris for allowing me to photograph some specimens preserved in their collections. I also thank very much the editor of Accademia Gioenia di Scienze Naturali, Catania for allowing me to use some figures of the paper of La Greca (1993). Attilio Carapezza and Heriberto López provided some specimens of Pamphagidae, Carlo Di Leo, Alain Louveaux, Marcello Romano and Haralabos Tsolakis kindly provided valuable information. I also thank two anonymous referees for their useful suggestions to improve the first draft.

\section{References}

Ajaili, A.A. \& Usmani, M.K. (1999) A new subspecies, Tmethis cisti khaledi (Orthoptera: Pamphagidae: Akicerinae) from Libya. Shashpa, 6, 1-4.

Benkenana, N., Harrat, A. \& Petit, D. (2012) The Pamphagidae (Orthoptera) from East Algeria and description of a new species. Zootaxa, 3168, 22-38.

Biondi, M. \& Massa, B. (1995) Le specie nordafricane e italiane del genere Acinipe (Orthoptera Pamphagidae). Fragmenta entomologica, 27, 61-115.

Bolivar, I. (1907) Los «Pamphagus» de Marruecos. Boletin de la real Sociedad española de Historia natural, Madrid, 3,324 336.

Bolivar, I. (1908) Algunos Ortópteros nuevos de España, Marruecos y Canarias. Boletin de la real Sociedad española de Historia natural, Madrid, 8, 317-334.

Bolivar, I. (1912) Los panfaginos Paleárticos. Trabajos del Museo de Ciencias Naturales Madrid, 6, 3-33.

Bolivar, I. (1914) Dermapteros y Ortopteros de Marruecos. Memorias de la real Sociedad española de Historia natural, Madrid, 8, 157-238.

Bolivar, I. (1935) Apuntes para la fauna entomológica de Ifni (Ortópteros). Eos, Madrid, 11, 395-426, pls. 17-21.

Bounechada, M., Doumandji, S.E. \& Çiplak, B. (2006) Bioecology of the Orthoptera species of the Setifian Plateau, North-East Algeria. Turkish Journal of Zoology, 30, 245-253.

Chopard, L. (1943) Faune de l'Empire Français. I. Orthoptéroides de l'Afrique du Nord. Librairie Larose, Paris, 450 pp.

Descamps, M. (1968) Contribution à la faune du Maroc II. Le genre Eunapiodes (Orth. Pamphagidae). Annales de la Societé entomologique de France, 4, 601-613.

Descamps, M. \& Mounassif, M. (1972) Le complexe Orchamus, Paracinipe, Acinipe et Pamphagus (Acridomorpha Pamphagidae). Acrida, 1, 247-303.

Dirsh, V.M. (1958) Acridological notes. Tijdschrift voor Entomologie, 101, 51-63.

Eades, D.C., Otte, D., Cigliano, M.M. \& Braun, H (2013) Orthoptera Species File Online. Version 2.0/4.0 Available from: http://Orthoptera.SpeciesFile.org (Accessed 1 Feb. 2013)

Fieber, F.X. (1853) Synopsis der europäischen Orthopteren mit besonderer Rücksicht auf die in Böhmen vorkommenden Arten. Lotus, Praha, 3, 90-104, 115-131, 138-154, 168-176, 184-188, 201-207, 232-238, 252-261.

Jannone, G. (1938) Primo contributo alla conoscenza dell'ortotterofauna della Libia. Bollettino del Laboratorio di Zoologia di Portici, 30, 87-120.

Kirby, W.F. (1910) A synonymic catalogue of the Orthoptera. III. Orthoptera Saltatoria. Part II (Locustidae vel Acridiidae). London, $674 \mathrm{pp}$.

Krauss, H.A. (1902) Beitrag zur Kenntnis der Orthopterenfauna der Sahara. Verhandlungen der Zoologisch-Botanischen Gesellschaft Wien, 52, 230-254

La Greca, M. (1969) Su alcuni Blattodei ed Ortotteri di Tripolitania. Studi Sassaresi, 17, 19-25.

La Greca, M. (1993) Le specie marocchine dei generi Euryparyphes Fischer, Paraeumigus Bolivar, Paraeuryparyphes gen. n., Nadigeumigus gen. n., Pseudamigus Chopard, e Amigus Bolivar (Orthoptera, Pamphagidae). Bollettino Accademia gioenia di Scienze naturali, Catania, 26, 293-414. 
Llorente del Moral, V. \& Presa Asensio, J.J. (1997) Los Pamphagidae de la Peninsula Iberica (Insecta: Orthoptera: Caelifera). Universidad de Murcia, 248 pp.

Lucas, P.H. (1851) Quelques remarques géographiques sur les Acridides qui habitent les possessions francaises du Nord de l'Afrique et description de deux espèces nouvelles. Annales de la Société entomologique de France, Paris, 9 (2), $349-383$.

Massa, B. (1996) Le specie del gen. Paracinipe Descamp \& Mounassif del gruppo zebrata (Brunner) (Insecta Orthoptera Pamphagidae). Il Naturalista siciliano, 20, 71-97.

Massa, B. (1998) Attuali conoscenze sugli Ortotteri della Libia (Insecta Orthoptera). Il Naturalista siciliano, 22, $235-320$.

Massa, B. (2009) Annotated check-list of Orthoptera of Libya. Journal of Orthoptera Research, 18, 75-93. http://dx.doi.org/10.1665/034.018.0109

Massa, B. (2012a) The role of the Krauss's organ in sound production in Pamphagidae (Caelifera: Orthoptera). Italian Journal of Zoology, 79, 441-449. http://dx.doi.org/10.1080/11250003.2012.667158

Massa, B. (2012b) New species, records and synonymies of West Palaearctic Pamphaginae (Orthoptera: Caelifera: Pamphagidae). Annales de la Société entomologique de France, 48, 371-396. http://dx.doi.org/10.1080/00379271.2012.10697786

Massa, B. \& Biondi, M. (1986) Le specie del genere Ocneridia Bolivar 1912 (Orthoptera Pamphagidae). Annales de la Société entomologique de France, 23, 169-182.

Massa, B., Fontana, P., Buzzetti, F.M., Kleukers, R. \& Odé, B. (2012) Fauna d'Italia. XLVIII. Orthoptera. Calderini, Bologna, $563+$ CCXIV pp.

Massa, B., Lo Valvo, M. \& Lo Verde, G. (1993) Le specie del gen. Pamphagus Thunberg 1815 (Orthoptera Pamphagidae). Bollettino del Museo regionale di Scienze naturali di Torino, 11, 445-486.

Maurel, H. (2006) Deux taxons nouveaux pour les hautes montagnes de Kabylie (Algérie), Paraeumigus sp. et Omocestus (Dreuxius) lecerfi Chopard (1936) (Orthoptera, Pamphagidae, Acrididae). Matériaux orthoptériques et entomocénotiques, $11,115$.

Maurel, H. (2008) Premiers inventaires des Orthoptères de la «collection systématique» du laboratoire de zoologie de l'Institut National Agronomique d'El-Harrach (Algérie) (Ensifera, Caelifera). Matériaux orthoptériques et entomocénotiques, 13, $33-42$.

Morales Agacino, E. \& Descamps, M. (1968) Contribution à la faune du Maroc. I. Genres Glauia I. Bolivar, Gauvarovia Morales Agacino et Psuedoglauia nov. (Oth. Pamphagidae). Annales de la Société entomologique de France, 4, $419-435$.

Salfi, M. (1926) Contribuzioni alla conoscenza degli Ortotteri libici - 3. Di alcune specie cirenaiche di Mantidae, Phasgonuridae e Locustidae. Archivio zoologico italiano, 11, 65-104.

Saussure, H. (1884) Prodromus Oedipodiorum Insectorum ex ordine Orthopterorum. Memoires de la Société de Physique et Histoire naturelle de Genève, 28 (9), 1-243. http://dx.doi.org/10.5962/bhl.title.9514

Saussure, H. (1887) Spicilegia Entomologica Genavensis. II. Tribu des Pamphagiens. H. Georg ed., Genève, 92 pp.

Saussure, H. (1888) Additamenta ad Prodromus Oedipodiorum Insectorum ex ordine Orthopterorum. Memoires de la Société de Physique et Histoire naturelle de Genève, 30, 1-180. http://dx.doi.org/10.5962/bhl.title.9514

Storozhenko, S.Y. \& Paik, J-C. (2011) Review of the genus Haplotropis Saussure, 1888 (Orthoptera: Pamphagidae), with notes on classification of the subfamilies Pamphaginae and Trinchinae. Zootaxa, 2897, 27-34.

Uvarov, B.P. (1927) Notes on Orthoptera from Morocco. Bulletin de la Société des Sciences naturelles du Maroc, 7, $199-215$.

Uvarov, B.P. (1943) The tribe Thrinchini of the subfamily Pamphaginae, and the interrelations of the Acridid subfamilies (Orthoptera). Transactions of entomological Society of London, 93, 1-72. http://dx.doi.org/10.1111/j.1365-2311.1943.tb00429.x

Usmani, M.K. (2007) Studies on some Libyan species of Pamphagidae (Orthoptera: Acridoidea). Zootaxa, 1625, 47-60.

Usmani, M.K. (2008) A new genus and a new species of Akicerinae (Orthoptera: Acridoidea: Pamphagidae) from Libya. Entomological Research, 38 (3), 230-232. http://dx.doi.org/10.1111/j.1748-5967.2008.00167.x

Vosseler, J. (1903) Beiträge zur Faunistik und Biologie der Orthopteren Algeriens und Tunesiens. II. Zoologische Jahrbücher, $17,1-98$.

Yin, X.C., Husemann, M. \& Li, X.J. (2011) A new species of the genus Tuarega Uvarov from Morocco (Orthoptera, Pamphagidae). Acta zootaxonomica sinica, 36, 539-542.

Yin, X.C. \& Li, X.J. (2011) A taxonomic study of the genus Tuarega Uvarov, 1943 with descriptions of two new species from Sahara (Orthoptera: Acridoidea, Pamphagidae, Prionotropisinae). Acta entomologica sinica, 54, 97-103.

Werner, F. (1932) Ergbnisse einer zoologischen Forschungsreise nach Marokko. IV. Orthoptera. S.B. Akademie der Wissenschaften Wien, Mathematisch-Naturwissenschaftliche Klasse, 141, 111-174.

Werner, F. (1933) Orthopteren aus Marokko. II Teil. Zoologische Anzeiger Leipzig, 103, 78-88. 

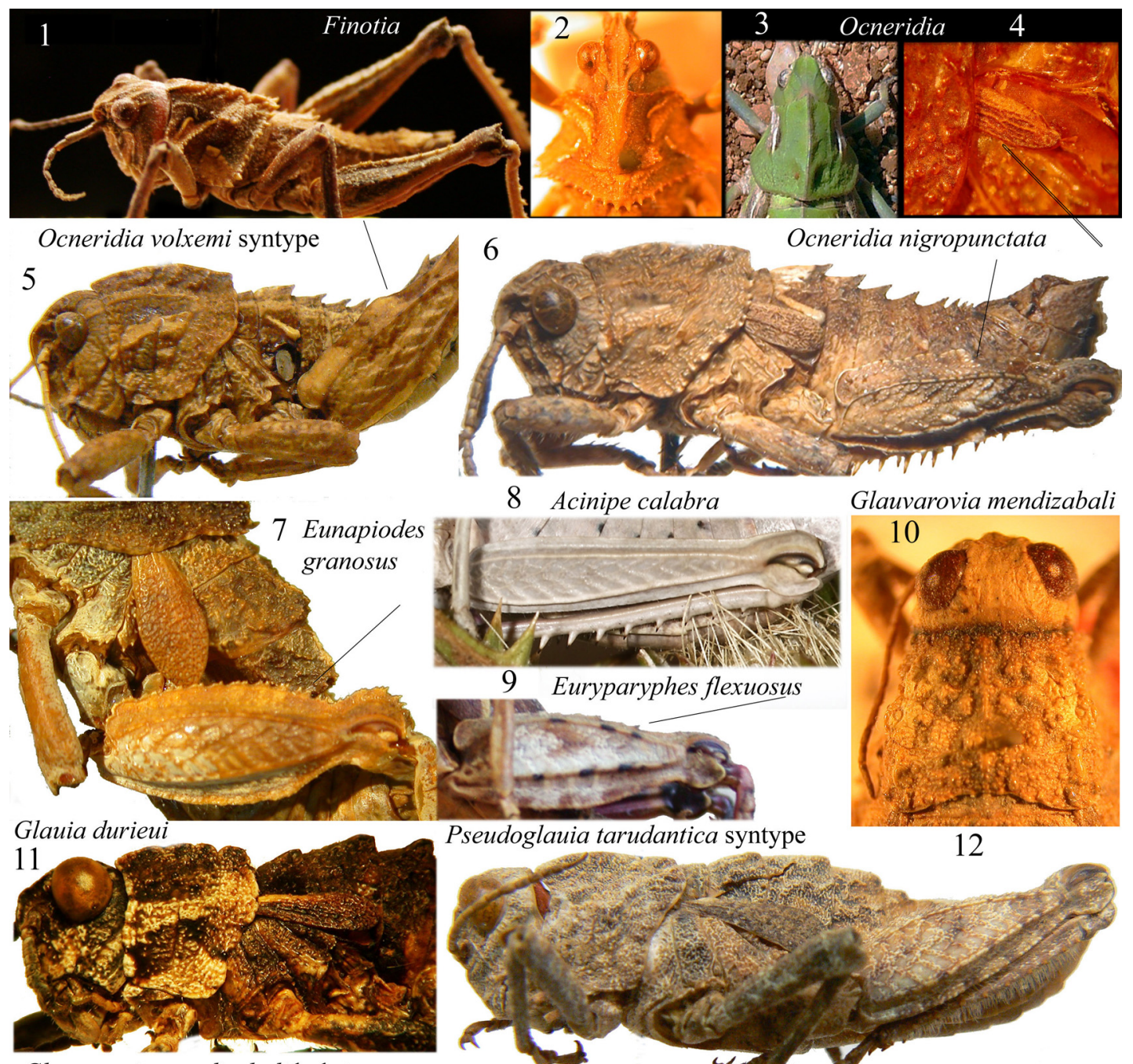

8 Acinipe calabra

Glauvarovia mendizabali
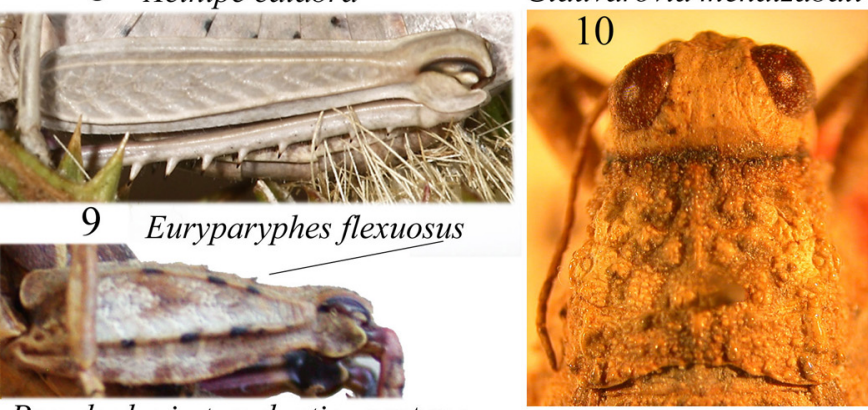

Pseudoglauia tarudantica syntype

12

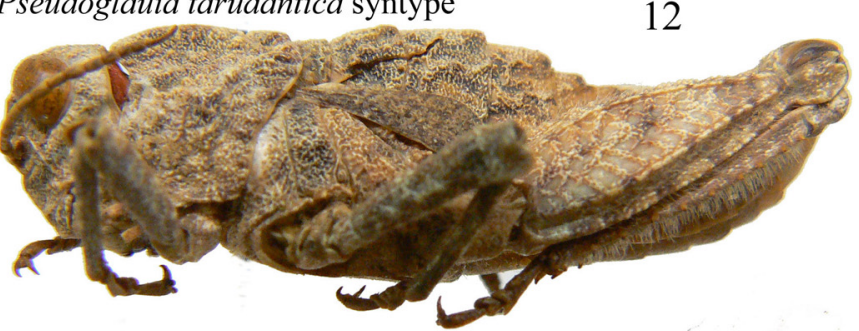

Glauvarovia mendizabali holotype

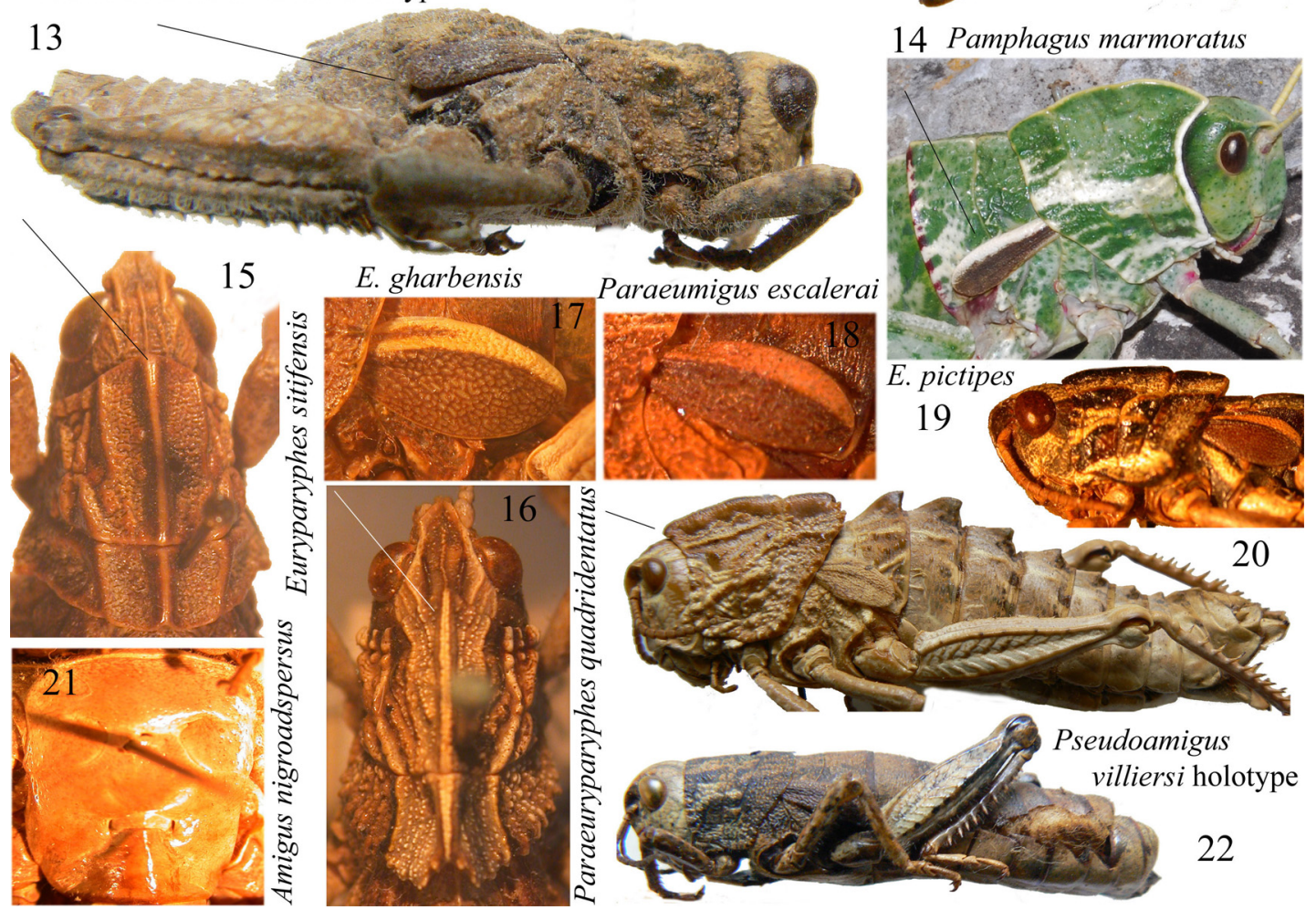

FIGURES 1-22. Characters of some Pamphagidae cited in the key to genera. 


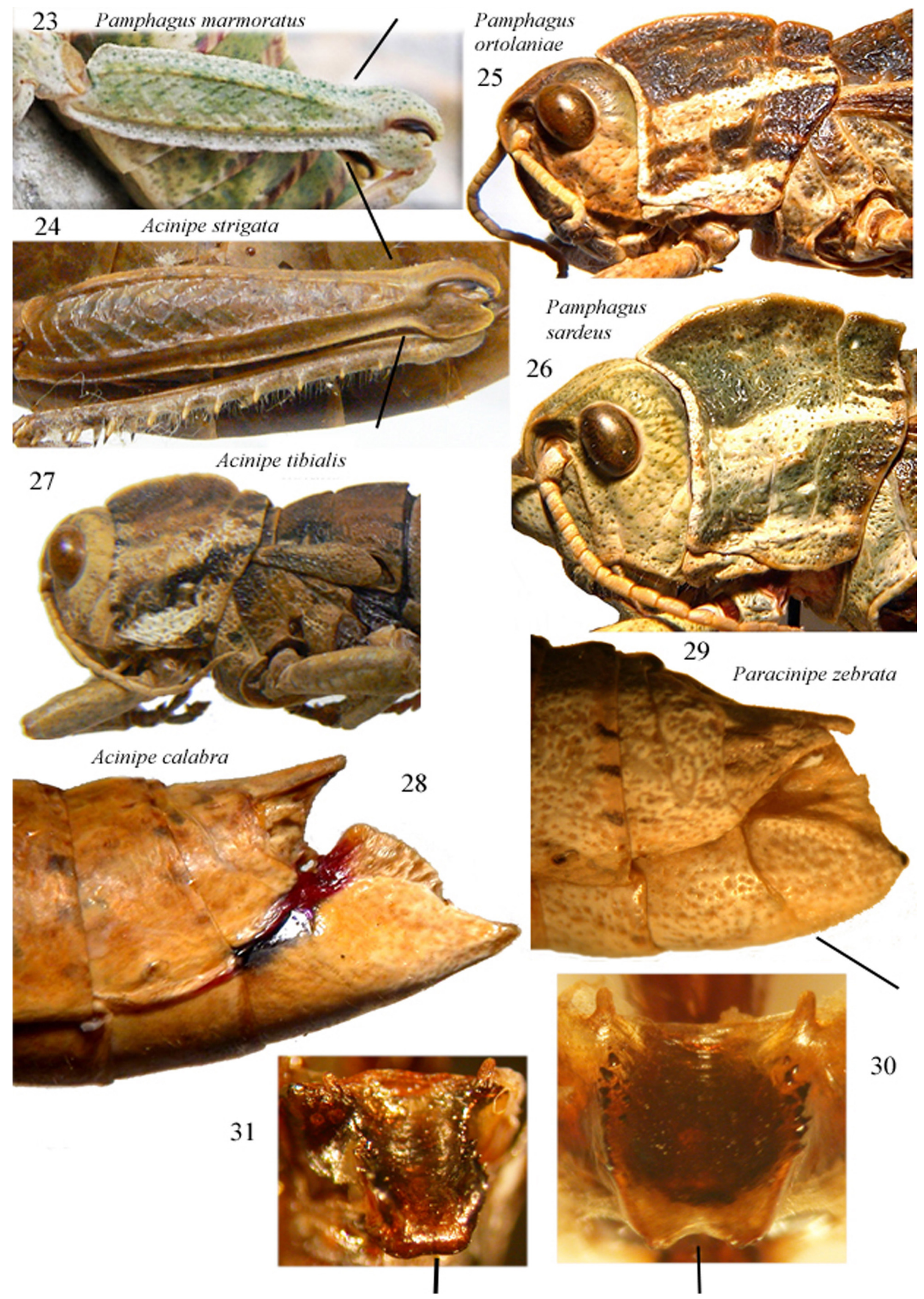

FIGURES 23-31. Characters of some Pamphagidae cited in the key to genera. 

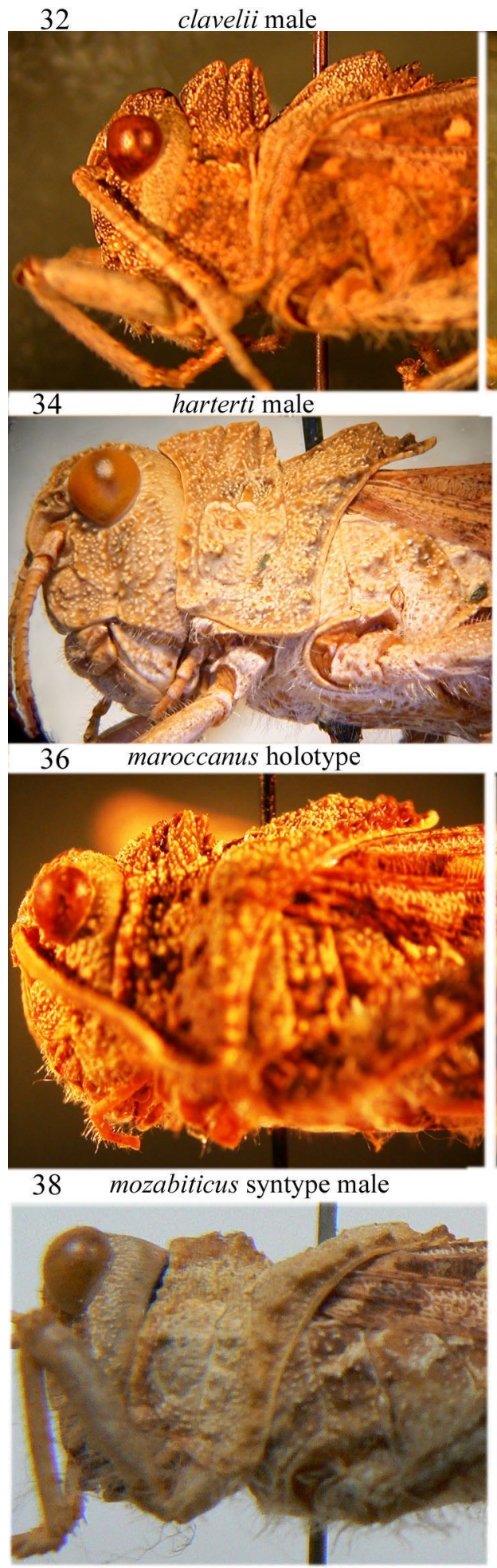

33 clavelii female

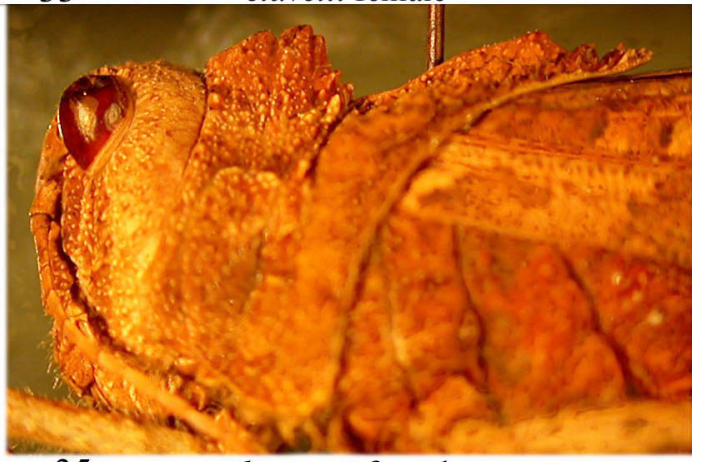

35 harterti female

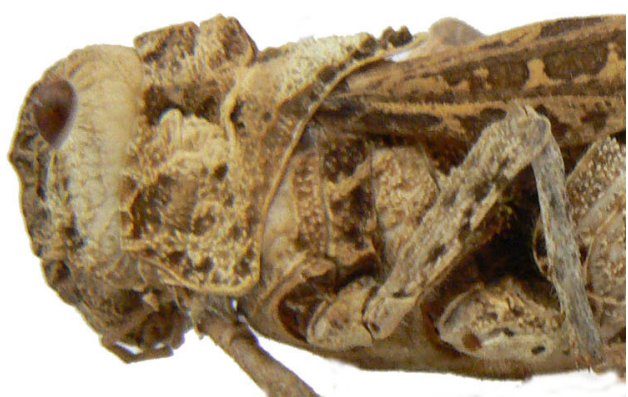

maroccanus allotype

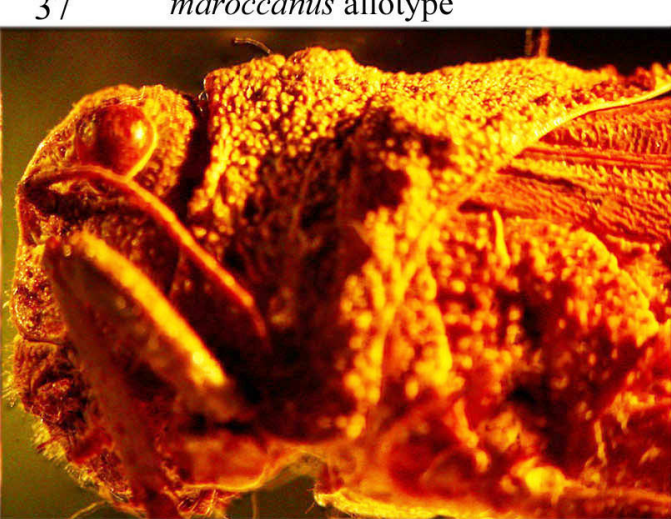

39 mozabiticus syntype female

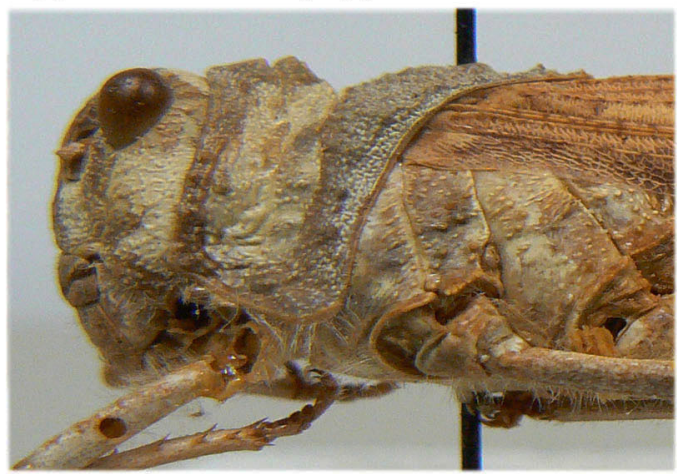

FIGURES 32-39. Lateral view of pronotum of some taxa described in the genus Tmethis, here revised. 

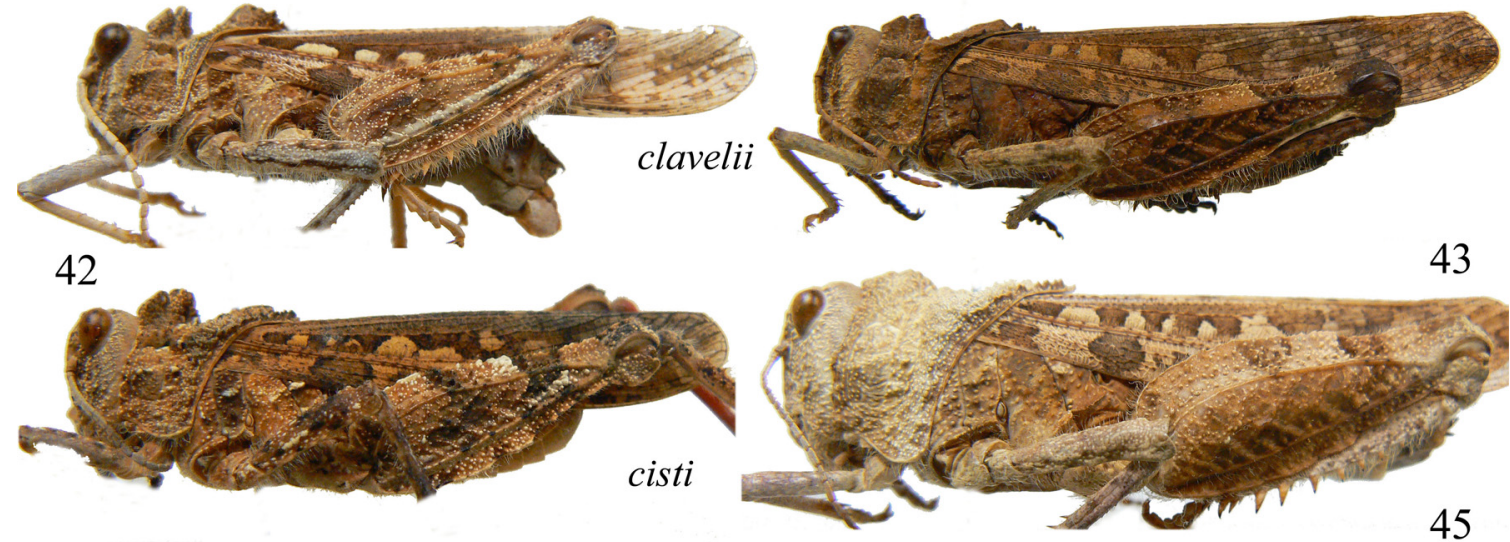

43
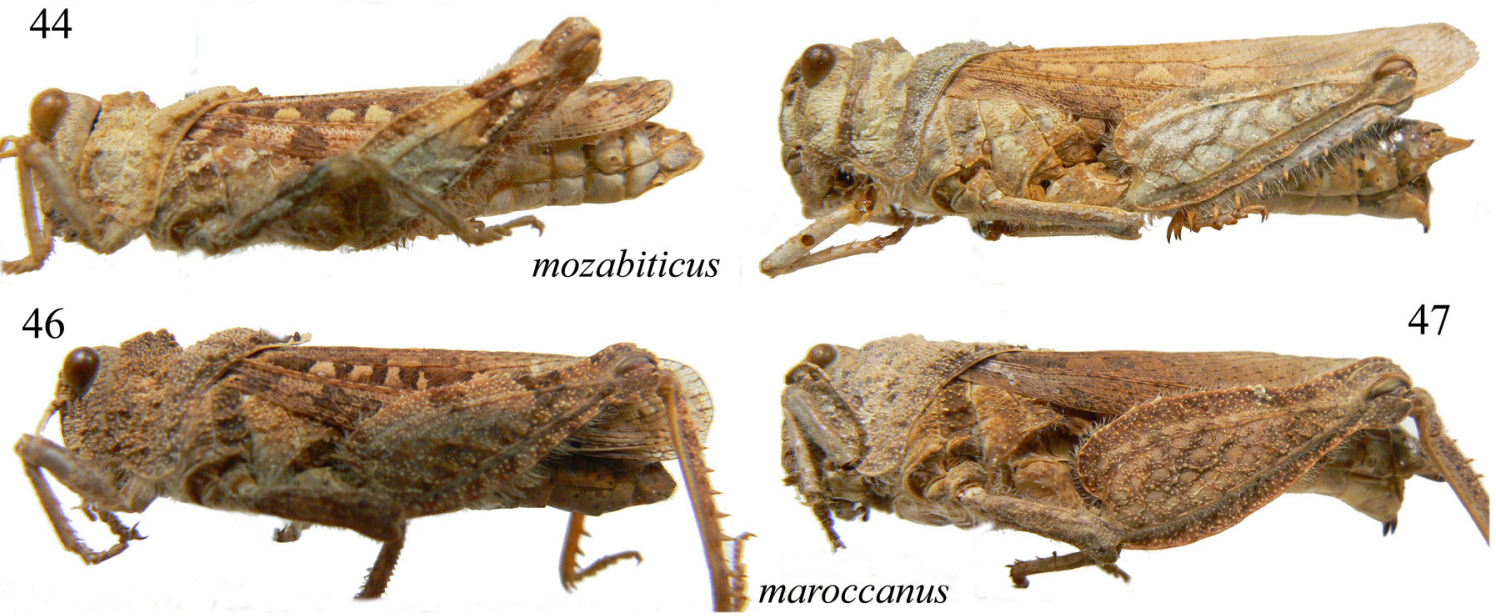

48
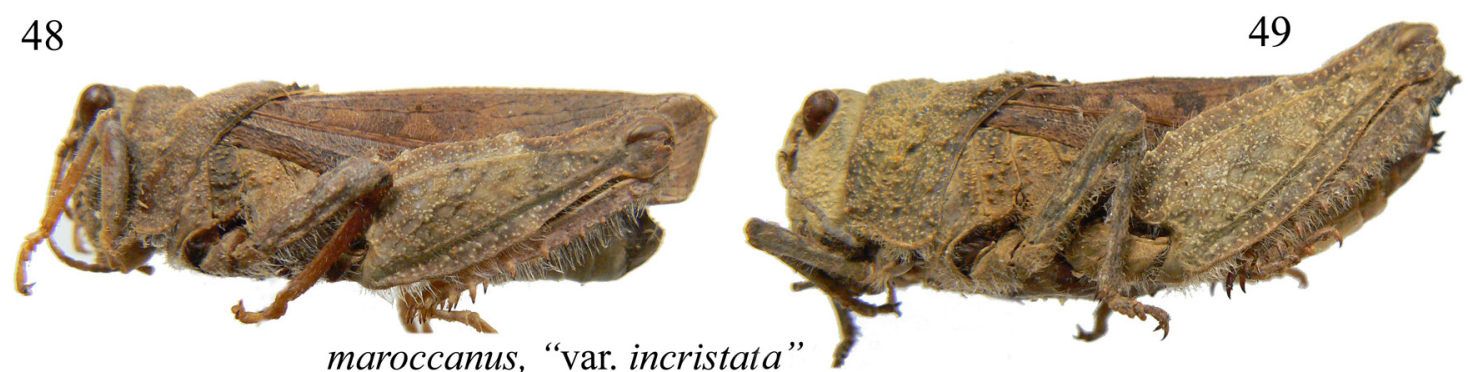

maroccanus, "var. incristata"

51
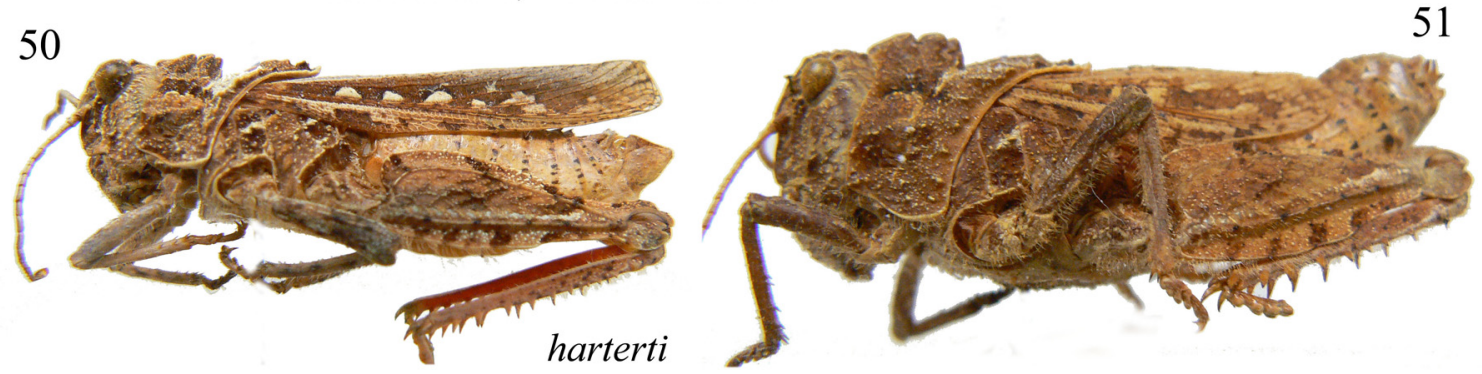

52
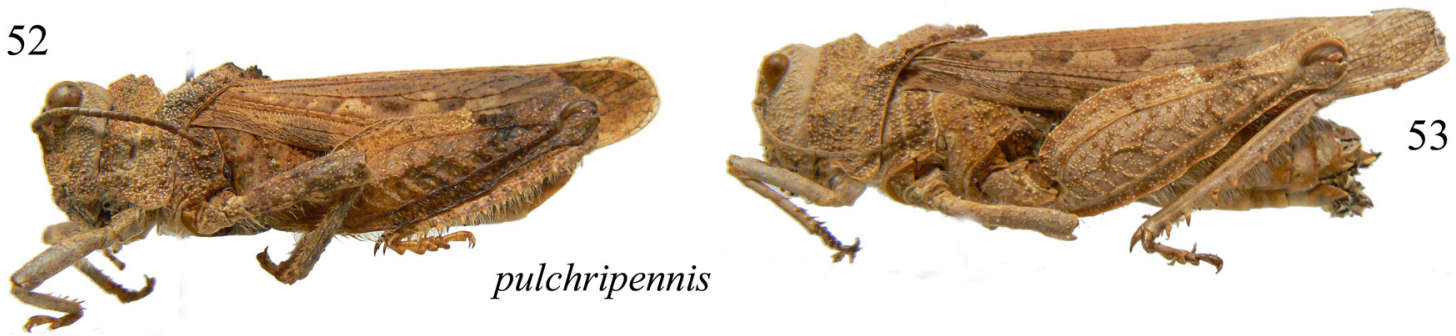

FIGURES 40-53. Lateral view of males and females of some taxa described in the genus Tmethis, here revised. 

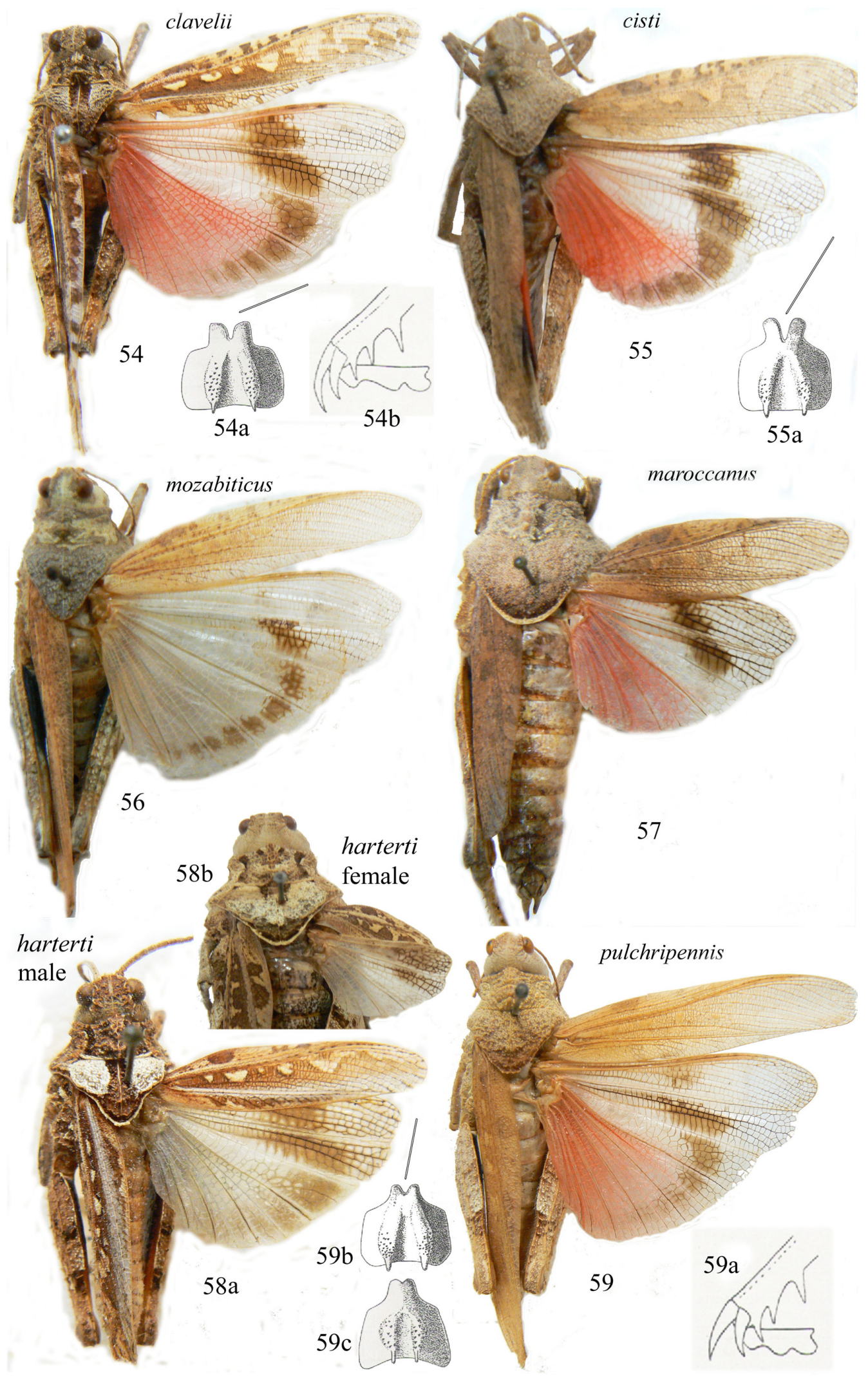

FIGURES 54-59. Some of the taxa described in the genus Tmethis, view from above to show the pattern of wing colour pattern and the ratio between the length of wings and the body. Figs. 58a and 58b show the pattern of pronotum and wings of male and female of $T$. harterti n. status. Figs. 54a and 55a show the apical lobes, large and broadly separated, of epiphallus of $T$. cisti, while Figs. 59b and 59c show the relatively small and narrowly separated lobes of epiphallus of T. pulchripennis (after Uvarov 1943). Figs 54b and 59a show the differences in the spurs of hind tibiae, long and slender, with the first tarsal joint long, and its second pulvillus longer than the first or third in T. cisti; shorter and stouter, with first tarsal joint short, its second pulvillus not longer than the first or the third in T. pulchripennis (after Uvarov 1943). 
Tuarega insignis
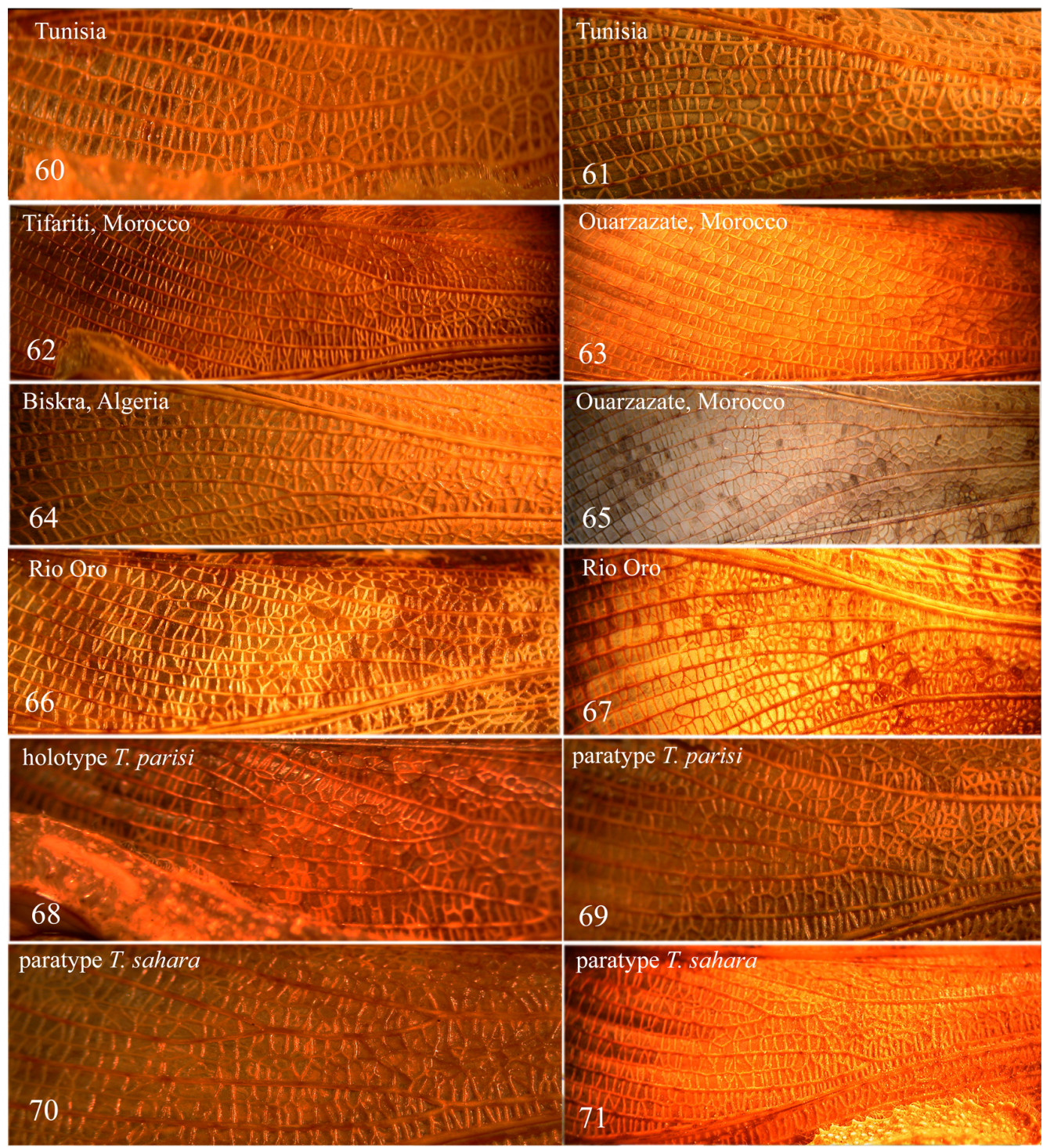

72
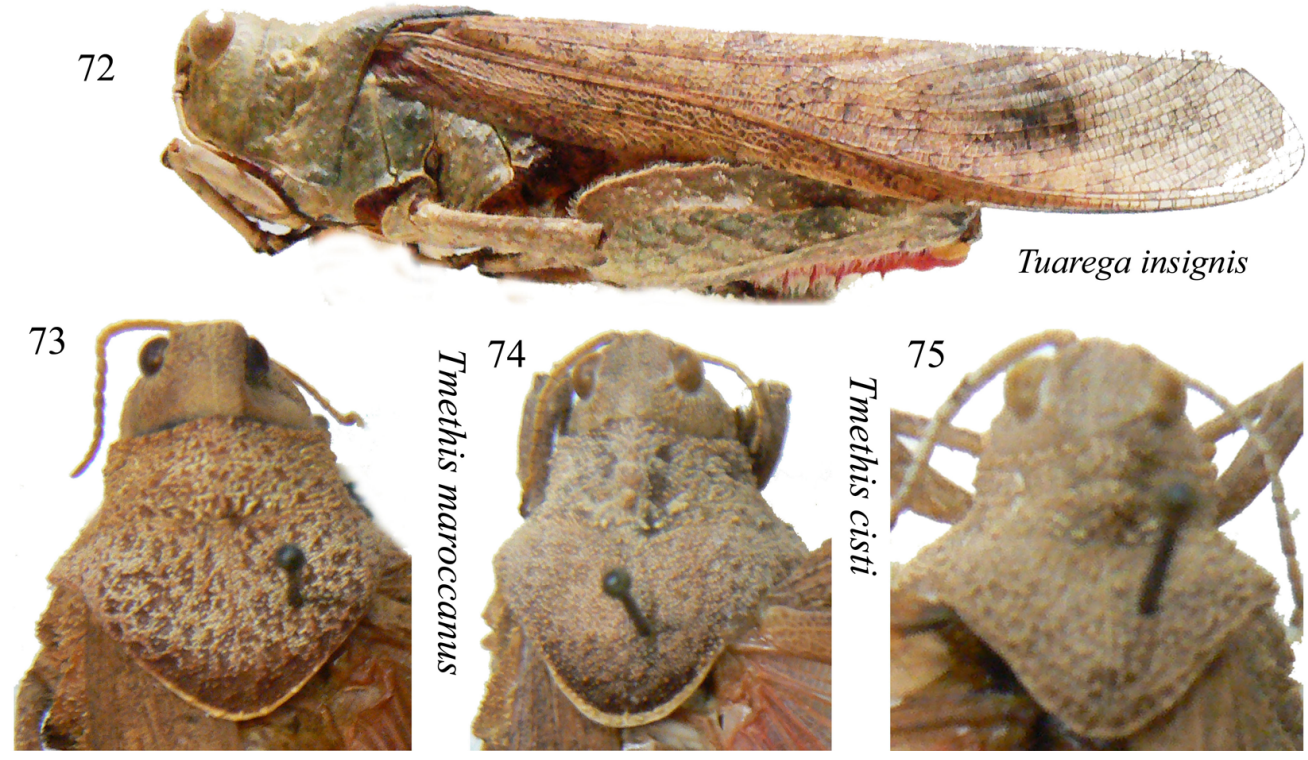

FIGURES 60-75. 60-71. Tegmina of Tuarega insignis from different North African localities to show the variability of vein branches, including topotype locality of $T$. ouarzazatensis $(63,65)$ and types of T. parisi $(68-69)$ and $T$. sahara $(70-71)$. 72. Lateral view of $T$. insignis. 73-75. Tmethis maroccanus and $T$. cisti from above to show variability of body stoutness. 

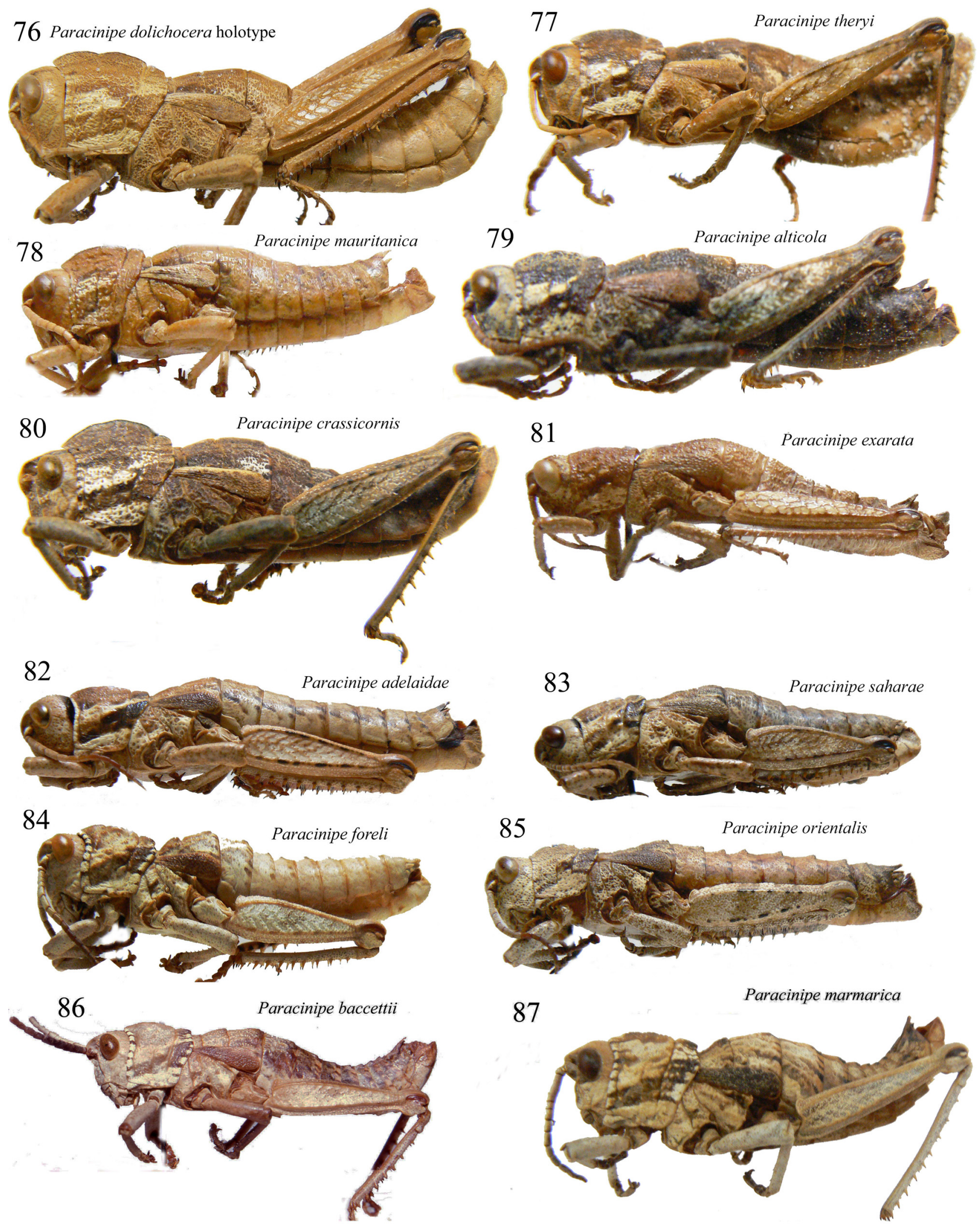

87

Paracinipe marmarica

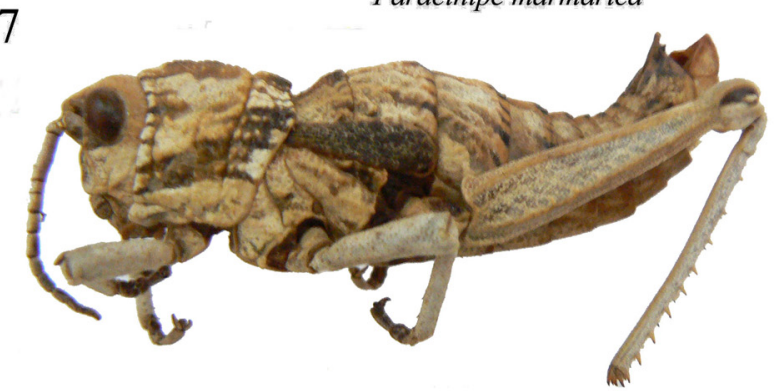

FIGURES 76-87. Lateral view of twelve species of North African Paracinipe. 


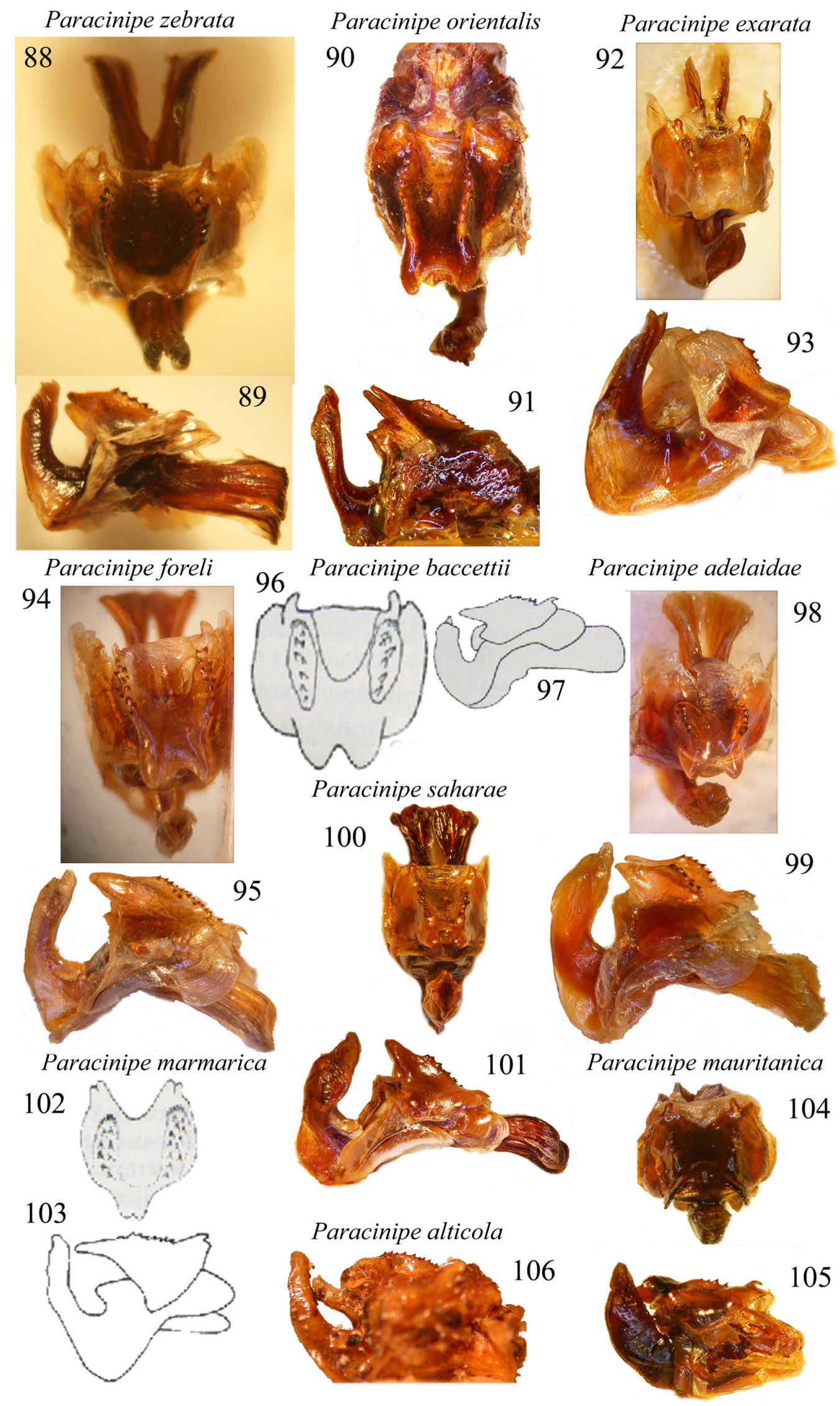

FIGURES 88-106. Phallic complex of ten species of North African Paracinipe: P. zebrata (88-89), P. orientalis (90-91), P. exarata (92-93), P. foreli (94-95), P. baccettii (96-97), P. adelaidae (98-99), P. saharae (100-101), P. marmarica (102-103), P. mauritanica (104-105), P. alticola (106). Figs. 96, 97, 102, 103 after Massa (1996, 1998). 


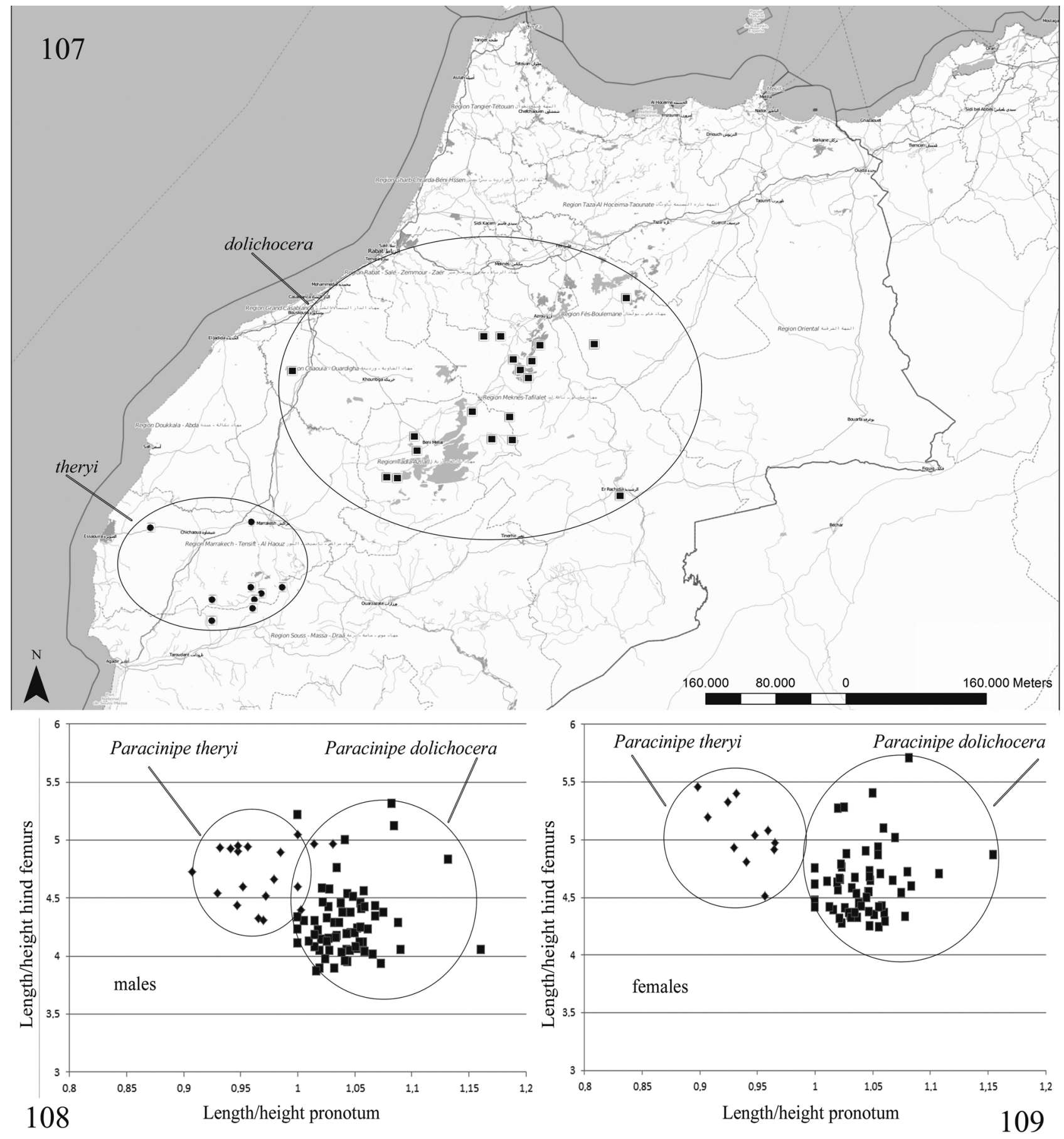

FIGURES 107-109. 107. Distribution of Paracinipe dolichocera and P. theryi. 108-109. Ratio length/height of pronotum versus length/height of hind femurs of males (108) and females (109) of P. dolichocera and P. theryi. 


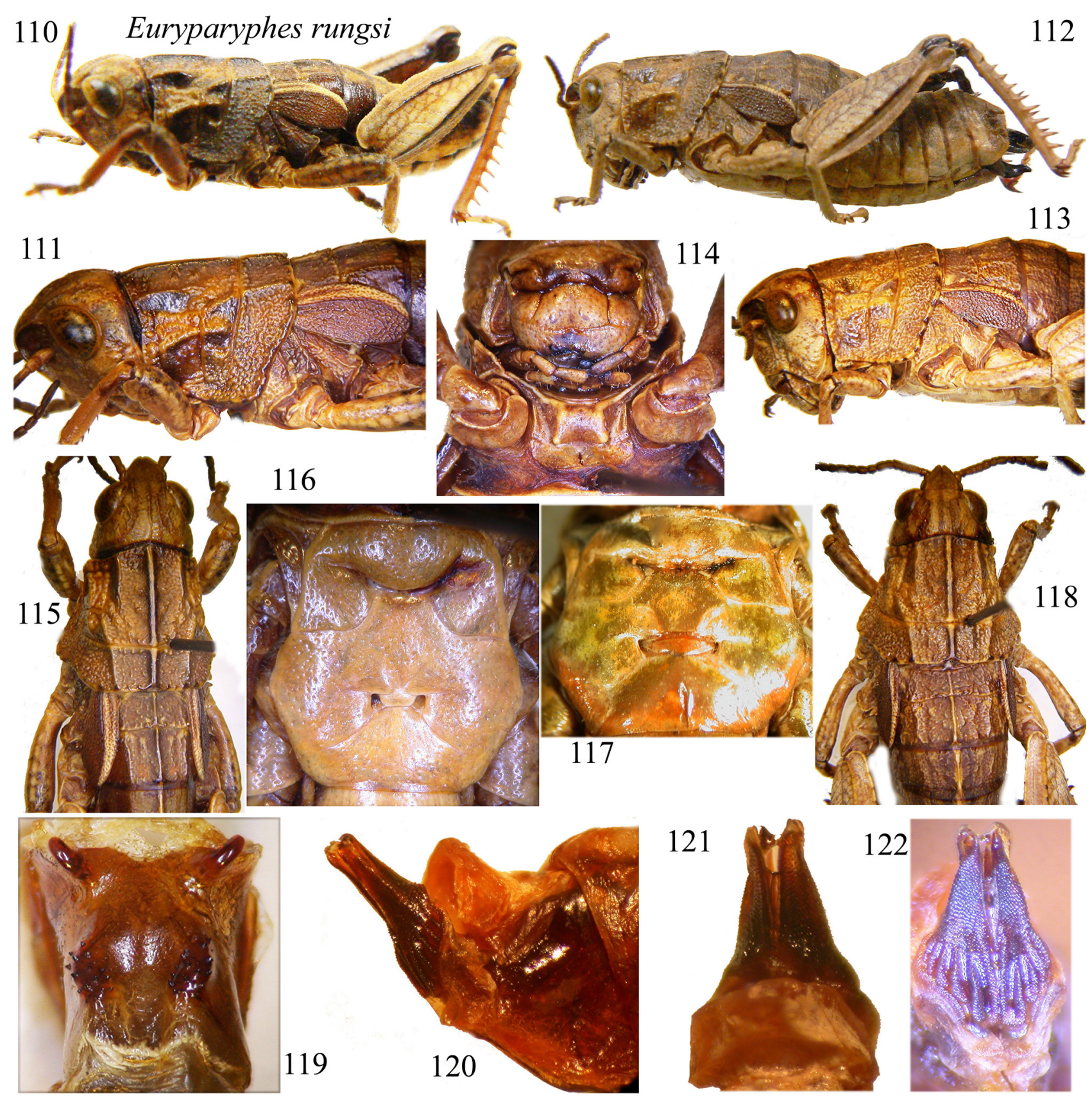

FIGURES 110-122. Characters of Euryparyphes rungsi n. sp. from Middle Atlas; holotype (110, 111, 114, 115, 116) and allotype (112, 113, 117, 118); epiphallus (119) and aedeagus valves of holotype, in lateral (120), front (121) and back view (122) (MNCN). 


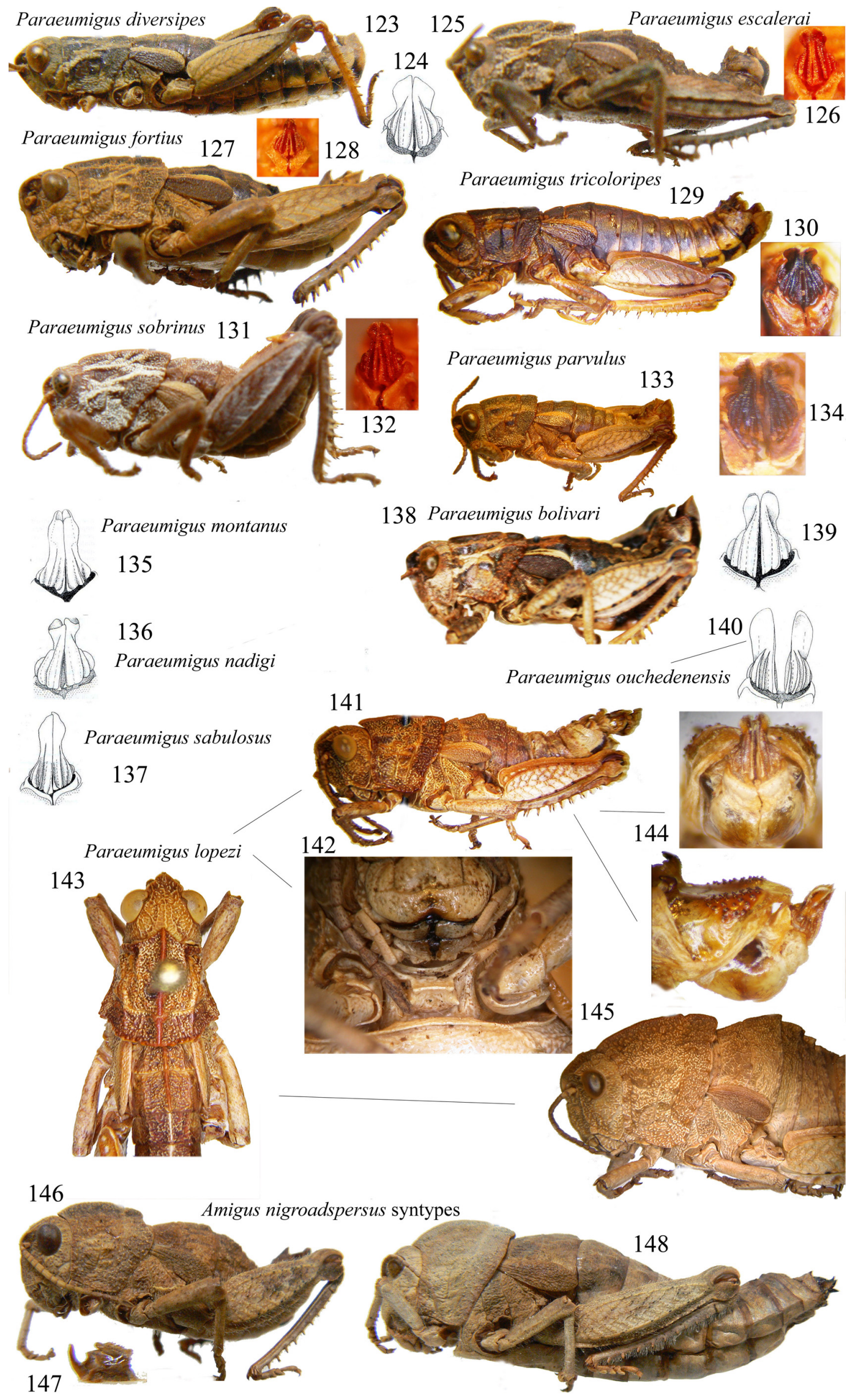

FIGURES 123-148. 123-145. Characters of species of the Moroccan genus Paraeumigus, included P. lopezi n. sp. (141-145, holotype and allotype, BMCP). 146-148. Lateral view of Amigus nigroadspersus and its phallic complex. Figs. 124, 135-137, 139-140 after La Greca (1993). 

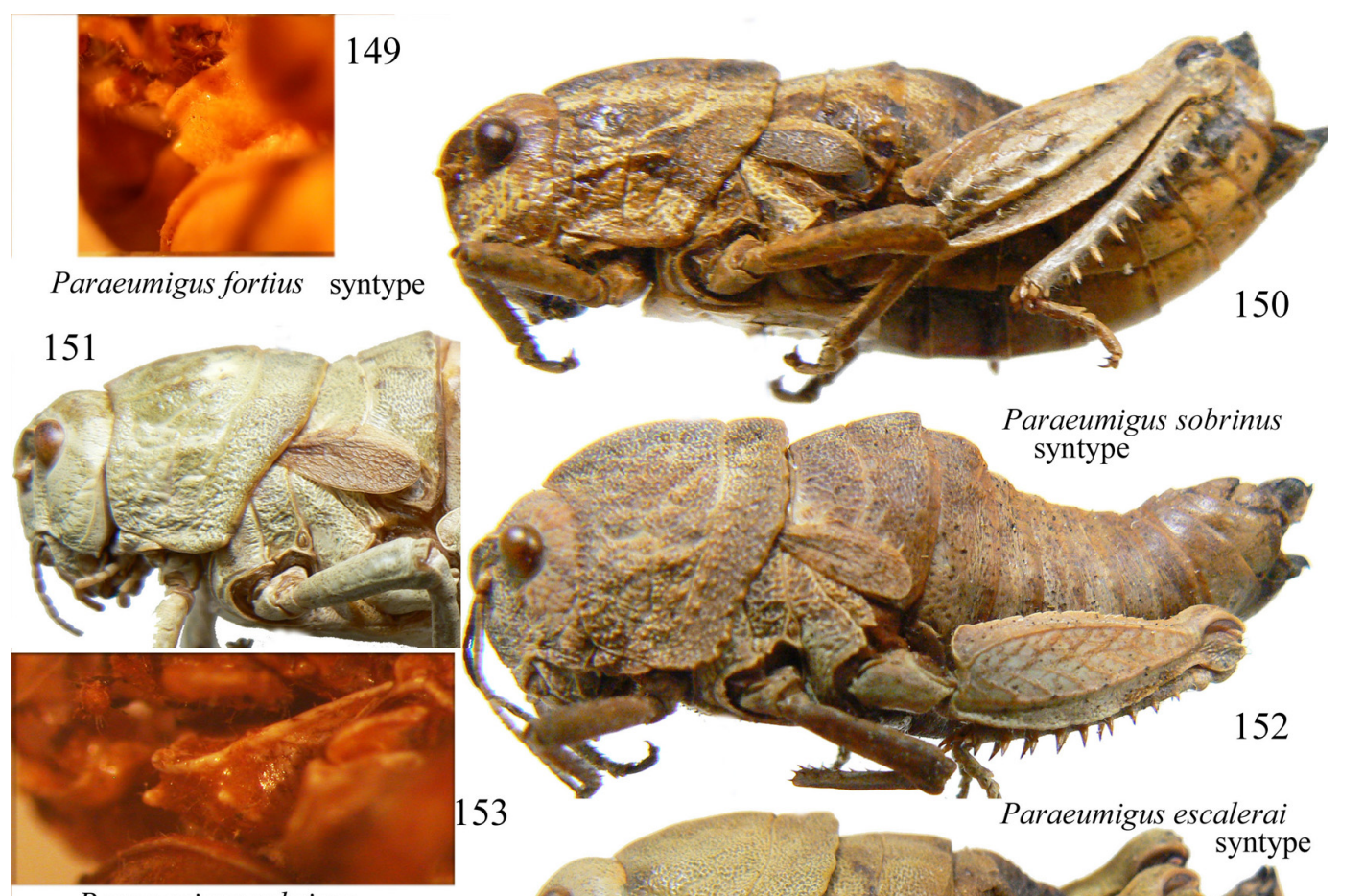

Paraeumigus sobrinus

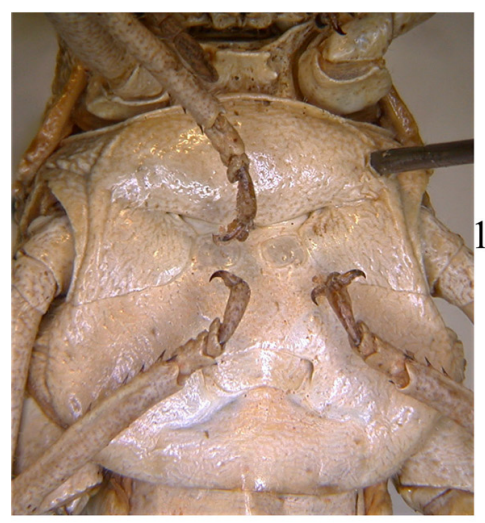

Paraeumigus lopezi allotype

155

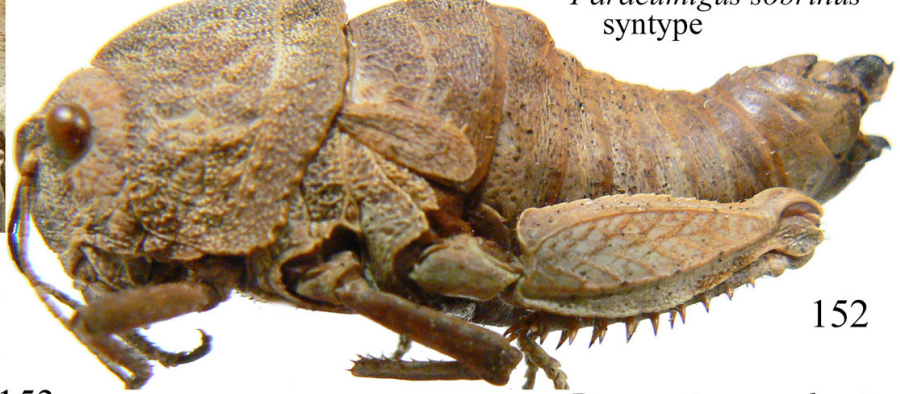

153
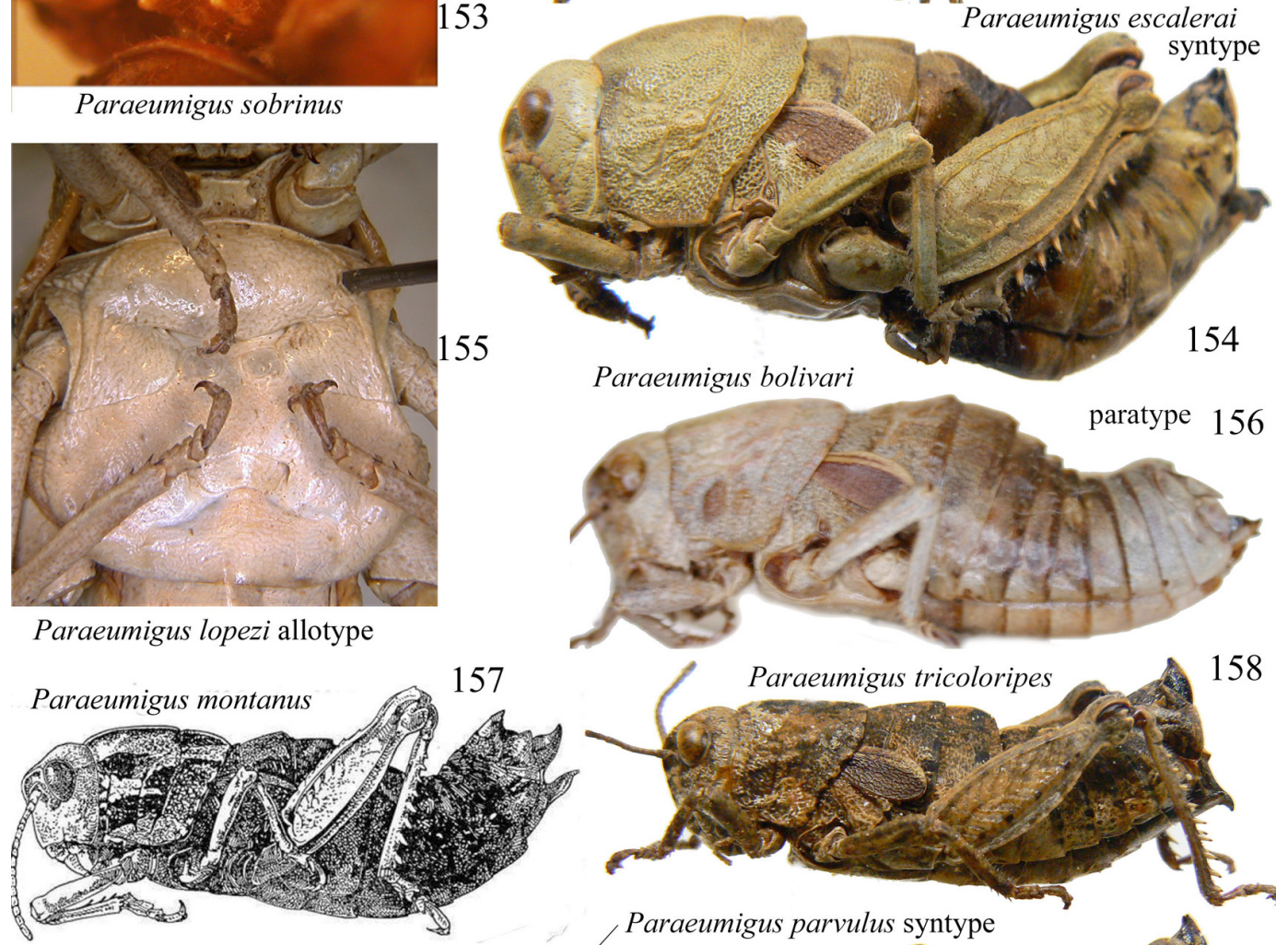

159
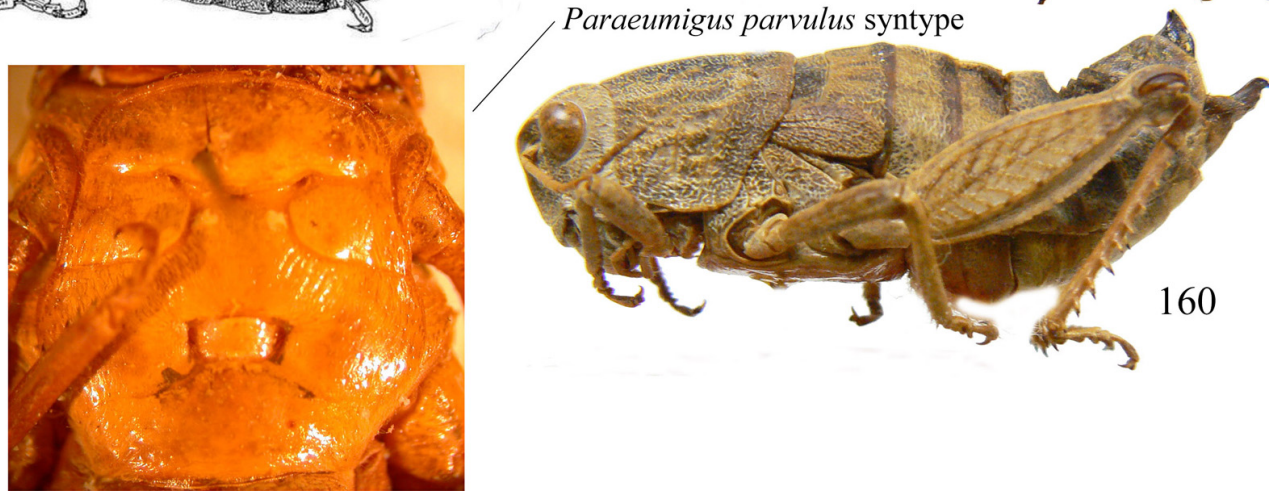

FIGURES 149-160. Females of some species of the Morocco genus Paraeumigus: P. fortius syntype (149-150), P. sobrinus syntypes (151-153), P. escalerai syntype (154), P. lopezi n. sp. allotype (155), P. bolivari paratype (156), P. montanus (157, after Chopard 1943), P. tricoloripes (158), P. parvulus (159-160). 


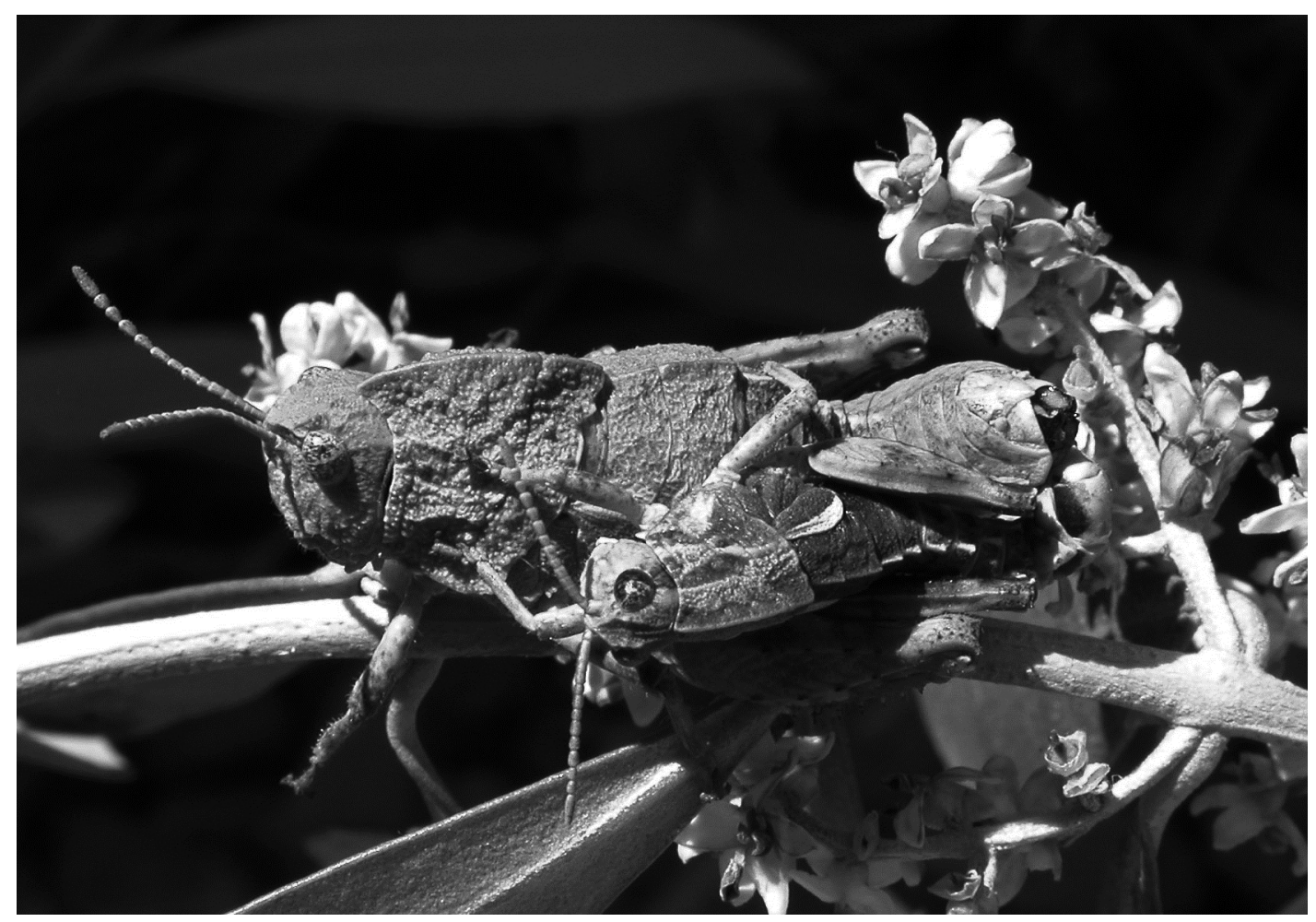

FIGURES 161. Mating of Paraeumigus lopezi n. sp. (male holotype and female allotype) (photo by H. Lopéz). 

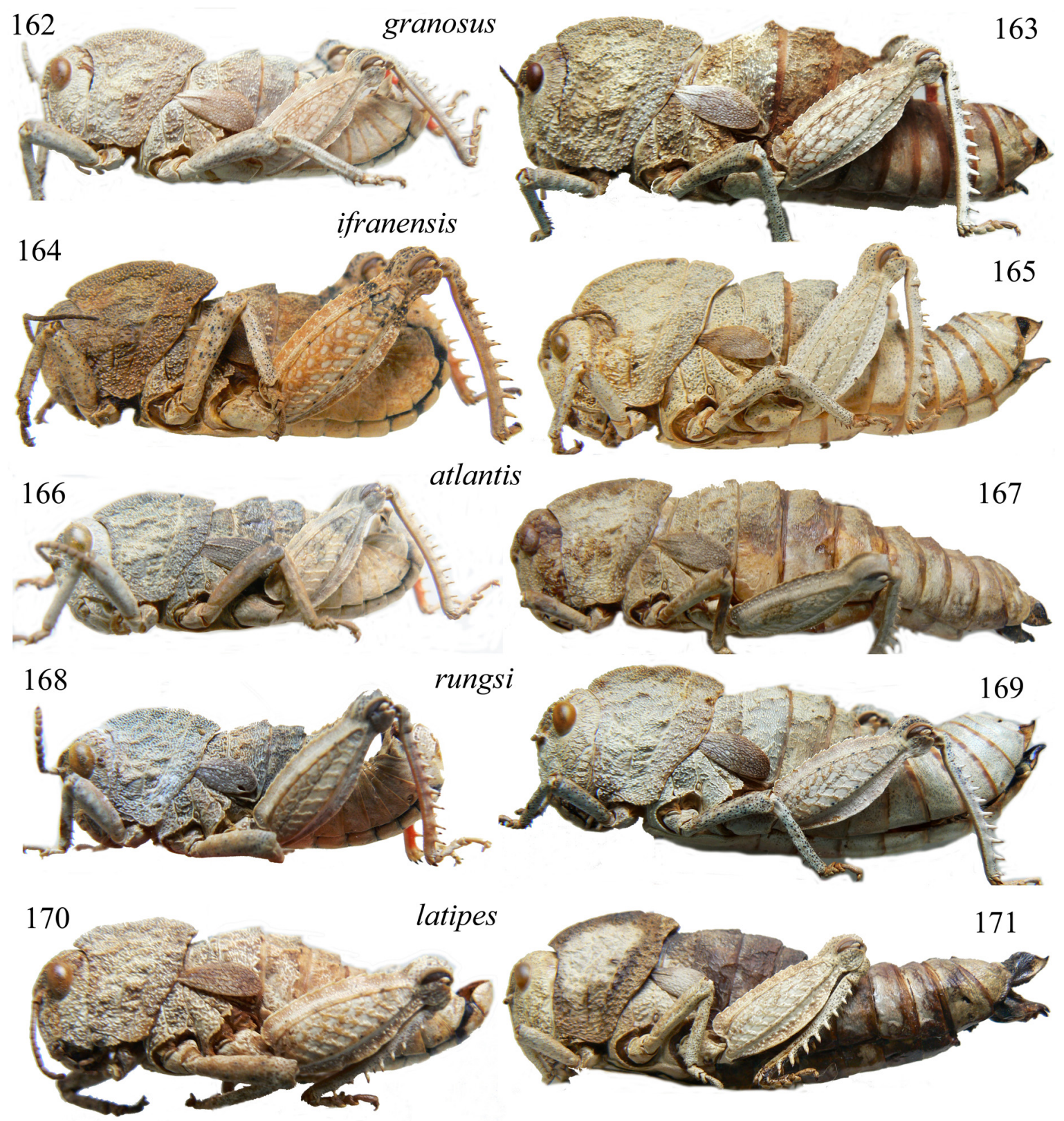

172

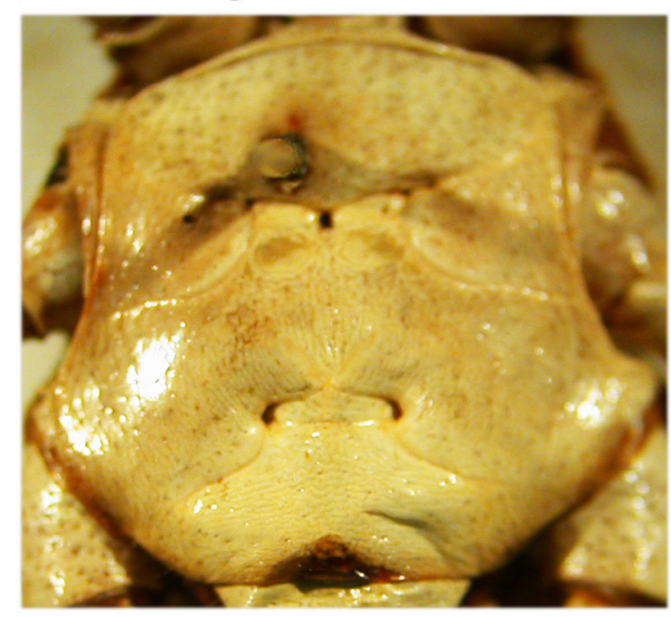

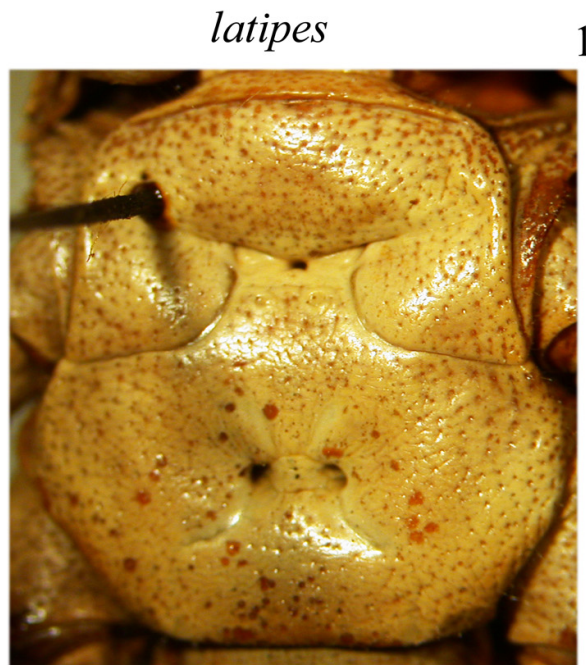

173

FIGURES 162-173. Characters of taxa described in the Moroccan genus Eunapiodes; on the left males, on the right females. 


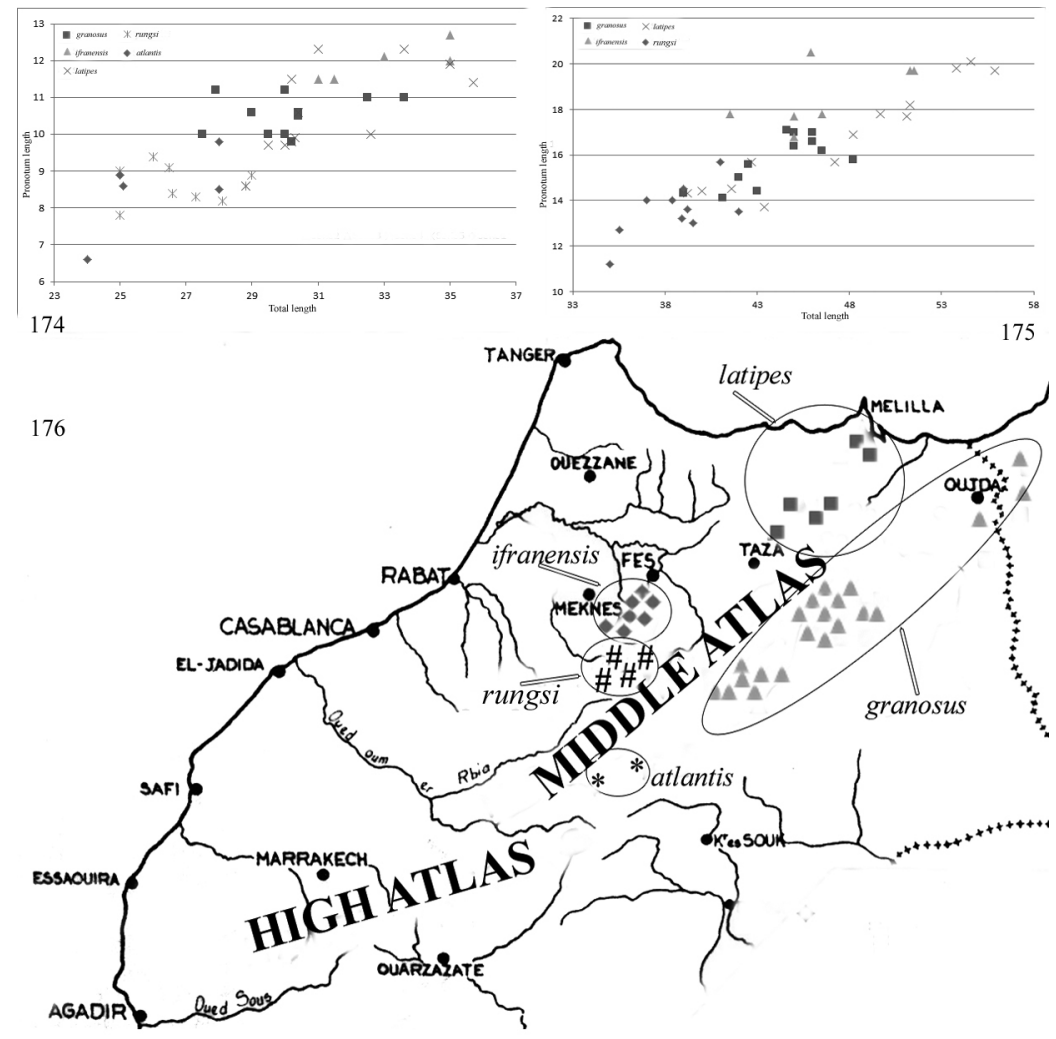

FIGURES 174-176. 174-175. Total length versus pronotum length in males (174) and females (175) of taxa belonging to the genus Eunapiodes. 176. Distribution of Eunapiodes taxa (after Descamps 1968, modified). 